ANA PAULA CREMASCO TAKANO

\title{
ANÁLISE DO PAPEL DA PROTEÍNA QUINASE ATIVADA PELA AMP (AMPK) NA HIPERTROFIA DO CARDIOMIÓCITO INDUZIDA PELO HORMÔNIO TIROIDEANO
}

Dissertação apresentada ao Programa de Pós-Graduação em Ciências Morfofuncionais do Departamento de Anatomia do Instituto de Ciências Biomédicas da Universidade de São Paulo, para a obtenção do Título de Mestre em Ciências. 


\section{ANÁLISE DO PAPEL DA PROTEÍNA QUINASE ATIVADA PELA AMP (AMPK) NA HIPERTROFIA DO CARDIOMIÓCITO INDUZIDA PELO HORMÔNIO TIROIDEANO}

Dissertação apresentada ao Programa de Pós-Graduação em Ciências Morfofuncionais do Departamento de Anatomia do Instituto de Ciências Biomédicas da Universidade de São Paulo, para a obtenção do Título de Mestre em Ciências.

Área de concentração: Ciências Morfofuncionais

Orientadora: Prof ${ }^{\mathrm{a}}$. $\mathrm{Dr}^{\mathrm{a}}$. Maria Luiza Morais Barreto de Chaves

Versão Original 
DADOS DE CATALOGAÇÃO NA PUBLICAÇÃO (CIP)

Serviço de Biblioteca e Informação Biomédica do

Instituto de Ciências Biomédicas da Universidade de São Paulo

reprodução não autorizada pelo autor

Takano, Ana Paula Cremasco.

Análise do papel da proteina quinase ativada pela AMP (AMPK) na hipertrofia do cardiomiócito induzida pelo hormônio tiroideano / Ana Paula Cremasco Takano. -- São Paulo, 2011.

Orientador: Maria Luiza Morais Barreto de Chaves.

Dissertação (Mestrado) - Universidade de São Paulo. Instituto de Ciências Biomédicas. Departamento de Anatomia. Área de concentração: Ciências Morfofuncionais. Linha de pesquisa: Vias de sinalização intracelular relacionadas à hipertrofia cardiaca.

Versão do titulo para o inglês: Role of AMP-actived protein kinase (AMPK) in the cardiomyocyte hypertrophy induced by thyroid hormone.

Descritores: 1. AMPK 2. Sinalização intracelular 3. Cardiomiócito 4. Hipertrofia cardíaca 5. Hormônio tiroideano I. Chaves, Maria Luiza Morais Barreto de II. Universidade de São Paulo. Instituto de Ciências Biomédicas. Programa de Pós-Graduação em Ciências Morfofuncionais III. Título. 
Candidato(a):

Título da Dissertação:

Orientador(a):
Ana Paula Cremasco Takano.

Análise do papel da proteína quinase ativada pela AMP (AMPK) na hipertrofia do cardiomiócito induzida pelo hormônio tiroideano.
A Comissão Julgadora dos trabalhos de Defesa da Dissertação de Mestrado, em sessão pública realizada a
( ) Aprovado(a)
( ) Reprovado(a)
Examinador(a): Assinatura:
Nome:
Instituição:
Examinador(a): Assinatura:
Nome:
Instituição:
Presidente:
Assinatura:
Nome:
Instituição:




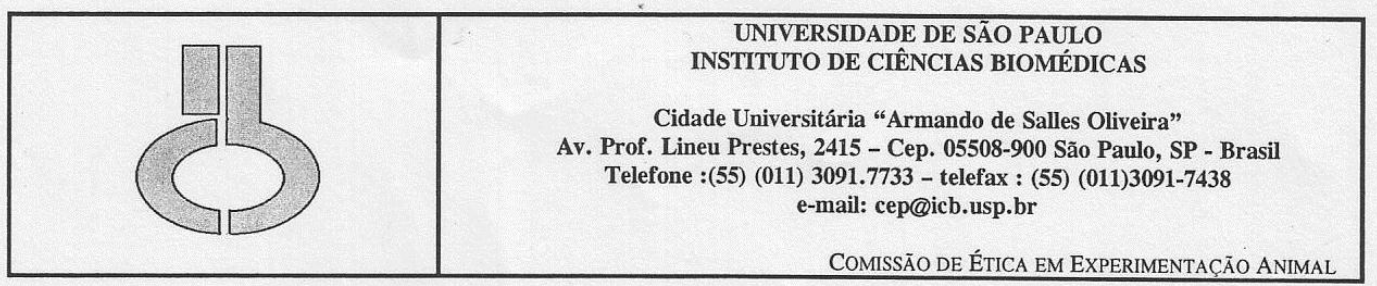

Decl. CEEA.023.09

\author{
D E C L A R A Ç Ã O
}

Em adendo ao Certificado 114/04/CEEA datado de 16.12.04, por solicitação da Profa. Dra. Maria Luiza Morais Barretos de Chaves, responsável pela linha de Pesquisa, autorizo a inclusão do aluno Ana Paula Cremasco Takano ao projeto de pesquisa "Papel do sistema renina-angiotensina na hipertrofia cardíaca elou renal induzida pelos hormônios tiroideanos", uma vez que se trata de utilização da mesma espécie animal e de métodos experimentais similares ao referido certificado.

São Paulo, 13 de maio de 2009.

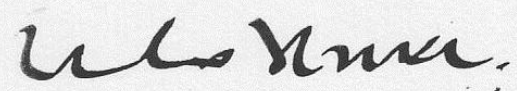

Prof. Dr. Wothan TAVARES DE LIMA

Coordenador -CEEA- ICB/USP 
Aos meus pais, Reginaldo e Solange, pelo constante incentivo para a minha formação. Mais uma etapa cumprida graças ao apoio de vocês. Muito obrigada por tudo! 


\section{AGRADECIMENTOS}

À minha orientadora, Prof ${ }^{\mathrm{a}}$. $\mathrm{Dr}^{\mathrm{a}}$. Maria Luiza Morais Barreto de Chaves, pela oportunidade que me foi concedida e confiança em mim depositada. Muito obrigada pelos ensinamentos, paciência, conselhos e por todos os momentos compartilhados. Com imenso respeito e admiração que tenho por você, sou eternamente grata por ter contribuído para meu amadurecimento científico, humano e profissional.

Aos meus pais, Reginaldo e Solange pelo incentivo e apoio em todas as minhas decisões em busca da realização dos meus sonhos. Obrigada por compreenderem minha ausência e por acreditarem em minha capacidade de vencer desafios. Saibam que cada conquista não seria alcançada sem 0 amor e reconhecimento de vocês!

Ao Vinicius, por todo amor, companheirismo, força e apoio ao longo destes últimos anos.

Ao Prof. Dr. Renato Paulo Chopard, agradeço imensamente pela oportunidade e pelo apoio na minha chegada ao laboratório.

À $\mathrm{Dr}^{\mathrm{a}}$. Gabriela Placoná Diniz, companheira e amiga muito querida, fundamental em meus "primeiros passos" dentro do laboratório. Muito obrigada pelos ensinamentos, pela paciência, parceria, e pela disposição em me ajudar sempre! Obrigada pela amizade e orgulho que sinto de termos trabalhado juntas.

Aos colegas e amigos do laboratório, Ana Cláudia S. Barbosa, Caroline A. Lino, Caroline Emy R. Shibata, Cristina F. Basso, Dayane A. Gomes, Felix M. Tavares, Linconl S. Beringui, Marina R. Fevereiro, Mary Oliveira, Priscilla S. Monteiro e Vanessa M. Lima, pelo companheirismo, apoio na realização dos experimentos e amizade que cativamos durante este período de convívio.

Aos professores Anselmo Sigari Moriscot, Luciana Venturini Rossone e Marcelo Augusto Christoffolete, pela participação em meu exame de qualificação e pelas valiosas sugestões.

À Prof. $\mathrm{Dr}^{\mathrm{a}}$. Marcela Sorelli Carneiro-Ramos, pela confiança, apoio e prontidão para contribuir com a realização de nossos trabalhos.

À secretária da pós-graduação Patrícia, pela atenção e disponibilidade em todos os momentos. 
Aos funcionários, professores e pós-graduandos do Departamento de Anatomia, pelo convívio e momentos compartilhados, que contribuíram de alguma forma para a realização desta pesquisa.

Aos funcionários do Biotério do Instituto Butantan, que sempre nos receberam com disponibilidade, obrigada pela gentileza e apoio para a realização deste trabalho.

Aos funcionários da Biblioteca do ICB que contribuíram na revisão textual e no suporte de informática das diretrizes para elaboração da dissertação.

A todos aqueles cujos nomes não foram citados, mas que direta ou indiretamente colaboraram para a realização deste trabalho.

Às instituições de fomento, CAPES, CNPq, e especialmente à FAPESP, que concederam auxílio financeiro para a realização deste trabalho e outro projetos desenvolvidos em nosso laboratório. 
"A mente que se abre a uma nova idéia jamais voltará ao seu tamanho original." 


\section{RESUMO}

TAKANO, A. P. C. Análise do papel da proteína quinase ativada pela AMP (AMPK) na hipertrofia do cardiomiócito induzida pelo hormônio tiroideano. 2011. 77 f. Dissertação (Mestrado em Ciências Morfofuncionais) - Instituto de Ciências Biomédicas, Universidade de São Paulo, São Paulo, 2011.

Alguns estudos prévios da literatura, incluindo os de nosso laboratório, já demonstraram que elevados níveis de hormônios tiroideanos (HT) induzem a significativa hipertrofia cardíaca, tanto observada in vivo como in vitro. Recentemente, alguns estudos demonstram que o HT também é capaz de modular rapidamente, por ações não-genômicas, o estado de fosforilação de proteínas quinases relacionadas ao processo de hipertrofia cardíaca. Nesse sentido, evidências experimentais indicam que a proteína quinase ativada por AMP (AMPK) seja um alvo importante no controle deste crescimento hipertrófico, uma vez que a ativação desta enzima determina ampla variedade de efeitos fisiológicos, incluindo o controle de algumas proteínas relacionadas à síntese protéica. Dessa forma, os objetivos do presente estudo foram os de avaliar os efeitos do HT sobre a modulação da via de sinalização da AMPK, além de verificar o possível envolvimento desta quinase no modelo de hipertrofia in vitro induzida pelo HT. Os resultados obtidos mostraram que rapidamente este hormônio ativa a AMPK e proteínas relacionadas a esta sinalização. Além disso, a estimulação farmacológica da AMPK atenuou a hipertrofia de cardiomiócitos induzida pelo HT. Estes dados sugerem que a AMPK seja uma possível e interessante ferramenta terapêutica em doenças cardiovasculares como a hipertrofia cardíaca.

Palavras-chave: AMPK. Sinalização intracelular. Cardiomiócito. Hipertrofia cardíaca. Hormônio tiroideano. 


\begin{abstract}
TAKANO, A. P. C. Role of AMP-activated protein kinase (AMPK) in the cardiomyocyte hypertrophy induced by thyroid hormone. 2011. $77 \mathrm{p}$. Master thesis (Morphological Sciences) - Instituto de Ciências Biomédicas, Universidade de São Paulo, São Paulo, 2011.

Previous studies of literature, including our laboratory results have shown that high levels of thyroid hormones (TH) induce significant cardiac hypertrophy, observed both in vivo and in vitro experiments. Recently, some studies have shown that $\mathrm{TH}$ are also able to rapidly modulate the phosphorylation state of protein kinases related to cardiac hypertrophy process by non-genomic actions. In this sense, experimental evidences indicate that AMP-activated protein kinase (AMPK) is an important target in the control of hypertrophic growth, since the activation of this enzyme determines wide variety of physiological effects, including the control of enzymes related to protein synthesis. Thus, the objectives of this study were to evaluate the effects of $\mathrm{TH}$ on the modulation of AMPK signaling pathway and to check the possible involvement of this kinase in vitro model of hypertrophy induced by $\mathrm{TH}$. The results showed that this hormone rapidly activates AMPK and related proteins to this signaling. Furthermore, pharmacological stimulation of AMPK attenuated cardiomyocyte hypertrophy induced by $\mathrm{TH}$. These data suggest that AMPK is a possible and interesting therapeutic tool in cardiovascular disease such as cardiac hypertrophy.
\end{abstract}

Keywords: AMPK. Intracelular signaling. Cardiomyocyte. Cardiac hypertrophy. Thyroid hormone. 


\section{LISTA DE FIGURAS}

Figura 1. Esquema representativo da estrutura e mecanismo de ativação da proteína quinase ativada por AMP (AMPK)..................................................... 22

Figura 2. Esquema representativo de algumas das proteínas controladas pela AMPK e relacionadas ao controle da síntese protéica...................................................... 23

Figura 3. Curva concentração-resposta de T3 em culturas de

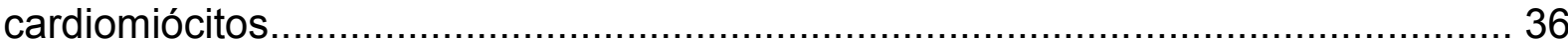

Figura 4. Análise dos níveis de AMPK fosforilada na Tre ${ }^{172}$, AMPK total e razão AMPKa fosforilada na Tre ${ }^{172} /$ AMPK total................................................................... 38

Figura 5. Análise da razão ACC fosforilada na $\operatorname{Ser}^{79} / A C C$ total, avaliada por Western Blotting.

Figura 6. Análise da razão AMPKa fosforilada na Ser ${ }^{485 / 491} / A M P K$ total avaliada por Western Blotting.

Figura 7. Análise dos níveis de LKB1 fosforilado na $\operatorname{Ser}^{428}$, LKB1 total e razão LKB1

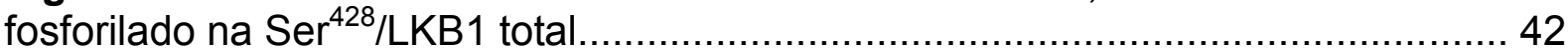

Figura 8. Análise da expressão protéica de CaMKKß …...................................... 43

Figura 9. Análise da expressão protéica da PP2C ............................................ 44

Figura 10. Esquema representativo do efeito do T3 nos componentes da via de sinalização da AMPK, em culturas de cardiomiócitos.

Figura 11. Blot representativo do efeito do tratamento com Metformina (Metf) sobre a AMPK em cardiomiócitos.

Figura 12. Efeito do tratamento por 24 horas com AICAR nos níveis de AMPKa fosforilada na Tre ${ }^{172}$

Figura 13. Efeito do tratamento com Composto $C$ (CC) nos níveis de AMPKa fosforilada na Tre ${ }^{172}$

Figura 14. Curva tempo-resposta de incorporação de leucina triciada. 50

Figura 15. Análise da ativação da AMPK pelo AICAR na hipertrofia de cardiomiócitos induzida pelo T3.

Figura 16. Análise da ativação da AMPK pela Metformina na hipertrofia de

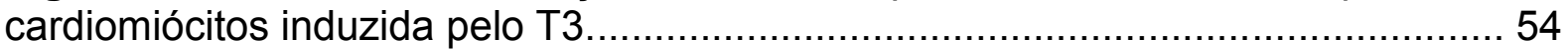

Figura 17. Análise da inibição farmacológica da AMPK com o Composto $C$ na hipertrofia de cardiomiócitos induzida pelo T3. 
Figura 18. Efeito da ativação da AMPK na expressão protéica da mTOR em

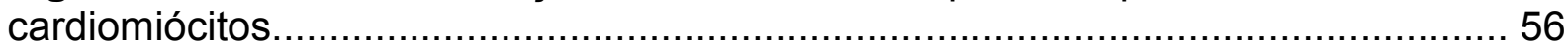

Figura 19. Modelo proposto para evidenciar a contribuição da AMPK na hipertrofia de cardiomiócitos induzida pelo T3 


\section{LISTA DE TABELAS}

Tabela 1 - Sequência dos diferentes primers utilizados nos experimentos de PCR em Tempo Real...................................................................................... 31

Tabela 2 - Lista de anticorpos primários utilizados para a análise de expressão protéica por Western Blotting. 


\section{LISTA DE ABREVIATURAS E SIGLAS}

ACC - acetil coA carboxilase

AMP - adenosina monofosfato

AMPK - proteína quinase ativada por adenosina monofosfato (AMP)

AMPKK - quinase da proteína quinase ativada por AMP

ATP - adenosina trifosfato

ANF - fator natriurético atrial

BNP - peptídeo natriurético cerebral

CaMKK $\beta$ - quinase ativada por proteína quinase dependente de cálcio/calmodulina do tipo beta

cDNA - DNA complementar

Ct - do inglês cycle threshold

DEPC - dietilpirocarbonato

DMEM - meio de cultura de Eagle modificado por Dulbecco

DNA - ácido desoxirribonucleico

GAPDH - gliceraldeído-fosfato-desidrogenase

HS - soro de cavalo

HT - hormônios tiroideanos

LKB1 - do inglês liver kinase B1

NCS - soro de bezerro neonato

PBS - tampão salina fosfato

PCR - reação em cadeia da polimerase

PP2C - proteína fosfatase $2 \mathrm{C}$

RNA - ácido ribonucleico

RNAm - ácido ribonucleico mensageiro

RT - reação de transcrição reversa

T3 - triiodotironina

T4 - tiroxina 


\section{LISTA DE SÍMBOLOS}

\section{Bases nitrogenadas dos nucleotídeos}

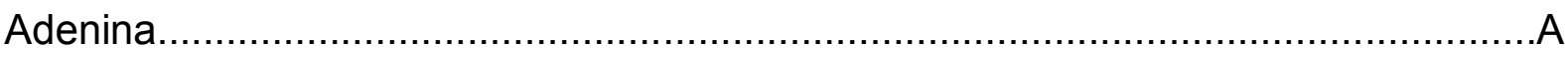

Citosina

Guanina

Timina

\section{Aminoácidos}

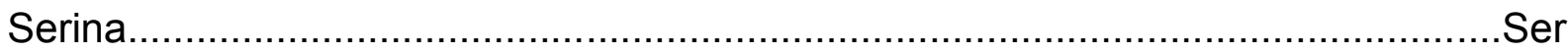

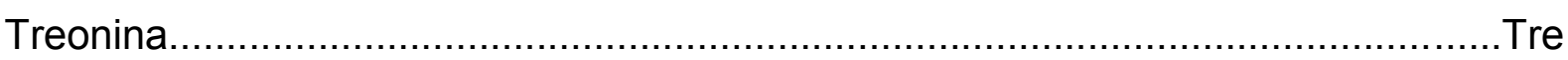

\section{Símbolos}

Alfa

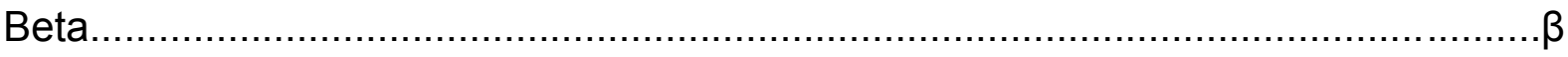

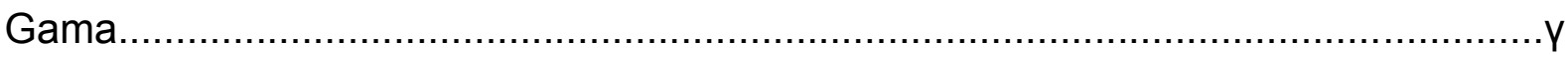




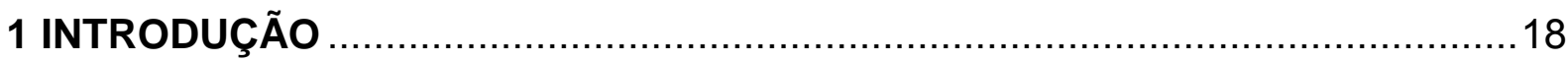

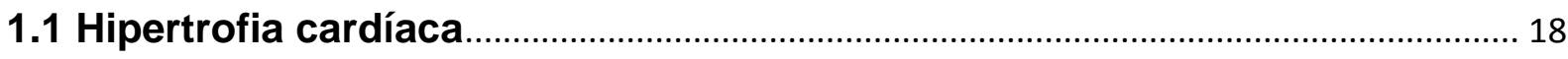

1.2 Hormônios tiroideanos e hipertrofia cardíaca …………………………………….... 19

1.3 AMPK

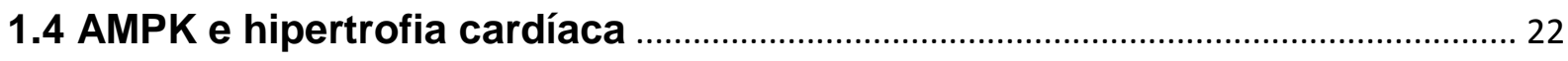

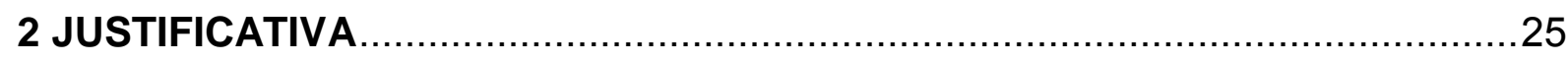

3 OBJETIVOS

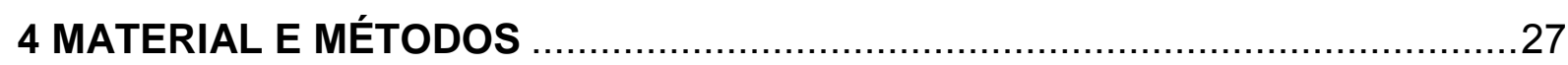

4.1 Culturas primárias de cardiomiócitos …………………………………………...... 27

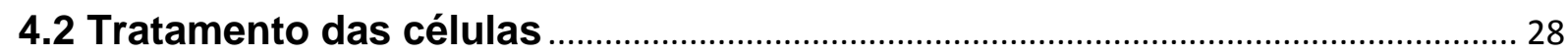

4.2.1 Análise do efeito do T3 em proteínas componentes da via de sinalização da AMPK

4.2.2 Avaliação da contribuição da AMPK no processo de hipertrofia cardiomiocítica induzida pelo T3.......................................................................... 28

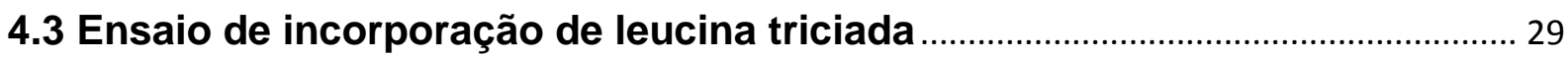

4.4 Análise da expressão gênica por RT-PCR em Tempo Real ................................... 30

4.4.1 Extração do RNA total e cDNA ………………………………………………........ 30

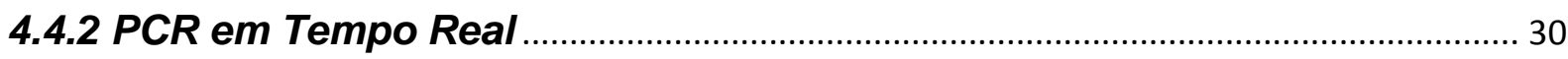

4. 5 Medida da área de superfície celular....................................................................... 31

4.6 Análise da expressão protéica por Western Blotting …………………………..... 32

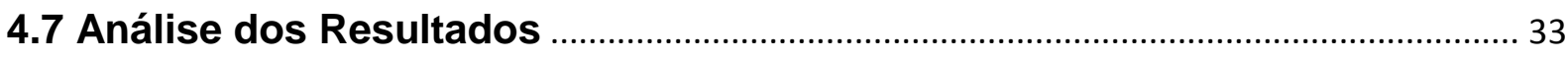

5 RESULTADOS

5.1 Padronização do tratamento com T3 …………………………………………........ 35

5.2 Análise do efeito do T3 em componentes da via de sinalização da AMPK .. 37

5.3 Padronização das concentrações dos agentes farmacológicos utilizados para tratamento dos cardiomiócitos 
5.3.2 Curva concentração-resposta de Aicar.

5.3.3 Curva concentração-resposta de Composto C 48

5.4 Avaliação da contribuição da ativação da AMPK na hipertrofia do cardiomiócito induzida pelo T3

6 DISCUSSÃO .58

6.1 Efeitos do T3 na fosforilação da AMPK. 59

6.2 Efeitos do T3 na fosforilação de AMPKKs 62

6.3 Efeitos do T3 na PP2C 63

6.4 Efeitos da ativação e inibição da AMPK na hipertrofia do cardiomiócito induzida pelo T3 64

7 CONCLUSÕES 67

REFERÊNCIAS .68 


\section{INTRODUÇÃO}

\subsection{Hipertrofia cardíaca}

A hipertrofia cardíaca representa um processo de natureza compensatória ou adaptativa do coração em resposta a um aumento de sua atividade ou de sobrecarga funcional, a qual pode se instalar em decorrência de várias etiologias fisiológicas e/ou patológicas (CHAN et al., 2004; FREY et al., 2004).

De maneira sucinta, em geral, esta adaptação ocorre em resposta ao aumento das necessidades metabólicas que impõem um aumento do débito cardíaco, como se observa no exercício físico (MACHIDA et al., 2000) e em situação de elevados níveis de hormônios tiroideanos (T3, T4) (MORGAN e BAKER, 1991). Ainda, pode ser resultante de sobrecarga de pressão ou de volume, como ocorre, por exemplo, na hipertensão arterial (WEBER e BRILLA, 1991), ou também decorrente de mecanismos intrínsecos de natureza genética, hipertrofias idiopáticas, as quais podem ocorrer mesmo na ausência de sobrecargas (RAPP, 2000).

A nível celular, a hipertrofia é caracterizada por um aumento do volume celular dos cardiomiócitos que correspondem a $70-80 \%$ da massa cardíaca (POPESCU et al., 2006), acompanhado por um alto grau de organização de proteínas contráteis dentro da unidade sarcomérica, mudanças na transcrição de inúmeros genes, reativação de genes expressos durante o período fetal e estimulação da tradução, os quais resultam em um aumento da síntese protéica, e consequentemente, em um aumento do volume da célula (BOHELER et al., 1992; CHAN e DYCK, 2005), sendo que tal crescimento não é acompanhado de divisão celular (ANVERSA; KAJSTURA; OLIVETTI, 1996; GERDES, 1992).

Atualmente, muitos estudos têm como foco a identificação dos mecanismos moleculares envolvidos na hipertrofia dos cardiomiócitos, avaliando essencialmente processos relacionados à maquinaria de síntese protéica, assim como aqueles relacionados a mecanismos de degradação protéica. Para uma análise mais complexa deste processo é fundamental que se conheçam alguns aspectos importantes, como os fatores que desencadeiam a resposta hipertrófica (fatores hemodinâmicos, neuro-humorais ou genéticos), as vias de sinalização intracelular que estão sendo ativadas frente a um determinado estímulo e a alteração da expressão de diversos genes, cuja ativação pode acabar resultando na hipertrofia do 
coração. Assim, uma vez deflagrado o estímulo, receptores de fatores químicos e/ou sensores de estímulos mecânicos lideram a ativação de cascatas de sinalização intracelular, compostas por proteínas quinases e proteínas fosfatases, as quais transmitem o sinal hipertrófico a diversos compartimentos da célula (HUNTER e GREENWOOD, 1962). Desta forma, a ativação dessas vias de sinalização induz múltiplas mudanças qualitativas e quantitativas nos níveis de expressão de várias proteínas contráteis, bombas ou canais iônicos, proteínas secretadas, proteínas de sinalização, componentes de matriz extracelular, reguladores da sobrevivência celular (FIEDLER e WOLLERT, 2004), os quais irão influenciar tanto o aumento da área dos cardiomiócitos como também a hipertrofia do coração. Neste sentido, a ativação de vias de sinalização envolvendo quinases específicas tem atraído cada vez mais a atenção de pesquisadores interessados no estudo das respostas hipertróficas essenciais observadas nos cardiomiócitos frente a diferentes estímulos (SADOSHIMA e IZUMO, 1993; SHUBEITA et al., 1992). A elucidação da contribuição dos diversos mecanismos envolvidos na modulação do trofismo cardíaco é fundamental para a melhor compreensão do processo hipertrófico como um todo, possibilitando dessa forma, o desenvolvimento de estratégias terapêuticas mais eficazes.

\subsection{Hormônios tiroideanos e hipertrofia cardíaca}

Atualmente, estima-se que doenças que afetam a glândula tireóide atinjam mais de $10 \%$ da população (CANARIS et al., 2000). Paralelamente, é importante ressaltar que o coração é considerado um dos principais órgãos-alvos da ação dos hormônios tiroideanos $(\mathrm{HT})$, uma vez que os distúrbios cardiovasculares correspondem aos primeiros e principais eventos deflagrados por alterações nos níveis circulantes destes hormônios (KAHALY e DILLMANN, 2005; KLEIN e OJAMAA, 2001). Assim, diversos estudos vêm demonstrando estreita relação entre os níveis de HT e a função cardíaca (CANARIS et al., 2000), considerando que alterações dos níveis desses hormônios são capazes de aumentar o fator de risco para o desenvolvimento e a progressão das doenças cardiovasculares (PANTOS et al., 2007; SCHMIDT-OTT e ASCHEIM, 2006).

Os HT promovem hipertrofia cardíaca agindo de forma direta sobre o tecido cardíaco, regulando a transcrição de vários genes relacionados à maquinaria 
contrátil do cardiomiócito e, consequentemente, alterando quantitativa e qualitativamente a sua síntese protéica (KLEIN e LEVEY, 1984). Além disso, atuam indiretamente através da modulação de diversos parâmetros hemodinâmicos (KLEIN, 2003), por meio dos quais a função e a estrutura cardíaca são alteradas.

Por muito tempo, os efeitos exercidos pelos HT foram descritos como sendo decorrentes de ações exclusivamente genômicas (PORTMAN, 2008). Desta forma, após acesso do HT ao interior da célula, ocorre a sua translocação para o núcleo, o qual induz a alteração da razão de transcrição gênica, tradução e mudanças no conteúdo celular de proteínas específicas. Para que essas ações genômicas ocorram são necessárias algumas horas (DAVIS; LEONARD; DAVIS, 2008). No entanto, ações muito rápidas, as quais ocorrem na ordem de segundos ou minutos, que independem inicialmente da formação do complexo intra-nuclear entre HT e receptor de hormônio tiroideano, já foram descritas, e denominadas então de ações não-genômicas (DAVIS e DAVIS, 2002; HIROI et al., 2006). Tais ações estão intimamente associadas com o estado de fosforilação de algumas proteínas envolvidas em diversas vias de sinalização intracelular (BERGH et al., 2005; DAVIS; LEONARD; DAVIS, 2008), as quais parecem hoje ter um papel fundamental em diversas funções fisiológicas e patológicas. Assim, os HT atuam em várias cascatas de sinalização, como ocorre com a via de sinalização das MAPKs (LIN et al., 1999; SHIH et al., 2001), com a via de ativação de ERK1/2 promovida pela ligação do HT à integrina aVß3 (DAVIS; DAVIS; CODY, 2005), bem como com a sinalização da $\mathrm{PI3K} / \mathrm{Akt} / \mathrm{mTOR}$, a qual é rapidamente ativada pelo T3, e importante mediadora do processo de hipertrofia do cardiomiócito (DINIZ; CARNEIRO-RAMOS; BARRETOCHAVES, 2009; KENESSEY e OJAMAA, 2006; KUZMAN; O'CONNELL; GERDES, 2007).

Neste contexto, nosso grupo de pesquisa vem estudando os eventos cardiovasculares desencadeados por alterações crônicas ou agudas das concentrações dos hormônios tiroideanos na circulação e, em especial, o processo de hipertrofia cardíaca. Inicialmente, foram desenvolvidos estudos que melhor caracterizassem o modelo de hipertrofia que acompanha o hipertiroidismo (ANJOSRAMOS et al., 2006; HU; LIBERTI; BARRETO-CHAVES, 2005), para em seguida, partirmos para uma abordagem de identificação de mecanismos moleculares deflagrados em tal processo. 


\subsection{AMPK}

A proteína quinase ativada por adenosina monofosfato (AMPK) é uma serina/treonina quinase que atua como reguladora da homeostase energética celular e sistêmica e coordena vias metabólicas no sentido de equilibrar o suprimento de nutrientes com a demanda energética (OAKHILL; SCOTT; KEMP, 2009; TOWLER e HARDIE, 2007). Assim, a AMPK é considerada um sensor do balanço energético celular, sendo ativada principalmente pelo aumento intracelular da proporção AMP/ATP (adenosina monofosfato/adenosina trifosfato), resultando na inibição de vias metabólicas que consomem ATP, como por exemplo, o processo de síntese protéica. Ao mesmo tempo, a AMPK atua na estimulação de vias metabólicas que produzem ATP, como a oxidação de ácidos graxos, captação de glicose e glicólise (KEMP et al., 2003; OAKHILL; SCOTT; KEMP, 2009).

Em relação à sua estrutura, a AMPK é uma proteína heterotrimérica que consiste em uma subunidade $\alpha$ catalítica e subunidades $\beta$ e y regulatórias. Existem múltiplas isoformas de cada subunidade em mamíferos ( $\alpha 1, \alpha 2, \beta 1, \beta 2, \gamma 1, y 2$ e $\gamma 3$ ), as quais são codificadas por genes distintos, e são diferentemente expressas em vários tecidos (ARAD; SEIDMAN; SEIDMAN, 2007; HARDIE, 2003).

O mecanismo de ativação da AMPK (Figura 1) envolve a ligação da AMP à subunidade $\mathrm{Y}$, o que induz uma mudança conformacional no complexo AMPK, que alostericamente ativa a subunidade catalítica $\alpha$, pelo aumento da fosforilação do resíduo Treonina 172 ( $\mathrm{Tre}^{172}$ ), o qual é promovido por uma quinase reguladora da AMPK (AMPKK) (HAWLEY et al., 2003). Ainda, a ligação da AMP à AMPK inibe a ação de proteínas fosfatases (HARDIE, 2003; HUTCHINSON; SUMMERS; BENGTSSON, 2008). A sinalização da AMPK pode ser influenciada por ação de duas quinases, a LKB1, atualmente considerada como a principal quinase reguladora da AMPK, por estar envolvida com a sua fosforilação e ativação em resposta à elevação da relação AMP/ATP no coração (SAKAMOTO et al., 2006), e também pode ser ativada por uma quinase da proteína quinase dependente de $\mathrm{Ca}^{2+} /$ calmodulina (CaMKKß) (CARLING; SANDERS; WOODS, 2008). Além disso, o processo de defosforilação e consequente inibição da AMPK ocorre principalmente por ação da proteína fosfatase 2C (PP2C) (DAVIES et al., 1995). 


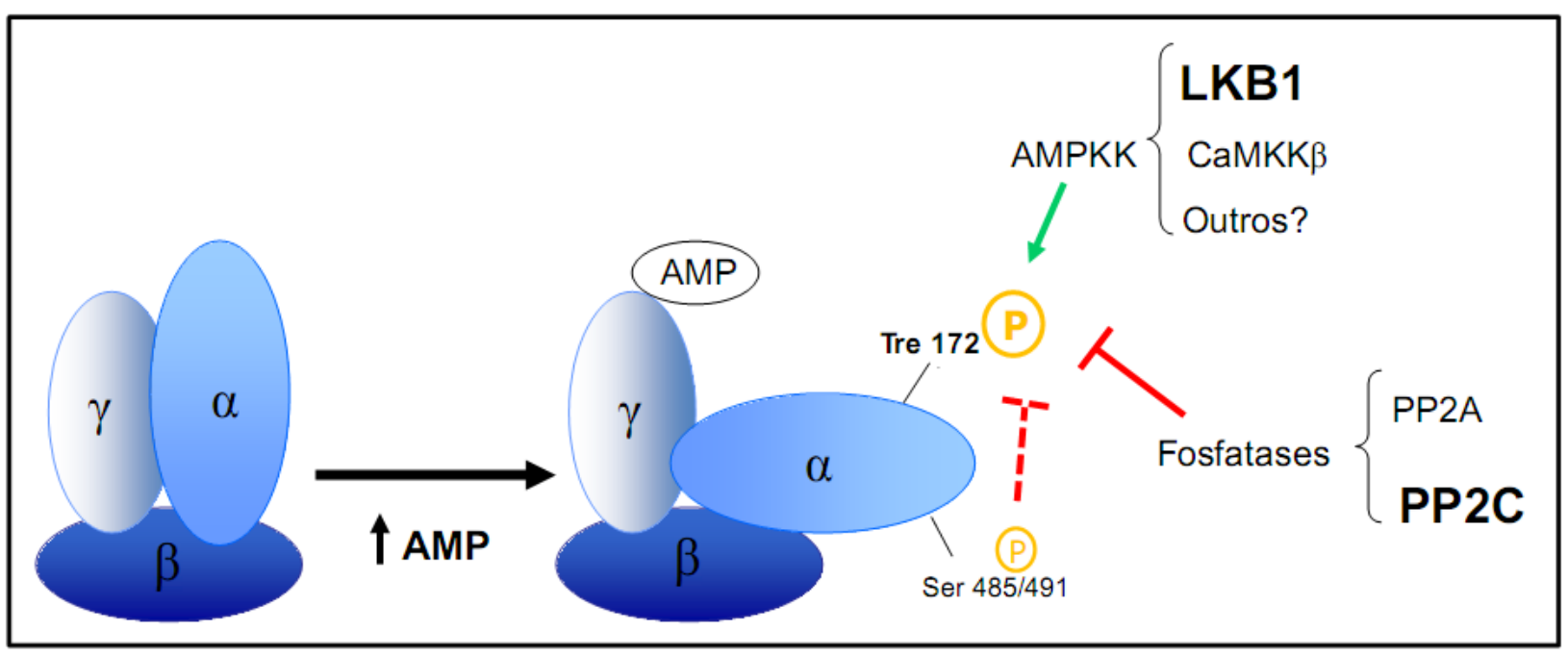

Figura 1. Esquema representativo da estrutura e mecanismo de ativação da proteína quinase ativada por AMP (AMPK). $\alpha, \beta$ e $\gamma=$ subunidades que compõem a estrutura da AMPK. A seta na cor verde indica ativação da AMPK por uma de suas quinases ativadoras. Em vermelho estão indicados mecanismos de inibição da ativação da AMPK, por ação de fosfatases (traço contínuo) e possível inativação da fosforilação da AMPK na Treonina 172, via fosforilação da própria enzima no resíduo Serina 485/491 (traço descontínuo).

FONTE: Baseado em Kim et al. (2009).

Como já mencionado anteriormente, uma vez ativada, a AMPK interage com diferentes vias metabólicas, atuando principalmente na regulação do metabolismo de ácidos graxos, metabolismo de glicose, e descrito mais recentemente, o envolvimento desta quinase no metabolismo protéico (DYCK e LOPASCHUK, 2006; WONG et al., 2009).

Atualmente, a sinalização da AMPK vem recebendo a atenção de muitos pesquisadores que a consideram um possível novo alvo terapêutico em doenças cardiometabólicas, por mediar, pelo menos em parte, ações de vários fatores fisiológicos e farmacológicos que exercem ações protetoras para o sistema cardiovascular como um todo. Neste sentido, destaca-se a importância da identificação e compreensão das funções desta quinase que podem, portanto, vir a contribuir na prevenção e tratamento de doenças cardiovasculares.

\subsection{AMPK e hipertrofia cardíaca}

A AMPK atua no sentido de compensar a redução dos níveis de ATP; por conseguinte, sua ativação leva à repressão de processos metabólicos que 
consomem energia e que não são requeridos para sobrevivência celular imediata. Um desses processos não essenciais, pelo menos a curto prazo, seria a síntese protéica (DOLINSKY e DYCK, 2006). Assim, a ativação da AMPK torna-a capaz de modular a atividade de enzimas extremamente importantes no controle da síntese protéica, como o complexo TSC2, mTOR, p70S6 e a eEF2 quinase (CHAN e DYCK, 2005). Dessa forma, a AMPK pode inibir a atividade da eEF2 via fosforilação e ativação da eEF2 quinase. Além disso, a AMPK também modula diretamente a atividade da mTOR, através de sua fosforilação, o que resulta em sua inibição, e indiretamente, através da fosforilação e ativação do complexo TSC1-TSC2, o qual funciona como um regulador negativo da mTOR. A figura a seguir apresenta algumas proteínas controladas pela AMPK e relacionadas à síntese protéica (Figura 2).

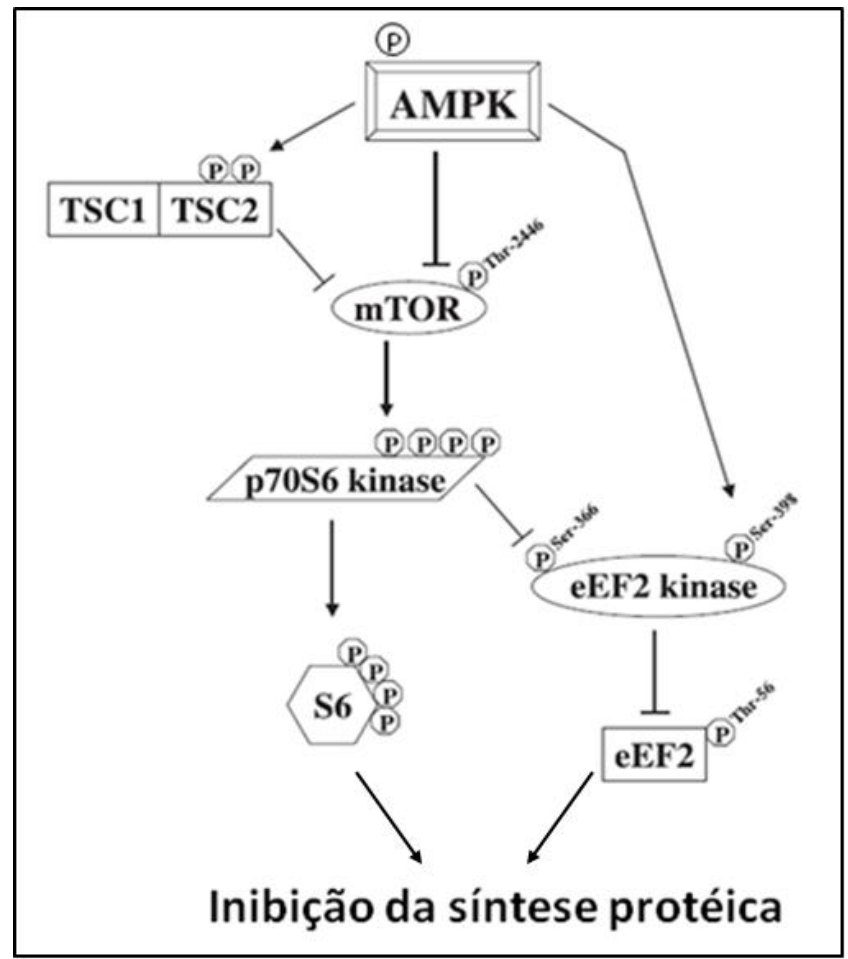

Figura 2. Esquema representativo de algumas das proteínas controladas pela AMPK e relacionadas ao controle da síntese protéica. FONTE: Adaptado de Chan e Dyck (2005).

Se por um lado a ativação da AMPK modula a ativação de proteínas diretamente envolvidas na síntese protéica, por outro, a ativação da Akt (ou PKB), uma proteína implicada na estimulação de diversos modelos de hipertrofia cardíaca, 
pode também regular negativamente a AMPK no coração. Com base nisso, uma das hipóteses para explicar como a Akt poderia promover crescimento hipertrófico seria através da inativação da AMPK (CHAN et al., 2004), quando aquela enzima diretamente fosforila a AMPK $\alpha 1 / \alpha 2$ na Serina 485/491 (Ser $\left.{ }^{485 / 491}\right)$, prevenindo a fosforilação no seu sítio de ativação (Treonina 172) por uma AMPKK (HORMAN et al., 2006; SOLTYS; KOVACIC; DYCK, 2006).

Considerando que a AMPK pode interagir com diferentes vias envolvidas na regulação da síntese protéica, é possível admitir que esta proteína também seja considerada como uma moduladora da hipertrofia cardíaca. Apoiando-se neste conceito, a ativação farmacológica da AMPK poderia atenuar a hipertrofia cardíaca e a síntese protéica induzida pela ação da Akt. Neste sentido, alguns estudos avaliaram a participação da AMPK na hipertrofia de cardiomiócitos induzida pelo tratamento com angiotensina II (STUCK et al., 2008) e fenilefrina (CHAN et al., 2004), os quais demonstraram que a ativação da AMPK reverteu ou atenuou o desenvolvimento da hipertrofia dessas células in vitro. No entanto, um recente estudo mostrou o aumento da atividade da AMPK associada com o desenvolvimento de hipertrofia cardíaca induzida por sobrecarga de pressão, porém, sem a elucidação completa dos mecanismos implicados neste modelo (TIAN et al., 2001).

Com base nestes achados, o envolvimento da AMPK no processo de hipertrofia cardíaca ainda é controverso, podendo ter um duplo papel, ora sendo necessária sua inibição para promover o crescimento hipertrófico em estágios iniciais (ou a ativação farmacológica da AMPK na fase inicial da hipertrofia cardíaca é capaz de prevenir o crescimento hipertrófico), ora sendo essencial sua ativação em estágios mais tardios na tentativa de manter o suprimento adequado de ATP para as células cardíacas.

Embora o papel da AMPK no controle da síntese protéica e/ou crescimento celular tenha sido evidenciado em alguns modelos hipertróficos, o possível envolvimento desta quinase no modelo de hipertrofia cardíaca induzido por HT ainda é desconhecido. 


\section{JUSTIFICATIVA}

De modo geral, o principal efeito dos HT no organismo é o de promover um aumento generalizado do metabolismo basal. No nível celular, este aumento do metabolismo está diretamente associado à maior mobilização ou gasto de ATP pela célula, aliado a outras importantes funções dos HT, as quais estão intimamente associadas ao tipo celular em questão. Na célula muscular cardíaca, ou cardiomiócito, os $\mathrm{HT}$, além das ações metabólicas, atuam diretamente estimulando o processo hipertrófico, o que ocorre tanto in vivo como in vitro. Considerando que a AMPK tem o papel de compensar a redução dos níveis de ATP, sua ativação levaria à repressão de processos metabólicos que consomem energia e que não são requeridos para sobrevivência celular imediata, como ocorre, pelo menos a curto prazo, com a síntese protéica. Desta forma, levando em consideração:

1 - o fato da hipertrofia cardíaca induzida pelo HT ser mediada por ativação da via PI3K/Akt/mTOR (DINIZ; CARNEIRO-RAMOS; BARRETO-CHAVES, 2009) e esta ser diretamente influenciada pela AMPK (CHAN e DYCK, 2005),

2 - o fato da ativação da AMPK levar à inibição da síntese protéica por diferentes vias de sinalização,

3 - e ainda o fato da ativação desta quinase ter se mostrado eficiente na atenuação da hipertrofia cardíaca induzida por outros agentes hipertróficos, como a angiotensina II (STUCK et al., 2008) e a fenilefrina (CHAN et al., 2004), torna-se justificável avaliar a hipótese de um possível papel da AMPK também no processo de hipertrofia cardíaca induzida pelo HT. Assim, o desenvolvimento deste estudo permitirá uma melhor compreensão do complexo de sinalização envolvido na resposta hipertrófica e talvez possibilite uma abordagem mais integrada, visando o desenvolvimento de novas estratégias para prevenir ou inibir a instalação da hipertrofia cardíaca associada à melhora da função, mediante a utilização da ativação dessa proteína (AMPK), neste modelo experimental. 


\section{OBJETIVOS}

Diante da hipótese aventada e justificada previamente, este estudo propõe-se a:

- Avaliar uma possível ação não-genômica do T3 sobre a modulação da via de sinalização da AMPK, mediada por ação rápida do hormônio nos cardiomiócitos em cultura.

- Verificar o envolvimento da AMPK no modelo de hipertrofia cardíaca induzido pelo tratamento prolongado com T3 em culturas primárias de cardiomiócitos. Uma vez confirmada a participação desta via, avaliar o possível efeito da ativação desta quinase no processo de prevenção (parcial ou total) da instalação da hipertrofia. 


\section{MATERIAL E MÉTODOS}

Todos os procedimentos realizados no presente estudo foram aprovados pela Comissão de Ética em Experimentação Animal (CEEA) do Instituto de Ciências Biomédicas da Universidade de São Paulo e estão de acordo com os Princípios Éticos na Experimentação Animal, adotados pelo Colégio Brasileiro de Experimentação Animal (COBEA).

\subsection{Culturas primárias de cardiomiócitos}

Para a obtenção das culturas primárias de cardiomiócitos foram utilizados ratos neonatos Wistar de 1 a 3 dias, de acordo com o protocolo descrito previamente (BARRETO-CHAVES; HEIMANN; KRIEGER, 2000). Após exposição do coração, os ventrículos foram separados dos átrios, e então submetidos a um processo de digestão enzimática a $37{ }^{\circ} \mathrm{C}$ em tampão à base de colagenase (Worthington, Lakewood, N.J., USA) e pancreatina (GIBCO, Grand Island, N.Y., USA). Após sucessivas digestões enzimáticas, os homogenatos celulares foram submetidos à centrifugação em um gradiente descontínuo de Percoll (GE Healthcare, Uppsala, Suécia), permitindo então a separação dos cardiomiócitos dos demais tipos celulares presentes no coração. A viabilidade celular foi estimada pelo uso do corante Trypan Blue Stain $0.4 \%$ (Amresco, Solon, Ohio, USA). Em seguida, os cardiomiócitos foram contados em hemocitômetro e cultivados em placa de 6 poços a uma densidade aproximada de $200 \times 10^{4}$ células/placa, em meio DMEM (GIBCO) contendo $5 \%$ de soro de bezerro neonato (NCS, GIBCO) e $10 \%$ de soro de cavalo (HS, GIBCO), suplementado com antibióticos (penicilina e streptomicina, GIBCO). O meio foi trocado a cada 48 horas, a partir do dia seguinte à extração das células. As placas foram mantidas em estufa de $\mathrm{CO}_{2}(5 \%)$ a $37{ }^{\circ} \mathrm{C}$, sob condições estéreis. Antes de iniciar os tratamentos, as células foram parcialmente privadas de soro, sendo mantidas em DMEM contendo $0,5 \%$ de NCS por aproximadamente 18 horas. 


\subsection{Tratamento das células}

\subsubsection{Análise do efeito do T3 em proteínas componentes da via de sinalização da AMPK}

Para esta análise, inicialmente foram testadas diferentes concentrações de T3 (Sigma Aldrich, Steinheim, Alemanha), com o intuito de escolher a concentração do hormônio a ser utilizada. Após esta padronização, as células receberam os seguintes tratamentos:

- Controle: células mantidas em DMEM;

- T3: DMEM contendo T3 10 ๆM por 5, 10, 15, 30 minutos e 24 horas.

Após o tratamento das células, a proteína total foi extraída e utilizada para a avaliação da expressão protéica da AMPK, assim como de outras proteínas envolvidas nesta sinalização intracelular, através da técnica de Western Blotting.

\subsubsection{Avaliação da contribuição da AMPK no processo de hipertrofia cardiomiocítica induzida pelo T3}

Antes de iniciar esta avaliação, foi necessário padronizar o protocolo de tratamento, através de curva concentração-resposta para cada um dos fármacos utilizados. A partir do estabelecimento das concentrações a serem empregadas, as células foram então tratadas por 24 horas com T3 e com um inibidor da AMPK, o Composto C (Calbiochem, La Jolla, C.A., USA), ou tratadas com T3 e ativadores específicos para AMPK, AICAR (Sigma) e Metformina (Sigma). Nas amostras que foram incubadas com tratamentos combinados, as células foram pré-tratadas com os ativadores ou com o inibidor da AMPK por 2 horas. As células foram então submetidas aos seguintes tratamentos:

- Controle: células mantidas em DMEM;

- T3: DMEM contendo T3 10 ๆM;

- T3 + Composto C: DMEM contendo T3 $10 \eta \mathrm{M}$ e Composto C $10 \mu \mathrm{M}$;

- T3 + AICAR: DMEM contendo T3 10 ๆM e AICAR 0,5 mM;

- T3 + Metformina: DMEM contendo T3 10 ๆM e Metformina 2 mM;

- Composto C: DMEM contendo Composto C $10 \mu \mathrm{M}$; 
- AICAR: DMEM contendo AICAR 0,5 mM;

- Metformina: DMEM contendo Metformina 2 mM.

Após as 24 horas de tratamento das células, o RNA total foi extraído para a análise da expressão gênica de marcadores de hipertrofia cardíaca, através da técnica de RT-PCR em Tempo Real. Além disso, outros grupos de células foram utilizados para a análise de síntese protéica, avaliada através da incorporação de leucina triciada (KENESSEY e OJAMAA 2006; STUCK et al., 2008). E ainda, previamente a estas extrações, foram obtidas imagens para mensuração da área da superfície dos cardiomiócitos.

\subsection{Ensaio de incorporação de leucina triciada}

Este procedimento foi utilizado para avaliar a incorporação deste aminoácido (leucina) em proteínas que estão sendo sintetizadas pelos cardiomiócitos, permitindo desta forma, estimar o crescimento hipertrófico destas células. Após 72 horas de plaqueamento em meio de crescimento (DMEM suplementado com $5 \%$ de NCS e $10 \%$ de HS), as células foram privadas, por aproximadamente 18 horas, com meio contendo $0,5 \%$ de soro NCS. Em seguida foram tratadas por 24 horas, conforme descrito anteriormente no item 4.2.2. Seis horas antes do término do tratamento, 0 meio foi retirado e novo meio contendo $5 \mu \mathrm{Ci} / \mathrm{ml}$ de $\mathrm{L}-\left[4,5-{ }^{3} \mathrm{H}\right]$ Leucina (GE Healthcare) foi adicionado às células. Ao final do tratamento, o meio foi descartado, as células foram lavadas com PBS1X e lisadas com $500 \mu$ de ácido tricloroacético (TCA) $10 \%$. O homogenato foi coletado e centrifugado a $4{ }^{\circ} \mathrm{C}$, por 10 minutos, a 14000 rpm. Após a centrifugação, o sobrenadante foi desprezado, o homogenato ressuspendido novamente em $500 \mu$ de TCA $10 \%$ e submetido novamente à centrifugação. O homogenato final foi dissolvido em $500 \mu \mathrm{l}$ de $\mathrm{NaOH} 0,2 \mathrm{~N}$ e as amostras foram então incubadas a $60{ }^{\circ} \mathrm{C}$ por 30 minutos. Em seguida, em um tubo de cintilação foram acrescentados $400 \mu \mathrm{l}$ da amostra e 3,6 ml do líquido de cintilação (Perkin Elmer, Shelton, C.T., USA). As amostras foram contadas em Cintilador para a quantificação da incorporação de leucina triciada em cada amostra. A incorporação do aminoácido marcado das amostras foi então normalizada pelo número total de células. 


\subsection{Análise da expressão gênica por RT-PCR em Tempo Real}

\subsubsection{Extração do RNA total e cDNA}

Ao final dos tratamentos descritos no item 4.2.2, o RNA total das amostras de células foi extraído utilizando-se o reagente Trizol (Invitrogen, Carlsbad, C.A., USA). De acordo com as especificações do fabricante, após a lise das células com Trizol, foi adicionado clorofórmio e as amostras foram centrifugadas a $0{ }^{\circ} \mathrm{C}$, por 10 minutos, a 14000 rpm para separação de fases. O RNA ficou na fase aquosa, que após a transferência para um novo tubo, foi recuperado com a adição de isopropanol. Após uma nova centrifugação, o pellet foi lavado com etanol $75 \%$ e seco à temperatura ambiente por 5 minutos. Ao término deste processo, o homogenato de RNA foi ressuspenso em água DEPC. Em seguida, as amostras foram dosadas em espectrofotômetro de alta sensibilidade (Nanodrop). Após a quantificação do RNA total, foi realizada uma eletroforese para a verificação da integridade do RNA total extraído, em gel de agarose $1 \%$ a 90 Volts, corado com brometo de etídio. A partir de $1 \mu \mathrm{g}$ de RNA total extraído foi realizada a reação de transcrição reversa para a síntese de uma fita de DNA complementar ao RNA mensageiro (RNAm), o cDNA. A transcrição reversa foi realizada utilizando-se as especificações fornecidas pelo fabricante da enzima (M-MLV Reverse Transcriptase, Invitrogen), em termociclador.

\subsubsection{PCR em Tempo Real}

Esta técnica foi realizada para análise dos níveis RNAm para ANF e BNP, amplamente utilizados como marcadores de hipertrofia cardíaca (EPPENBERGER et al., 1997). Como normalizador da reação utilizamos os níveis de RNAm para GAPDH, uma vez que a expressão deste gene não é alterada em cardiomiócitos, após tratamento com HT (dados do laboratório, não publicados).

Com base no $\mathrm{Ct}$, o qual representa a linha de base de deteç̧ão de fluorescência, correspondente à fase exponencial, foi possível estimar a quantidade inicial de cDNA aplicado nas diferentes amostras. Os níveis de RNAm foram determinados através da fórmula: $2^{-\Delta \Delta C t}$, onde $\Delta \Delta \mathrm{Ct}=[\mathrm{Ct}$ amostra $-\mathrm{Ct}$ GAPDH da mesma amostra] - [Ct controle - Ct GAPDH controle]. Os resultados obtidos foram 
expressos com base na relação do RNAm de cada gene de interesse, com os níveis de RNAm de GAPDH. Para todos os genes investigados foram realizadas curvas de quantidades progressivas de cDNA e iniciadores (primers). As amostras foram processadas em duplicata ( $n=2 /$ grupo experimental) e 4 experimentos independentes foram realizados. Após a padronização dos diferentes primers, foram escolhidas as concentrações ideais de cDNA para cada primer, com o objetivo de que não houvesse saturação de amostra durante a reação. Para cada reação foi também utilizado um controle negativo, em duplicata, o qual não continha cDNA. As reações foram realizadas utilizando $300 \eta \mathrm{M}$ de cada primer, cDNA (de 0.625 a $5 \mathrm{ng}$ de acordo com a padronização de cada primer), $\mathrm{H}_{2} \mathrm{O}$ DEPC e $6.25 \mu \mathrm{l}$ de SYBR Green PCR Master Mix (Invitrogen), em um volume final de $12.5 \mu \mathrm{l} /$ reação. As reações foram realizadas utilizando-se 40 ciclos e temperatura de anelamento de 60 ${ }^{\circ} \mathrm{C}$.

As sequências dos primers utilizados encontram-se descritas na tabela a seguir (Tabela 1).

Tabela 1 - Sequência dos diferentes primers utilizados nos experimentos de PCR em Tempo Real.

ANF

BNP

GAPDH
5'- AGT GCG GTG TCC AAC ACA G -3'

5'- CAG AAC AAT CCA CGA TGC AG -3'

5'- TGG TGG ACC TCA TGG CCT AC -3'
5'- CTT CAT CGG TCT GCT CGC T -3

5'- GCT GTC TCT GAG CCA TTT CC-3'

\section{5 Medida da área de superfície celular}

Para confirmação do efeito hipertrófico dos HT nas células, a medida da área dos cardiomiócitos foi também avaliada. Para tal, as células foram plaqueadas em uma densidade de $200 \times 10^{4}$ / placa e receberam os tratamentos descritos no item 4.2.2. Para cada grupo, foram aleatoriamente obtidas imagens de 50 células em 3 culturas distintas. Estas imagens foram capturadas usando um microscópio invertido 
(Nikon) com câmera acoplada, com magnificância de 200x e a área da superfície dos cardiomiócitos foi medida usando o programa Image J.

\subsection{Análise da expressão protéica por Western Blotting}

Este procedimento foi utilizado para avaliar a presença e a possível variação na expressão de determinadas proteínas no lisado total de cardiomiócitos, frente às diferentes condições experimentais. Ao final dos tratamentos mencionados no item 4.2, foi realizada a extração da proteína total, cujo homogenato de três poços correspondeu a uma amostra. Foi utilizado um tampão apropriado para células (1\% NP40, 10\% glicerol, $135 \mathrm{mM} \mathrm{NaCl}, 20 \mathrm{mM}$ Tris, $20 \mathrm{mM}$ aprotinina, $20 \mathrm{mM}$ pepstatina, 20 mM leupepstatina, $40 \mu \mathrm{M}$ PMSF e 100 mM ortovanadato), sendo a concentração protéica das amostras obtida pelo método de Bradford (BRADFORD, 1976). Em seguida, $100 \mu \mathrm{g}$ de proteína total foram submetidas à eletroforese em gel denaturante de poliacrilamida a $6 \%$ para proteínas de alto peso molecular e a $10 \%$ quando as proteínas apresentavam peso molecular intermediário. As proteínas foram então transferidas para membrana de nitrocelulose (Bio Rad, Hercules, C.A., USA) e coradas com solução Ponceau para demonstrar que a concentração de proteínas era similar entre as diferentes amostras. Em seguida, a membrana foi incubada com solução de TBST (Tris 50 mM, NaCl 150 mM, pH 7.5 e Tween-20 2\%) por 10 minutos em temperatura ambiente. Posteriormente, a membrana foi então incubada com um dos anticorpos primários para cada proteína avaliada (Tabela 2), em agitação durante aproximadamente 18 horas, a $4{ }^{\circ} \mathrm{C}$. Após a lavagem da membrana, esta foi então incubada com anticorpo secundário conjugado à peroxidase (Jackson Immuno Research, West Grove, P.A., USA). Novamente, esta foi lavada e incubada com solução de ECL (Thermo Scientific, Rockford, I.L., USA), a qual tem como função promover uma reação de luminescência, cujo produto final impressionará um filme de raio $\mathrm{X}$. A banda correspondente à proteína de interesse foi quantificada por densitometria em um sistema de fotodocumentação Gel Pro Imager (Media Cybernetics), sendo os valores expressos em porcentagem ou vezes de indução em relação ao controle. As amostras foram normalizadas pelos níveis de expressão da proteina GAPDH nos experimentos que foram utilizados géis a $10 \%$ e pelos níveis de expressão da proteína a actinina nos experimentos para identificação 
de proteínas mais pesadas, avaliadas em géis a $6 \%$. Os anticorpos utilizados encontram-se descritos na tabela a seguir (Tabela 2).

Tabela 2 - Lista de anticorpos primários utilizados para a análise de expressão protéica por Western Blotting.

\begin{tabular}{|c|c|c|c|}
\hline Proteínas analisadas & Origem & $\begin{array}{c}\text { Peso } \\
\text { molecular }\end{array}$ & Titulação \\
\hline AMPKa-p (Tre 172) & Cell Signaling (2531) & $62 \mathrm{kDa}$ & $1: 500$ \\
\hline AMPKa-p (Ser 485/491) & Cell Signaling (4185) & $62 \mathrm{kDa}$ & $1: 500$ \\
\hline AMPKa & Cell Signaling (2532) & $62 \mathrm{kDa}$ & $1: 500$ \\
\hline LKB1-p (Ser 428) & Cell Signaling (3482) & $52 \mathrm{kDa}$ & $1: 500$ \\
\hline LKB1 & Santa Cruz (sc-5640) & $52 \mathrm{kDa}$ & $1: 500$ \\
\hline PP2C $\alpha / \beta$ & Santa Cruz (sc-48829) & $46 \mathrm{kDa}$ & $1: 500$ \\
\hline CaMKK $\beta$ & Santa Cruz (sc-9629) & $66 \mathrm{kDa}$ & $1: 500$ \\
\hline ACC-p (Ser 79) & Cell Signaling (3661) & $280 \mathrm{kDa}$ & $1: 500$ \\
\hline ACC & Cell Signaling (3662) & $280 \mathrm{kDa}$ & $1: 500$ \\
\hline mTOR-p (Ser 2448) & Cell Signaling (2971S) & $289 \mathrm{kDa}$ & $1: 500$ \\
\hline mTOR & Cell Signaling (2972) & $289 \mathrm{kDa}$ & $1: 500$ \\
\hline a actinina & Santa Cruz (sc-15335) & $100 \mathrm{kDa}$ & $1: 1000$ \\
\hline GAPDH & Santa Cruz (sc-32233) & $37 \mathrm{kDa}$ & $1: 1000$ \\
\hline
\end{tabular}

\subsection{Análise dos Resultados}

Os resultados obtidos são apresentados como média \pm desvio-padrão da média e são expressos em porcentagem de variação em relação grupo controle, ou 
em vezes de indução em relação às células controle. O "n" representa o número de experimentos realizados com diferentes culturas de cardiomiócitos, sendo que em cada experimento foram utilizadas no mínimo três culturas distintas. Os dados foram analisados e comparados utilizando-se a Análise de Variância, considerando-se significativas as diferenças cujo $P<0.05$. O pós-teste de Tukey foi utilizado para as análises entre grupos, quando uma diferença significativa $(P<0.05)$ foi observada na Análise de Variância. 


\section{RESULTADOS}

\subsection{Padronização do tratamento com T3}

O envolvimento da AMPK como importante reguladora do processo de síntese protéica foi documentado recentemente em cardiomiócitos tratados com diferentes estímulos hipertróficos, como citado anteriormente. No entanto, ainda não havia sido avaliada se esta interação também estaria presente na hipertrofia cardíaca induzida pelo hormônio tiroideano. No intuito de definir as condições ideais para investigar este possível envolvimento da AMPK, algumas padronizações foram previamente realizadas.

Para a escolha da concentração hormonal a ser utilizada no tratamento dos cardiomiócitos foi realizada, inicialmente, uma curva concentração-resposta de T3 (1 $\eta \mathrm{M}, 10 \eta \mathrm{M}, 100 \eta \mathrm{M}$ e $1 \mu \mathrm{M}$ ), por 5 minutos. A escolha do tempo de 5 minutos para a realização desta curva baseou-se em resultados prévios do laboratório, os quais demonstraram que mesmo tempos curtos de tratamento com o hormônio já deflagram a ativação de cascatas de sinalização relacionadas ao processo hipertrófico, como ocorre, por exemplo, com a sinalização da Akt (DINIZ; CARNEIRO-RAMOS; BARRETO-CHAVES, 2009).

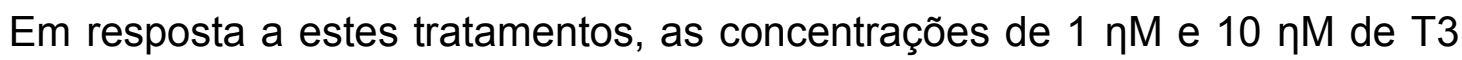
promoveram um aumento significativo nos níveis de expressão protéica de AMPK fosforilada na $\operatorname{Tre}^{172}(126,45 \% \pm 8,3$ e $154,97 \% \pm 9,6$, respectivamente), quando comparados àqueles observados nas células controle $(100,08 \% \pm 8,9)$, como podemos observar pela análise da Figura 3 , a seguir. 


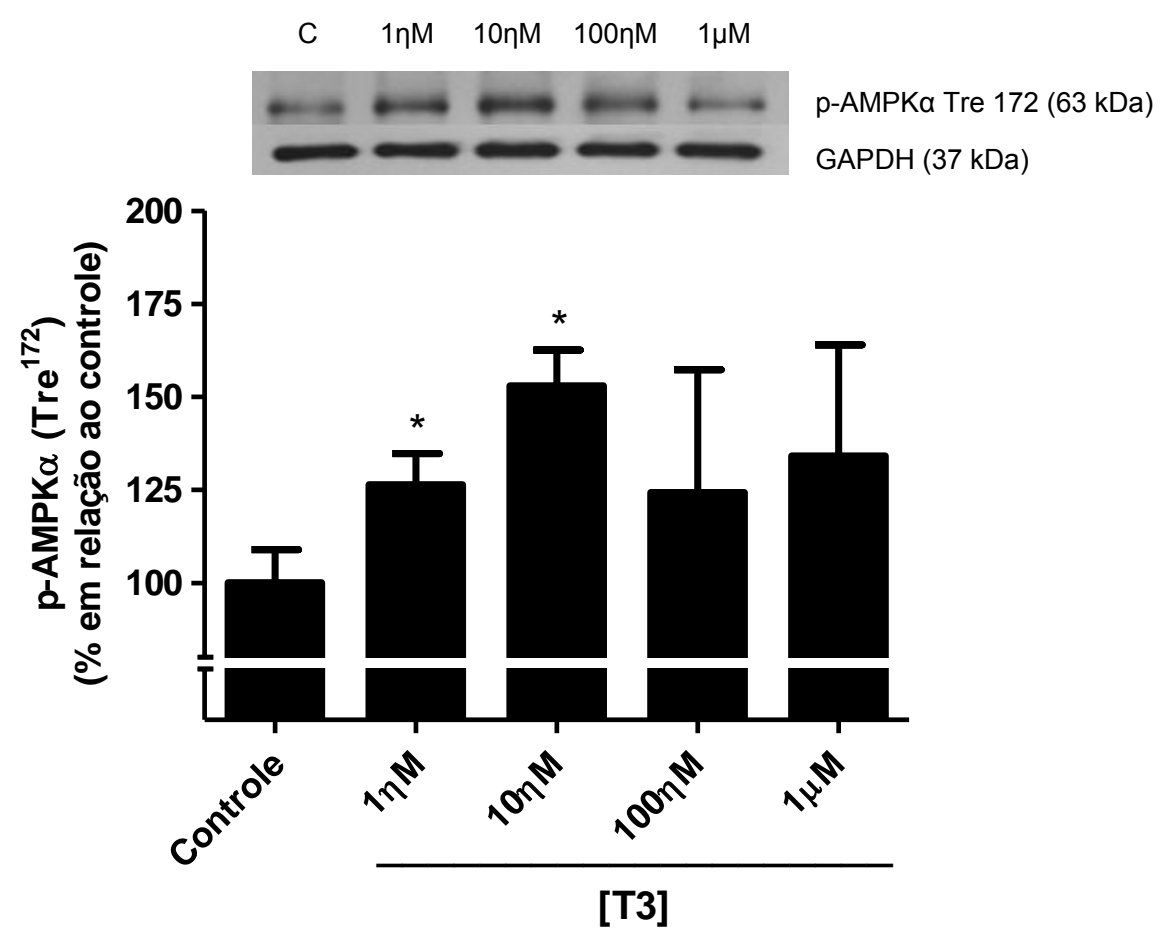

Figura 3. Curva concentração-resposta de T3 em culturas de cardiomiócitos. As células receberam o tratamento com concentrações crescentes de T3, ou ainda foram mantidas em DMEM sem soro (controle) durante 5 minutos. Foi avaliada a expressão protéica de AMPKa fosforilada no resíduo Tre ${ }^{172}$, por Western Blotting. Valores expressos como porcentagem em relação ao observado nas células do grupo controle. ${ }^{*} \mathrm{P}<0.05$ vs. controle $(n=3)$.

Estes resultados nos direcionaram a estabelecer a concentração de $10 \eta \mathrm{M}$ de T3 como tratamento para nossos experimentos. Em primeiro lugar porque esta concentração mostrou-se influenciar significativamente os níveis de fosforilação da AMPK, quando comparados àqueles observados nas células controle. Além disso, essas condições de tratamento já foram utilizadas anteriormente em experimentos do nosso grupo, para avaliação de outras vias de sinalização relacionadas a este modelo de hipertrofia (DINIZ; CARNEIRO-RAMOS; BARRETO-CHAVES, 2009), permitindo assim, a comparação de dados e discussão de possíveis relações entre essas diferentes vias de sinalização. 


\subsection{Análise do efeito do T3 em componentes da via de sinalização da AMPK}

Uma vez definidas as condições de tratamento, foram iniciados os experimentos para a avaliação da influência do T3 na sinalização da AMPK. Com o intuito de avaliar os efeitos a curto e a longo prazo do HT na via de sinalização da AMPK, os cardiomiócitos foram tratados com T3 a $10 \eta \mathrm{M}$, por curtos tempos (de 5 a 30 minutos) e também por 24 horas. Foram avaliados assim, os níveis protéicos de AMPK fosforilada na Tre ${ }^{172}$, AMPK fosforilada na Ser ${ }^{485 / 491}$, Acetil-CoA Carboxilase (ACC) fosforilada na Ser ${ }^{79}$, LKB1 fosforilada na $\mathrm{Ser}^{428}$, a expressão protéica total destas enzimas, e também os níveis de PP2C e CaMKK $\beta$.

Inicialmente avaliamos os níveis de AMPK fosforilada na Tre ${ }^{172}$, AMPK total, assim como a razão da expressão da AMPK fosforilada pela AMPK total (Figura 4), cujos resultados encontram-se a seguir.

A

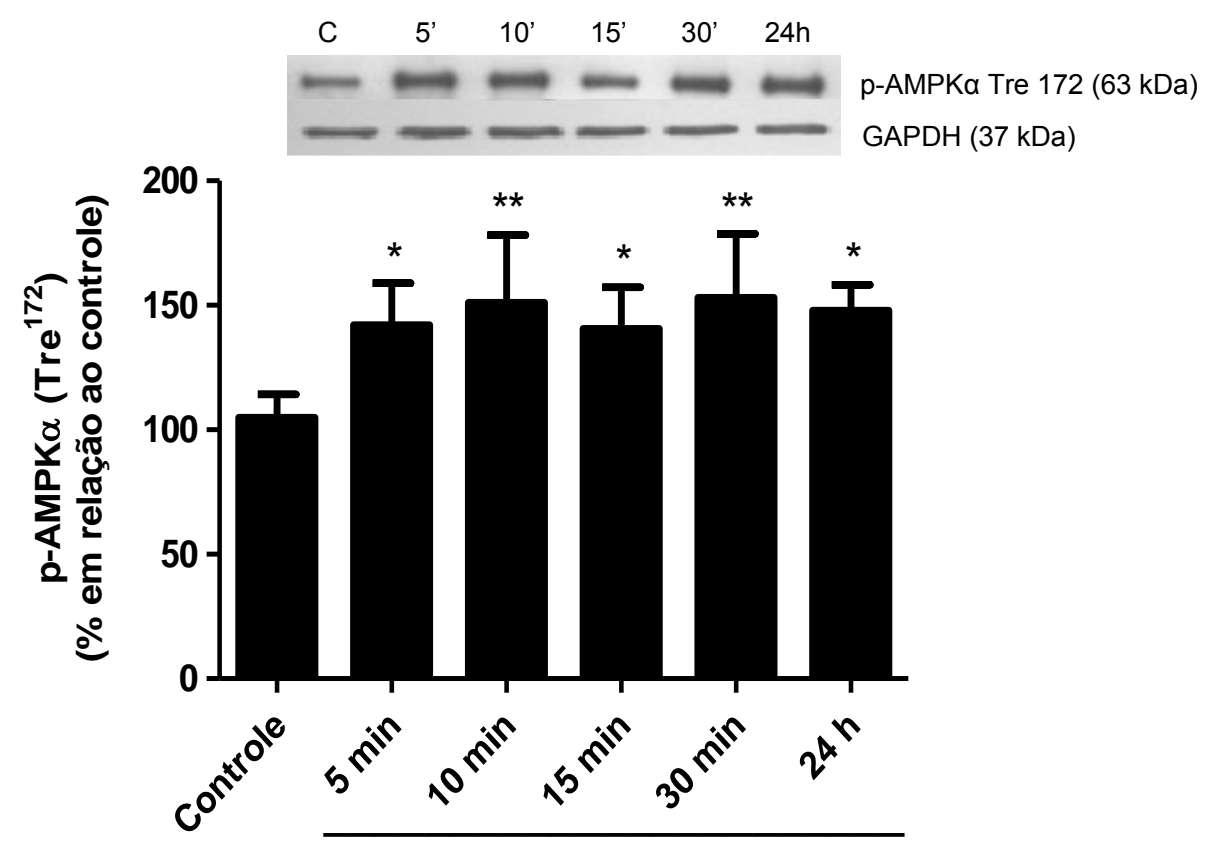

T3 
B

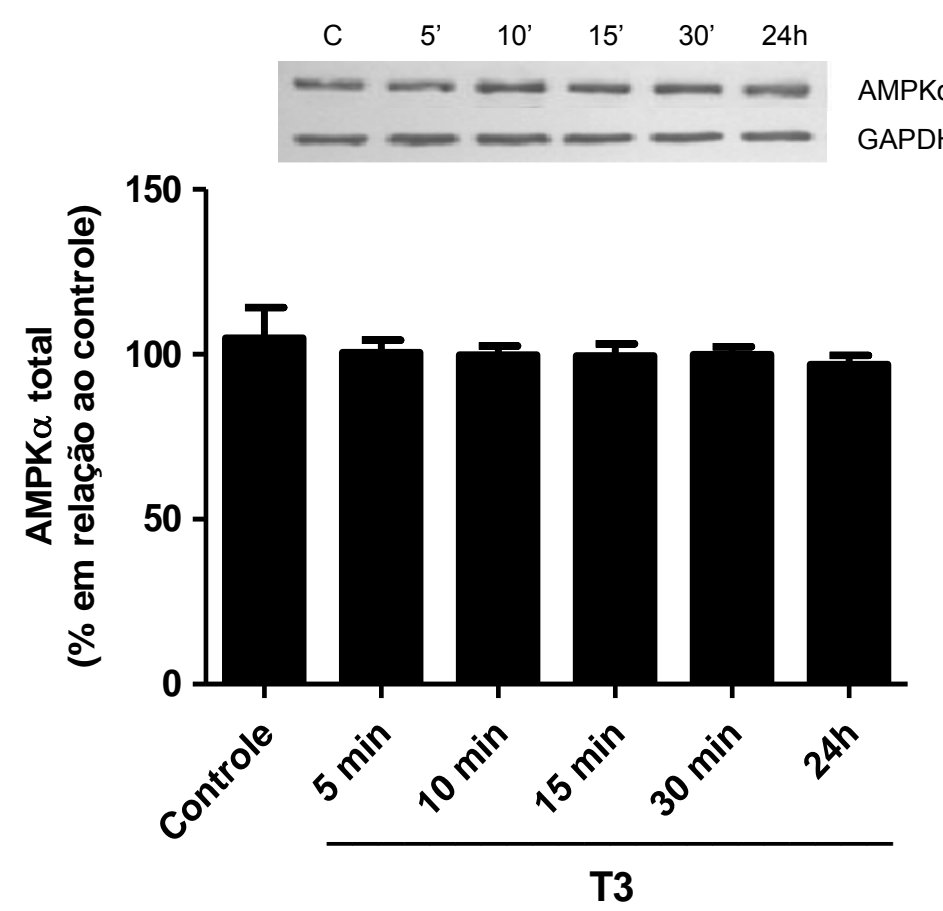

C

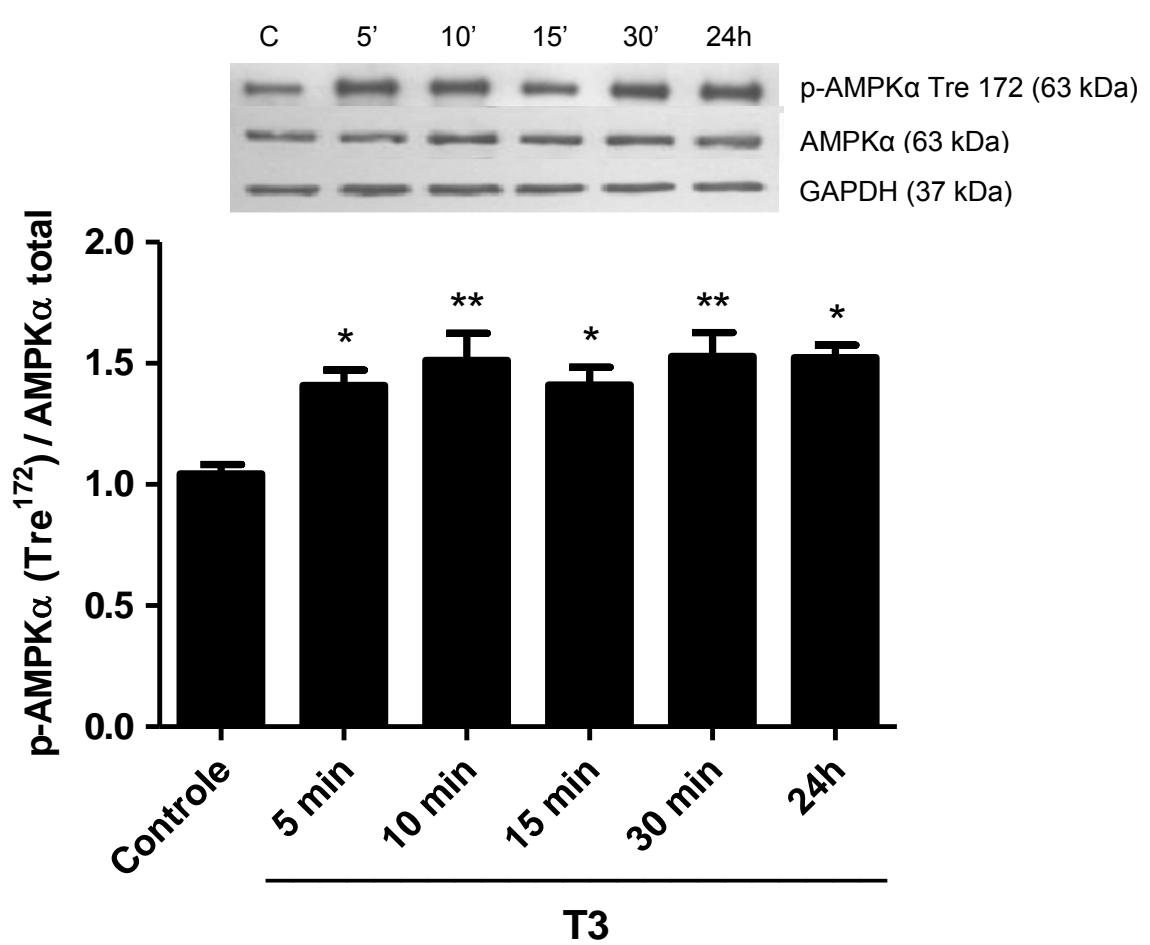

Figura 4. Análise dos níveis de AMPKa fosforilada na $\operatorname{Tre}^{172}(A)$, AMPK total (B) e razão AMPKa fosforilada na Tre ${ }^{172} /$ AMPK total (C). Os cardiomiócitos foram mantidos em DMEM sem soro (controle) ou tratados com 10 nM de T3 por 5, 10, 15, 30 minutos e 24 horas. Valores expressos como porcentagem em relação ao grupo controle (A, B), ou expressos como vezes de indução em relação às células controle $(C)$. ${ }^{*} P<0.05$ vs. controle; ${ }^{*} P<0.01$ vs. controle $(n=7)$. 
Os níveis de AMPK fosforilada na Tre ${ }^{172}$, assim como a razão AMPKa fosforilada na Tre ${ }^{172} / \mathrm{AMPK}$ total, aumentaram rapidamente após o tratamento com T3 e mantiveram-se ao longo de 24 horas de tratamento.

Embora a fosforilação na Tre ${ }^{172}$ seja um indicativo da ativação da AMPK, também avaliamos os níveis de fosforilação da acetil-CoA carboxilase ( $p-A C C$ no resíduo de $\operatorname{Ser}^{79}$ ), considerada alvo direto da AMPK (ARAD; SEIDMAN; SEIDMAN, 2007; CHAN et al., 2008). Como esperado, a fosforilação da ACC aumentou rapidamente após os tratamentos rápidos com T3 (Figura 5), corroborando, desta forma, um aumento da atividade da AMPK em resposta ao T3.

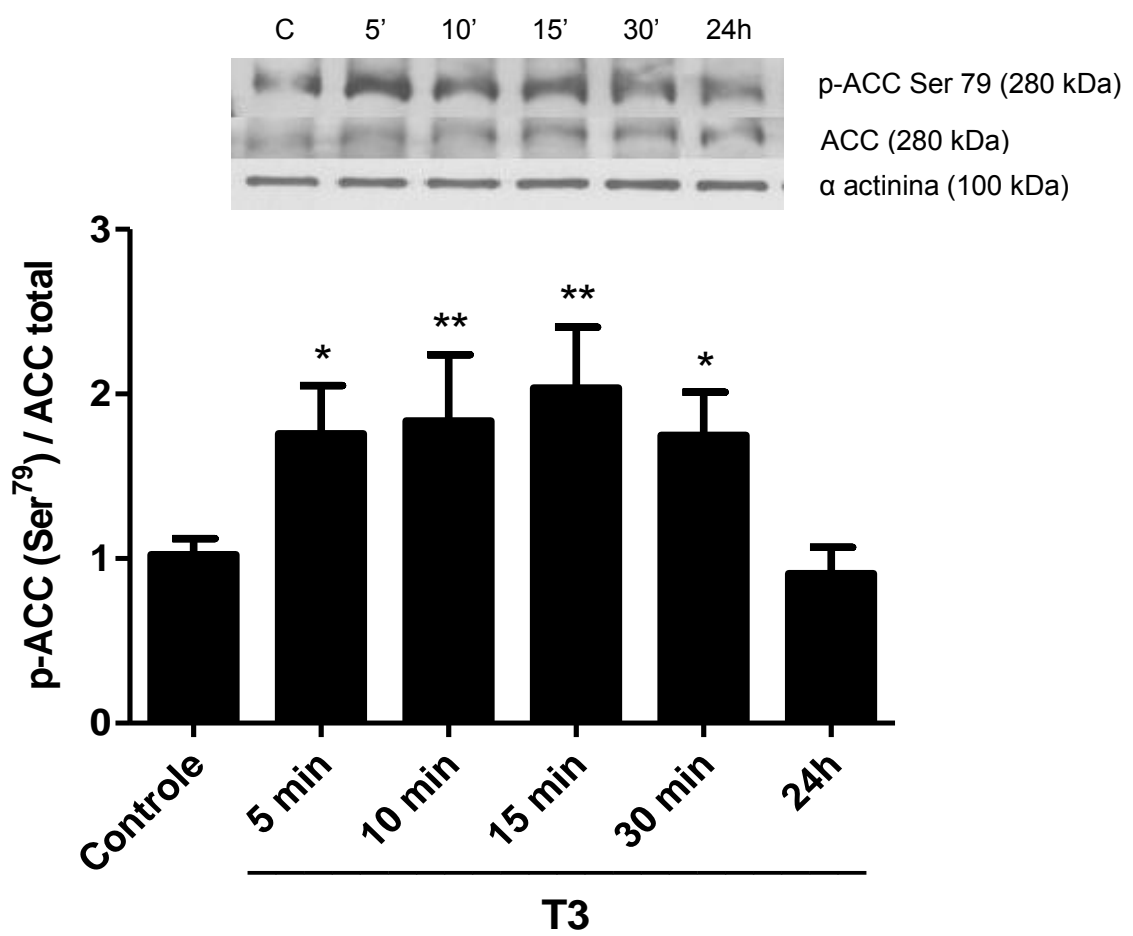

Figura 5. Análise da razão ACC fosforilada na $\operatorname{Ser}^{79} / A C C$ total, avaliada por Western Blotting. Os cardiomiócitos foram mantidos em DMEM sem soro (controle) ou tratados com 10 ๆM de T3 por $5,10,15,30$ minutos e 24 horas. Valores expressos como vezes de indução em relação às células controle. ${ }^{*} P<0.05$ vs. controle; ${ }^{* *} P<0.01$ vs. controle $(n=4)$.

Após a análise do efeito do T3 na ativação da AMPK, passamos a investigar se este hormônio também era capaz de modular a fosforilação desta quinase em outro resíduo, na $\operatorname{Ser}^{485 / 491}$ (Figura 6). Recentes pesquisas têm indicado que a fosforilação deste resíduo, considerado uma alternativa de auto-regulação da AMPK, 
uma vez fosforilado, pode prevenir a fosforilação na Tre ${ }^{172}$, impedindo, portanto, a ativação desta quinase no coração (HURLEY et al., 2006; SOLTYS; KOVACIC; DYCK, 2006).

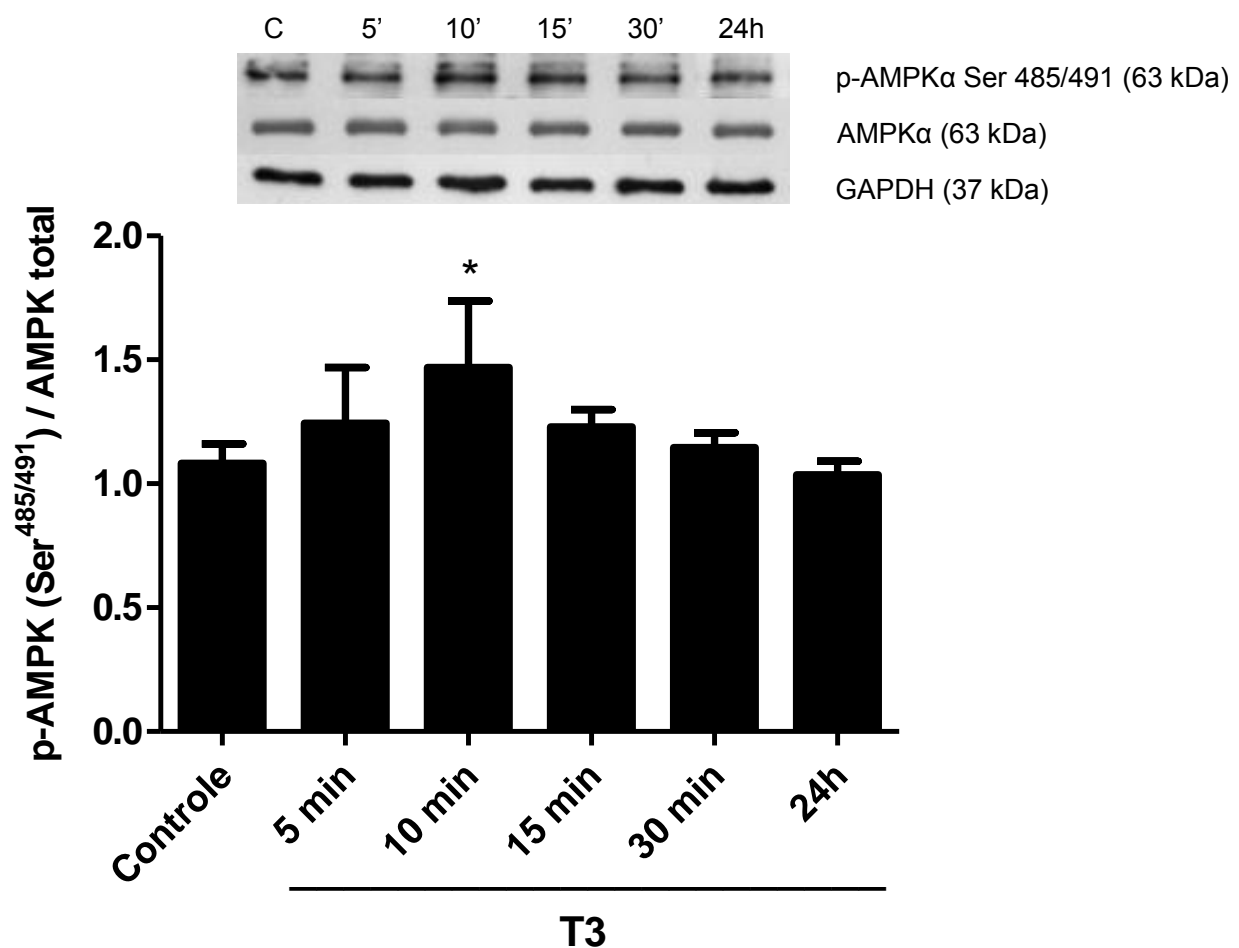

Figura 6. Análise da razão AMPKa fosforilada na Ser ${ }^{485 / 491} / A M P K$ total avaliada por Western Blotting. As células receberam DMEM sem soro (controle) ou foram tratadas com meio sem soro contendo $10 \eta \mathrm{\eta M}$ de T3 por 5, 10, 15, 30 minutos e 24 horas. Valores expressos como vezes de indução em relação às células controle. ${ }^{*} \mathrm{P}<0.05$ vs. controle $(n=4)$.

Os resultados mostraram que, embora seja notada uma tendência de rápida modulação da AMPK pelo T3, somente após 10 minutos de tratamento, houve um aumento significativo da AMPK fosforilada nos resíduos de $\operatorname{Ser}^{485 / 491}(1,47 \% \pm 0,26)$, em relação às células do grupo controle $(1,08 \% \pm 0,07)$ (Figura 6$)$.

O passo seguinte foi então o de avaliar a expressão protéica de LKB1, considerada a principal AMPKK descrita na literatura. Os resultados apresentados a seguir mostram que o T3 foi capaz de promover o aumento de LKB1 fosforilado na $\mathrm{Ser}^{428}$ somente em tempos muito curtos, não sendo mais observado este efeito após 15 minutos de tratamento com este hormônio (Figura 7). Assim, apesar do 
tratamento com T3 promover um aumento da AMPK fosforilada na Tre ${ }^{172} \mathrm{em}$ todos os tempos avaliados, a ativação desta quinase parece ocorrer também independentemente da influência de LKB1, sugerindo que outras AMPKKs possam estar envolvidas neste modelo.

A

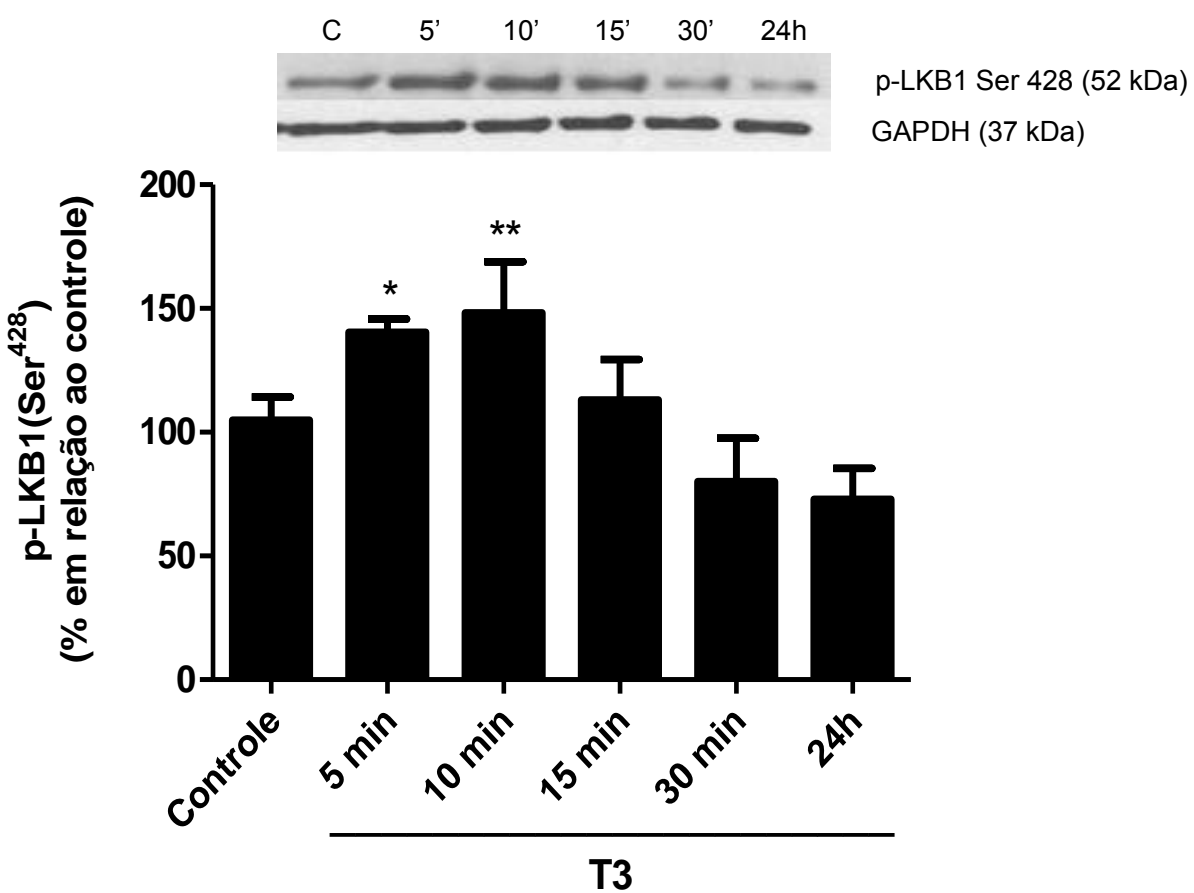

B

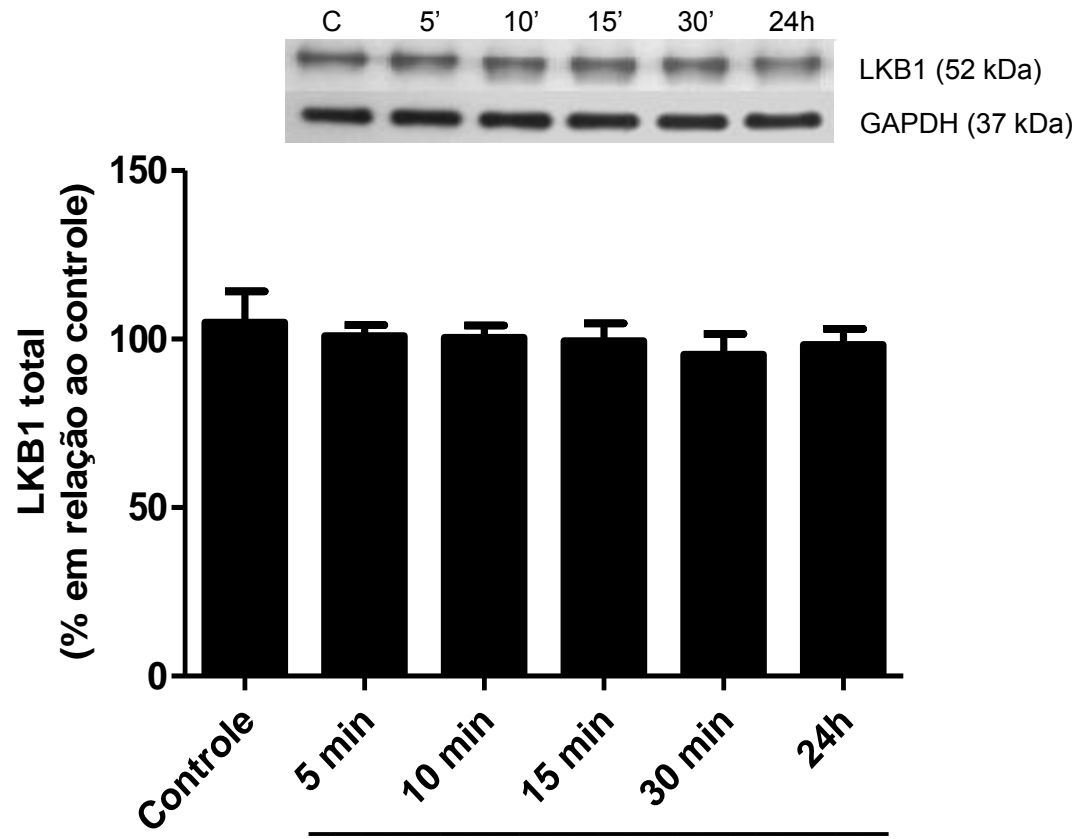


C

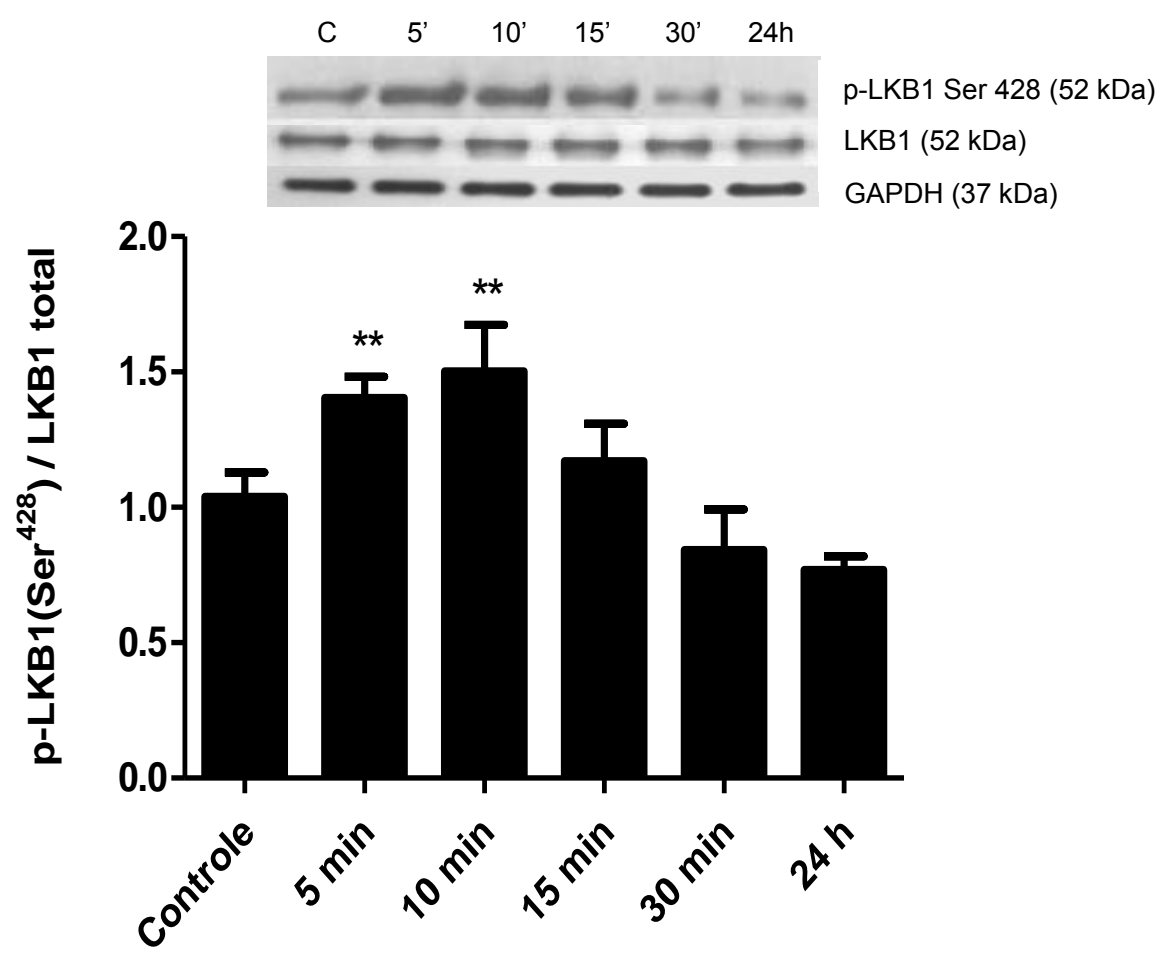

Figura 7. Análise dos níveis de LKB1 fosforilado na $\operatorname{Ser}^{428}$ (A), LKB1 total (B) e razão LKB1 fosforilado na $\operatorname{Ser}^{428} / \mathrm{LKB} 1$ total (C). As células foram mantidas em DMEM sem soro (controle) ou tratadas com $10 \eta \mathrm{\eta M}$ de T3 por 5, 10, 15, 30 minutos e 24 horas. Valores expressos como porcentagem em relação às células controle $(A, B)$ ou expressos como vezes de indução em relação às células controle $(C)$. ${ }^{*} P<0.05$ vs. controle; ${ }^{* *} P<0.01$ vs. controle $(n=6)$.

Apesar da LKB1 ser descrita como principal quinase ativadora da AMPK, a CaMKK $\beta$ também é capaz de promover a fosforilação da AMPK no resíduo Treonina 172 (HAWLEY et al., 2005; WOODS et al., 2005). Embora seja pouco expressa no coração (ANDERSON et al., 1998), buscamos avaliar se o T3 exerce influência na expressão desta AMPKK para ativação da AMPK. 


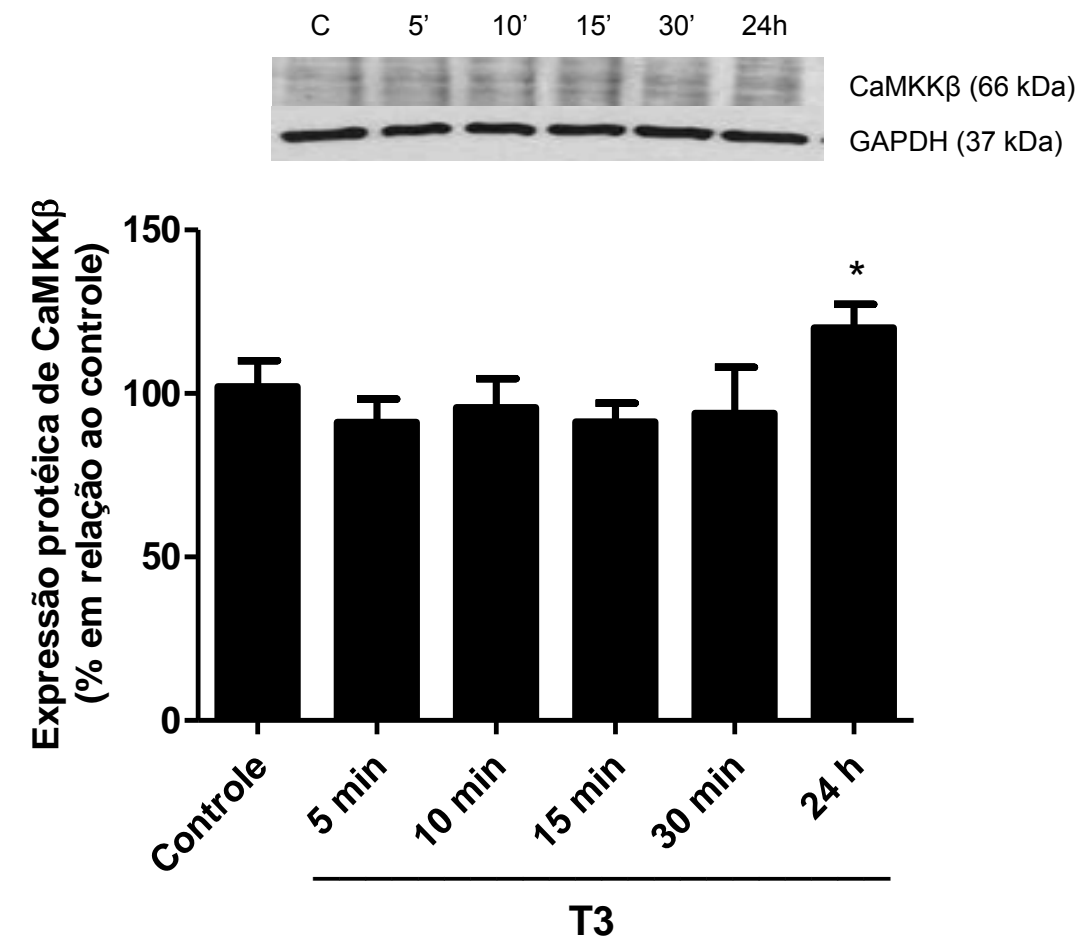

Figura 8. Análise da expressão protéica de CaMKKß. Os cardiomiócitos receberam DMEM sem soro (controle) ou foram tratados com 10 nM de T3 por 5, 10, 15, 30 minutos e 24 horas. Os valores são representados em porcentagem em relação às células controle. ${ }^{*} \mathrm{P}<0.05$ vs. controle $(n=4)$.

Como mostrado na Figura 8, o hormônio tiroideano não modula a expressão de CaMKK $\beta$ após tratamentos de duração mais curta. Entretanto, após um tempo mais longo de 24 horas, o T3 é capaz de aumentar significativamente os níveis protéicos desta quinase. Desta forma, a rápida ativação da AMPK pelo T3 pode ocorrer através da ativação de LKB1, enquanto que, após 24 horas de tratamento, esta ativação parece depender de outra AMPKK. O aumento da expressão de CaMKK $\beta$, observado após 24 horas de tratamento com T3, indica ser esta uma potencial candidata para a ativação da AMPK em tempos mais longos.

Uma vez avaliados os níveis de expressão dos principais ativadores da AMPK, passamos então a avaliar a resposta das fosfatases, frente ao tratamento com T3. Assim, a expressão protéica da PP2C foi avaliada, uma vez que esta é a principal fosfatase capaz de desativar a AMPK. Observamos que, paralelamente ao aumento da ativação da AMPK, sua defosforilação pela PP2C também é aumentada 
de maneira significativa pelo tratamento com T3 por 5 minutos $(124,34 \% \pm 4,59), 10$ minutos $(131,70 \% \pm 11,01)$ e 30 minutos $(125,30 \% \pm 9,97)$, em relação às células do grupo controle $(100,80 \% \pm 8,38)$. No entanto, com 15 minutos $(117,60 \% \pm 5,29) \mathrm{e}$ por um período mais longo, ou seja, com 24 horas $(117,30 \% \pm 6,35)$ de tratamento, a expressão protéica da PP2C apresenta valores próximos do controle (Figura 9).

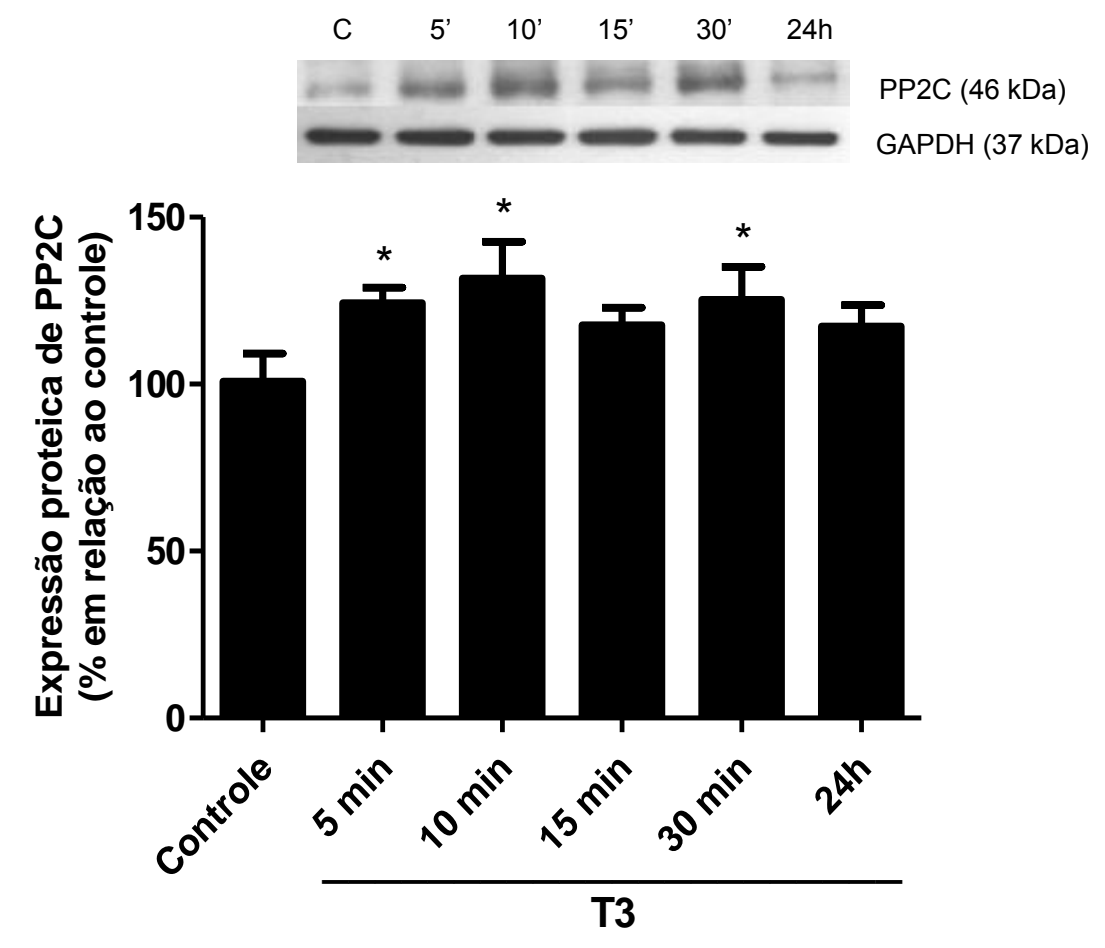

Figura 9. Análise da expressão protéica da PP2C. Os cardiomiócitos foram mantidos em DMEM sem soro (controle) ou tratados com 10 nM de T3 por 5, 10, 15, 30 minutos e 24 horas. Os valores são representados em porcentagem e relação às células controle. ${ }^{*} \mathrm{P}<0.05$ vs. controle $(n=6)$.

Esses resultados apresentados até o momento evidenciam, em seu conjunto, que o tratamento com T3 exerce efeitos significativos sobre a via de sinalização da AMPK, em culturas primárias de cardiomiócitos (Figura 10). A partir destes dados, considerando os objetivos propostos no presente estudo, passamos a investigar um possível envolvimento desta quinase no processo de hipertrofia do cardiomiócito induzida pelo HT. 


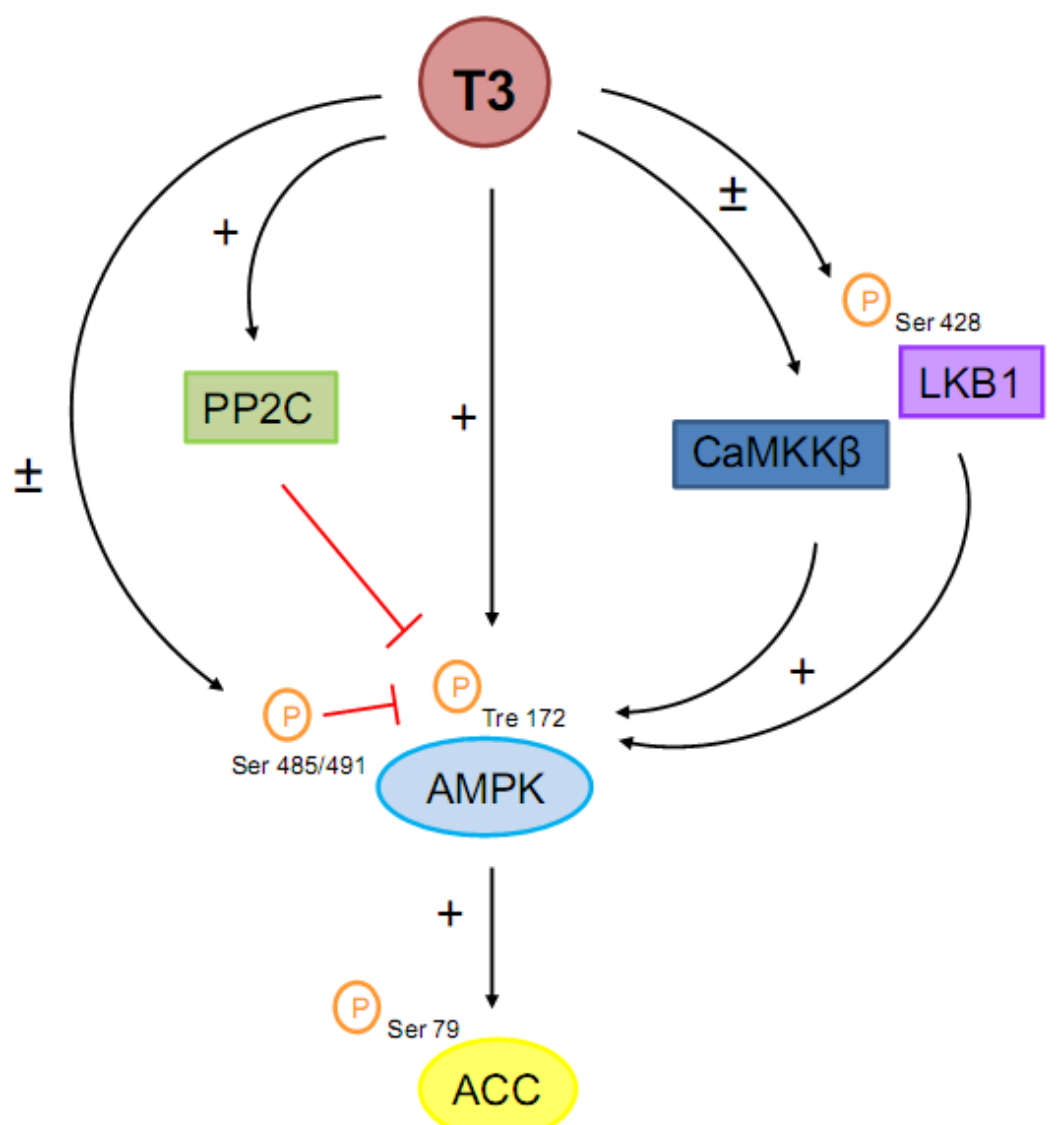

Figura 10. Esquema representativo do efeito do T3 nos componentes da via de sinalização da AMPK, em culturas de cardiomiócitos. O tratamento destas células com T3 levou a um aumento da AMPK fosforilada no resíduo da $\operatorname{Tre}^{172}$ e, consequentemente, também aumentou a fosforilação da ACC no resíduo da Ser ${ }^{79}$. Ainda, a ativação da AMPK em cardiomiócitos deflagrada pelo T3 pode ser influenciada rapidamente por ação de LKB1, ou através da CaMKK $\beta$ em um tempo mais longo (24 horas). Desta forma, estas duas distintas AMPKKs parecem atuar sobre a ativação da AMPK pelo T3 nestas células. Paralelamente, houve um aumento da expressão protéica da PP2C, acompanhada da rápida modulação da AMPK fosforilada no resíduo Ser 485/491 (10 min) pelo T3 que, conjuntamente, podem agir na defosforilação e desativação da AMPK na Tre 172. Setas com sinal + indicam ativação, com sinal \pm indicam pouca ativação (ativação em poucos dos tempos avaliados). Os traços em vermelho indicam inibição.

\subsection{Padronização das concentrações dos agentes farmacológicos utilizados para tratamento dos cardiomiócitos}

Para avaliar a possível contribuição da via de sinalização da AMPK no processo de hipertrofia do cardiomiócito induzido pelo tratamento com T3, passamos a utilizar diferentes agentes farmacológicos que, sabidamente, são conhecidos da literatura por serem agentes capazes de ativar ou inibir a AMPK. Inicialmente, 
tomamos como base as concentrações dos fármacos, já descritas na literatura, e utilizadas no mesmo tipo celular, cardiomiócitos. No entanto, não obtivemos bons resultados e, portanto, foi necessário realizar curvas concentração-resposta para cada um destes agentes farmacológicos. Logo após, para avaliação e confirmação de seus efeitos sobre a AMPK, avaliamos então, por Western Blotting, os níveis protéicos da AMPK fosforilada no resíduo de Tre ${ }^{172}$.

\subsubsection{Curva concentração-resposta de Metformina}

Iniciamos com os testes para a padronização da concentração de Metformina, agente capaz de ativar indiretamente a AMPK em coração intacto (ZHANG; HE; BALSCHI, 2007) e em cardiomiócitos isolados (KOVACIC et al., 2003; YANG e HOLMAN, 2006), assim como em outros órgãos e tecidos (FRYER; PARBU-PATEL; CARLING, 2002; ZHOU et al., 2001). Embora o mecanismo de ativação deste fármaco ainda não seja bem esclarecido, existem hipóteses de que esta droga seja capaz de inibir o complexo 1 da cadeia respiratória, o que provocaria, dessa forma, uma alteração na carga energética, resultando em um aumento de AMP intracelular, o qual ativaria a AMPK (HARDIE, 2006; OWEN; DORAN; HALESTRAP, 2000; ZHANG; HE; BALSCHI, 2007). No entanto, também existem estudos que sugerem que a AMPK pode ser ativada pela metformina sem mudanças na razão de AMP/ATP intracelular (HAWLEY et al., 2002). Como nos trabalhos da literatura encontramos tratamentos em cardiomiócitos com este fármaco em concentrações que variam de $1 \mathrm{mM}$ a $5 \mathrm{mM}$ (CHAN et al., 2004; SAEEDI et al., 2009; YANG e HOLMAN, 2006), decidimos assim, avaliar as seguintes concentrações: 0,1 mM, 0,5 $\mathrm{mM}, 1 \mathrm{mM}, 2 \mathrm{mM}$ e $5 \mathrm{mM}$ de Metformina, por 24 horas (Figura 11). 


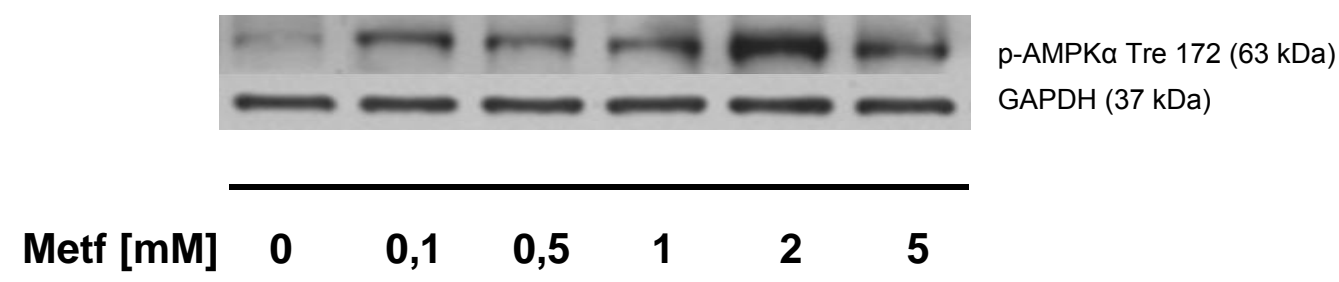

Figura 11. Blot representativo do efeito do tratamento com Metformina (Metf) sobre a AMPK em cardiomiócitos. As células receberam meio sem soro nas células controle (0), ou meio sem soro contendo Metformina em diferentes concentrações por 24 horas. Todas as concentrações de Metformina induziram um aumento dos níveis da AMPKa fosforilada na Tre ${ }^{172}$, com efeito máximo na concentração de $2 \mathrm{mM}$.

Como podemos observar na Figura 11, todas as diferentes concentrações utilizadas foram capazes de aumentar os níveis de AMPK fosforilada no resíduo de $\operatorname{Tre}^{172}$, e consequentemente, indicam que foram capazes de ativar a AMPK. Decidimos optar pela concentração de $2 \mathrm{mM}$, cuja ativação foi bem mais expressiva em relação ao grupo controle e aos outros grupos com diferentes concentrações.

\subsubsection{Curva concentração-resposta de Aicar}

Um segundo composto ativador da AMPK foi também avaliado, o 5-amino-4imidazolecarboxamide riboside, conhecido como AICAR. Diferentemente da metformina, esta droga é convertida em um análogo do AMP, que diretamente se liga e ativa a AMPK (WONG et al., 2009). Também iniciamos os testes com a concentração utilizada em alguns trabalhos da literatura, ou seja, a de $1 \mathrm{mM}$ (CHAN et al., 2004; STUCK et al., 2008), e ainda testamos outras menores, de 0,5 mM e 0,1 $\mathrm{mM}$ de AICAR, por 24 horas (Figura 12).

As duas maiores concentrações de $\operatorname{AICAR}(0,5 \mathrm{mM}$ e $1 \mathrm{mM})$, levaram a um significativo aumento dos níveis de AMPK fosforilada, e, uma vez que essas concentrações mostraram resposta similar quanto à ativação da AMPK, elegemos a menor concentração $(0,5 \mathrm{mM})$ para tratamento dos cardiomiócitos (Figura 12). 


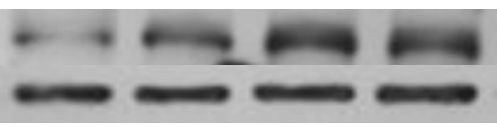

p-AMPKa Tre 172 (63 kDa)

GAPDH (37 kDa)

\section{AICAR [mM] $\quad 0 \quad 0,1 \quad 0,5 \quad 1$}

Figura 12. Efeito do tratamento por 24 horas com AICAR nos níveis de AMPKa fosforilada na Tre ${ }^{172}$. Ao longo deste período, os cardiomiócitos receberam meio sem soro nas células controle (0), ou meio sem soro contendo AICAR em diferentes concentrações.

\subsubsection{Curva concentração-resposta de Composto C}

Além das drogas capazes de ativar a AMPK, fizemos uma curva concentração-resposta para o Composto $C$, inibidor farmacológico da AMPK. Demos início aos tratamentos com uma concentração de $40 \mu \mathrm{M}$, baseada em Saeedi et al. (2009), porém esta mostrou-se tóxica aos cardiomiócitos. Desta forma, tratamos as células com concentrações menores, de 0,1 $\mathrm{M}, 1 \mu \mathrm{M}, 5 \mu \mathrm{M}, 10 \mu \mathrm{M}$ e $20 \mu \mathrm{M}$, por 24 horas (Figura 13).

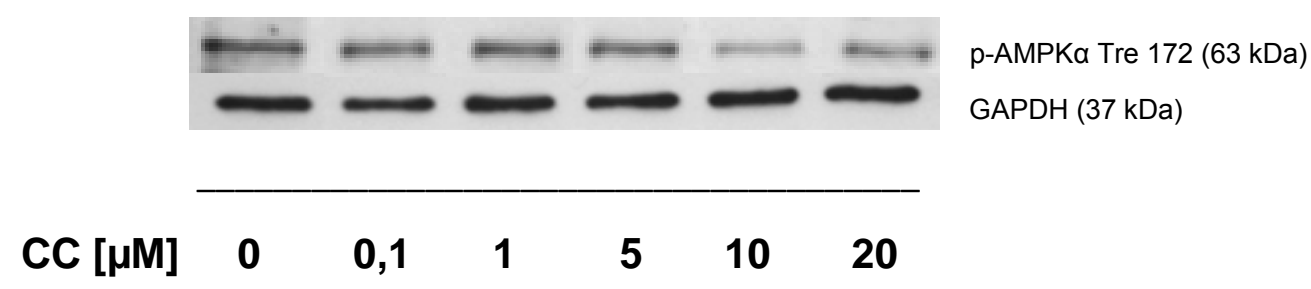

Figura 13. Efeito do tratamento com Composto $C$ (CC) nos níveis de AMPKa fosforilada na Tre ${ }^{172}$. As células receberam meio sem soro nas células controle (0), ou meio sem soro contendo Composto $\mathrm{C}$ em diferentes concentrações por 24 horas.

Pode-se observar na Figura 13 que as diferentes concentrações deste fármaco não foram eficientes na inibição da AMPK, não sendo possível utilizar concentrações ainda maiores, devido ao seu alto grau de toxicidade com consequente morte celular. A concentração de $10 \mu \mathrm{M}$ foi a mais eficiente, resultando na diminuição em torno de $50 \%$ nos níveis da AMPK fosforilada na Tre ${ }^{172}$. Diante 
deste resultado, esta foi inicialmente a concentração escolhida para promover a inibição da AMPK nos cardiomiócitos.

Uma vez realizada a padronização das concentrações dos agentes farmacológicos a serem utilizados, partimos para a análise do possível envolvimento da AMPK no processo de hipertrofia cardíaca induzida pelo HT.

\subsection{Avaliação da contribuição da ativação da AMPK na hipertrofia do cardiomiócito induzida pelo T3}

Nesta etapa do trabalho foram utilizados três métodos complementares bem estabelecidos e aceitos na literatura com o objetivo de avaliar a hipertrofia do cardiomiócito: a análise da síntese protéica, através do ensaio de incorporação de leucina triciada, a avaliação da expressão gênica de marcadores de hipertrofia cardíaca, através da técnica de RT-PCR em Tempo Real, e ainda a mensuração da área da superfície destas células.

Em relação à análise de incorporação de leucina, inicialmente foi realizada uma curva tempo-resposta para avaliar o espaço de tempo em que a incorporação deste aminoácido ocorre de maneira linear, ou seja, por quanto tempo há linearidade de síntese protéica nos cardiomiócitos. Assim, as células foram incubadas com leucina triciada por 3, 6, 9, 12, 24 e 36 horas (Figura 14). Os resultados indicam claramente que até 24 horas a incorporação deste aminoácido ocorre de forma linear. A partir de 36 horas a incorporação deixa de apresentar um comportamento relativamente linear, atingindo um plateau. Desta forma, com base no protocolo de incubação de leucina triciada utilizado, observamos que ao final das 24 horas de tratamento estamos avaliando a incorporação deste aminoácido em um período em que ainda está ocorrendo síntese protéica nos cardiomiócitos. 


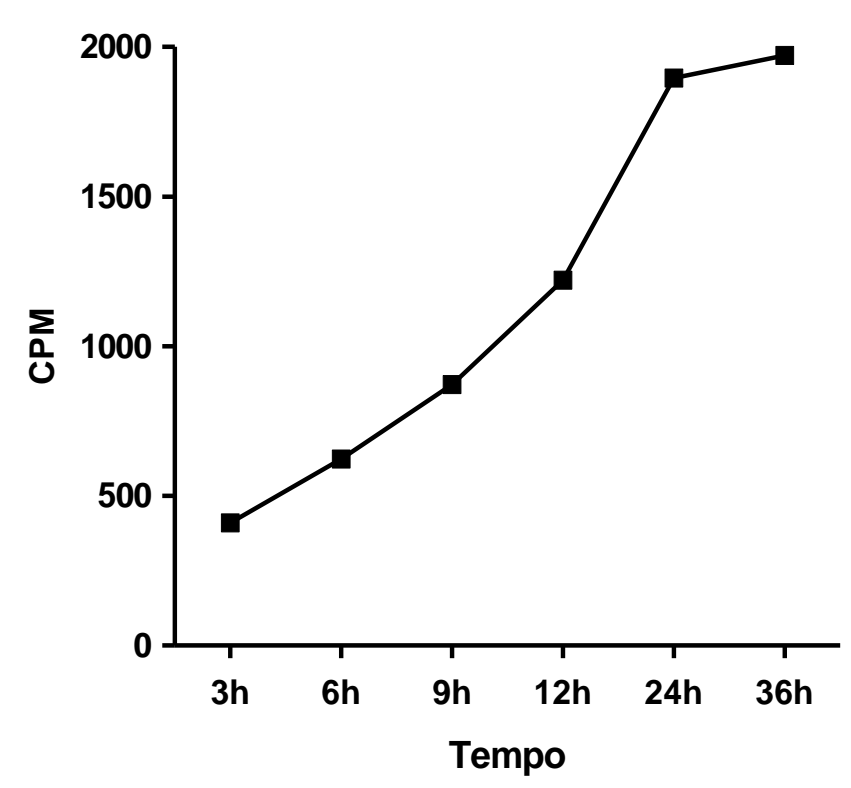

Figura 14. Curva tempo-resposta de incorporação de leucina triciada. As células receberam DMEM contendo $5 \mu \mathrm{Ci} / \mathrm{ml}$ de L-[4,5- $\left.{ }^{3} \mathrm{H}\right]$ leucina por $3,6,9,12,24$ e 36 horas. As amostras em duplicata foram processadas e contadas em Cintilador.

Uma vez padronizados esses ensaios avaliamos o efeito do tratamento por 24 horas com T3 sobre a hipertrofia do cardiomiócito, determinado indiretamente pela avaliação da síntese protéica. Como esperado, pelo ensaio de incorporação de leucina triciada, as células tratadas com T3 $(10 \mathrm{nM})$ apresentaram um aumento significativo, da ordem dos 60\%, na sua síntese protéica (Figura 15 - A). Da mesma forma, este grupo apresentou um aumento significativo da expressão de BNP e ANF, bem como um aumento da superfície celular, confirmando o estado hipertrófico destas células após o tratamento com T3 (Figura 15 - B e C).

$A$ ativação farmacológica da AMPK com AICAR, embora não tenha resultado na prevenção total, foi capaz de atenuar a hipertrofia desencadeada pelo T3, como demonstrado nos resultados de incorporação de leucina e confirmados pela análise da expressão gênica e área da superfície dos cardiomiócitos (Figura 15). 
A

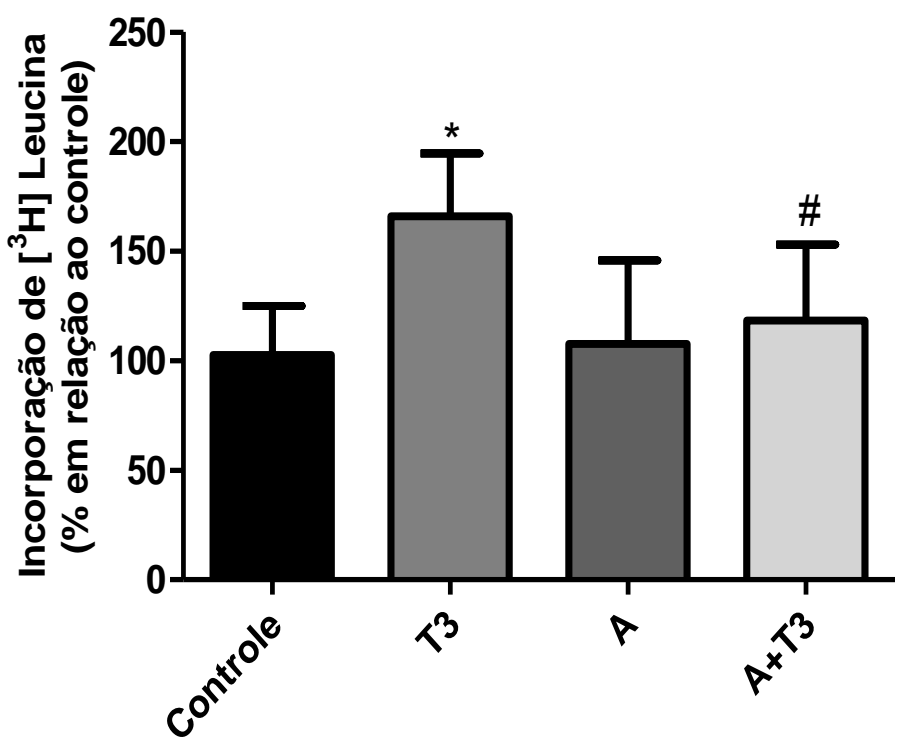

B

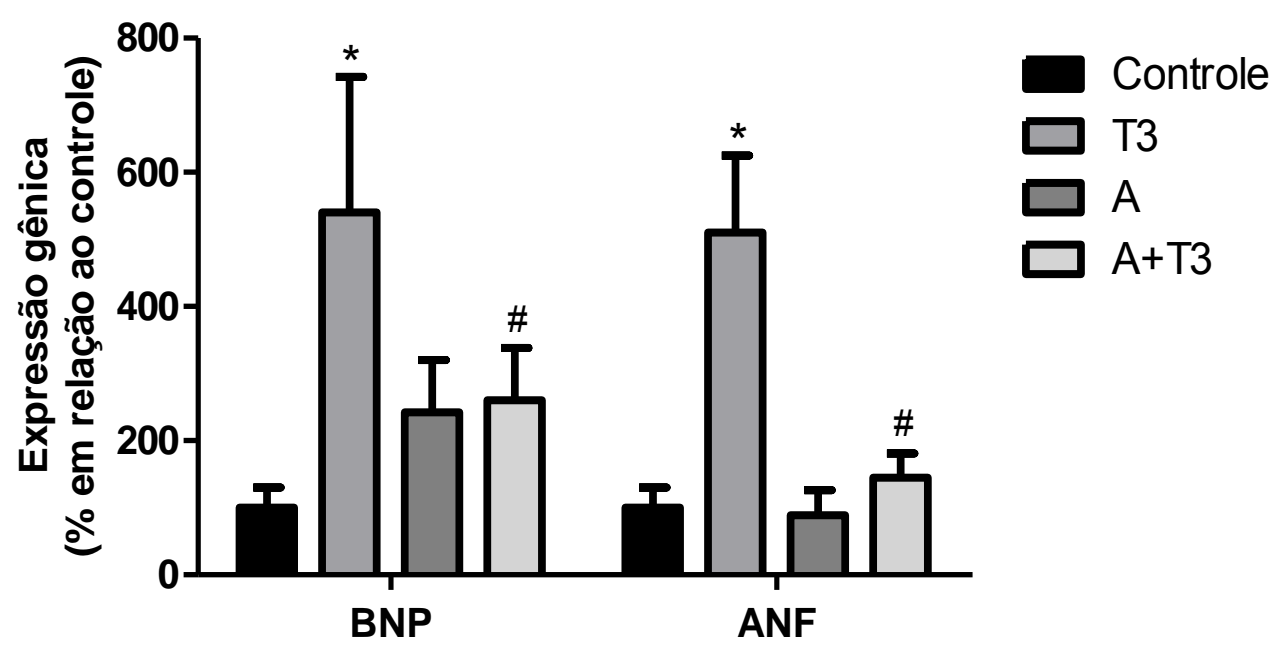


C

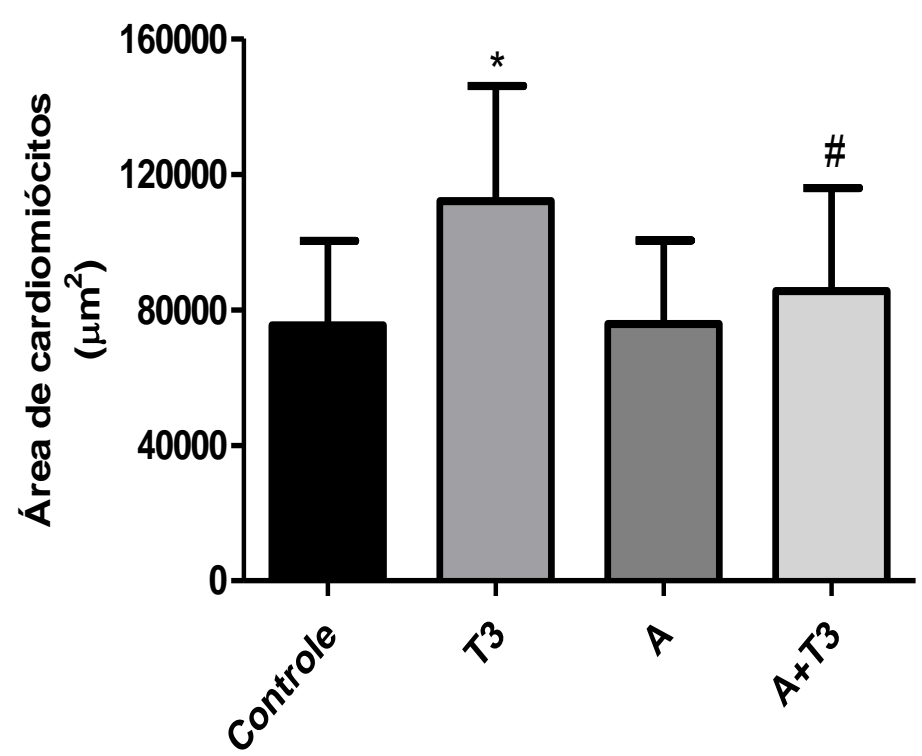

Figura 15. Análise da ativação da AMPK pelo AICAR na hipertrofia de cardiomiócitos induzida pelo T3. Ensaio de incorporação de leucina triciada $(n=8)(A)$, análise da expressão gênica de ANF e BNP $(n=4)(B)$ e medida da área de cardiomiócitos $(n=3)(C)$. As células foram

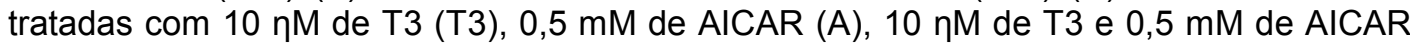
(A+T3), ou mantidas com DMEM (controle) por 24 horas. Os resultados são expressos em porcentagem em relação às células controle $(A, B)$ ou valores absolutos em $\mu m^{2} .{ }^{*} P<0.05$ vs. controle; \#P<0.05 vs. T3.

Os resultados referentes à ativação da AMPK pela Metformina evidenciaram que, apesar deste agente farmacológico agir indiretamente na ativação desta quinase, seus efeitos são capazes de amenizar a hipertrofia das células estimuladas com T3. No que se refere aos dados de incorporação de leucina pelas células e à área dos cardiomiócitos, os resultados obtidos frente à Metformina foram semelhantes àqueles observados após tratamento com AICAR (Figura 16 - A e C). Entretanto, a avaliação dos níveis de RNA mensageiro para ANF e BNP das células tratadas com metformina e T3 não demonstrou prevenção da hipertrofia, quando comparadas às células estimuladas somente com T3 (Figura 16 - B). 
A

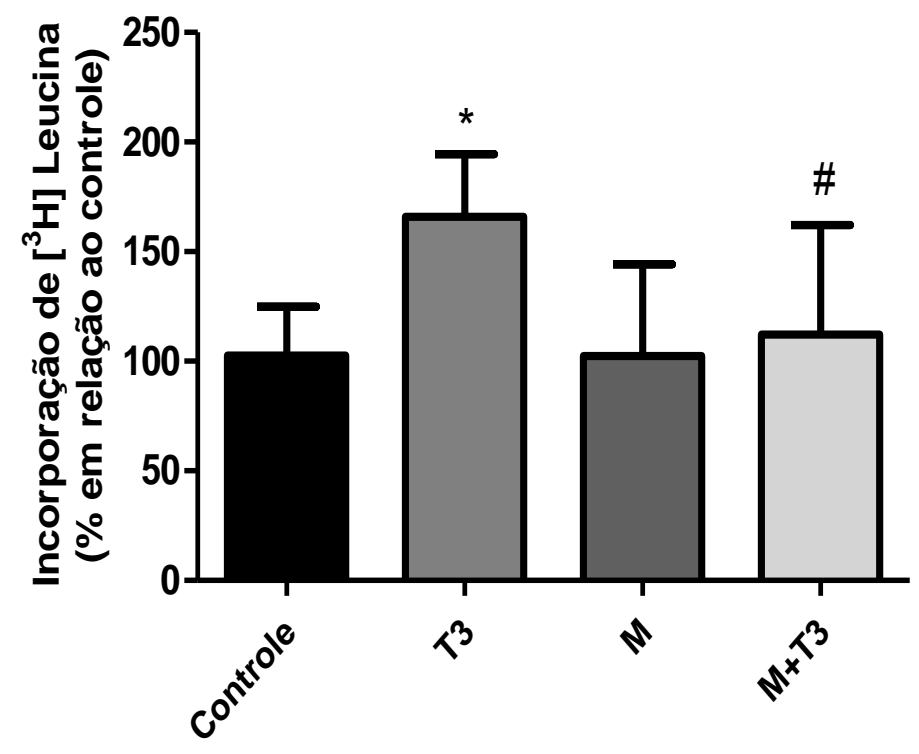

B

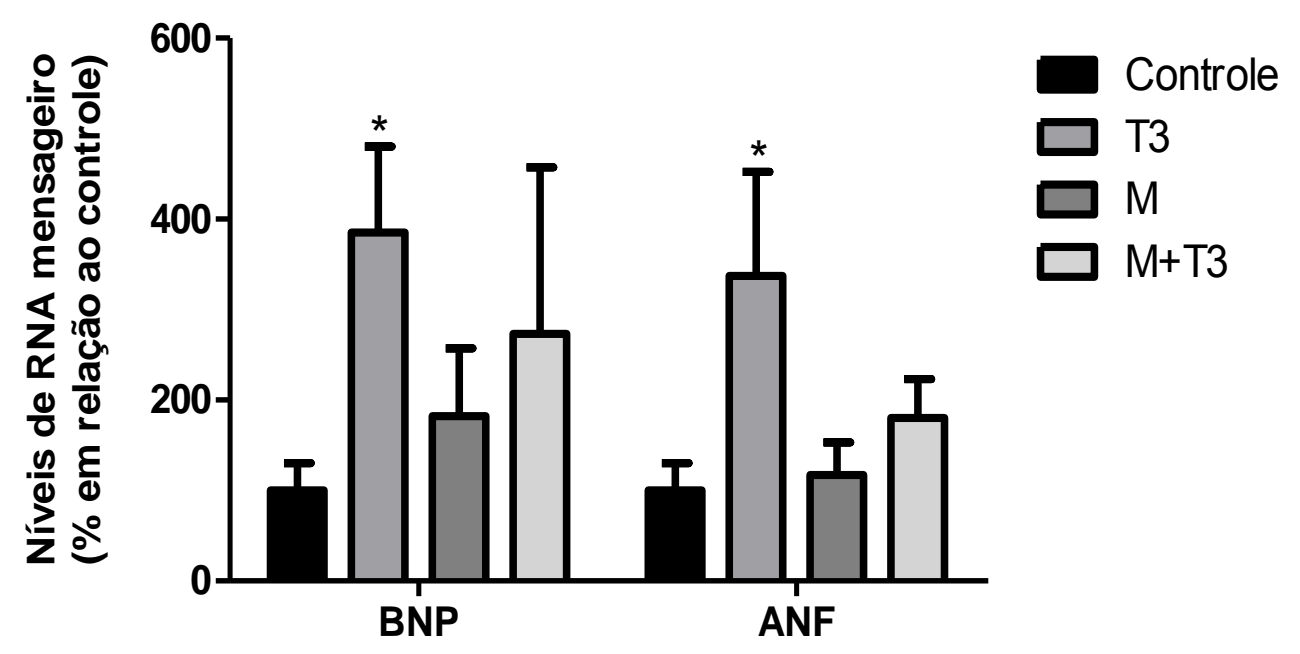


C

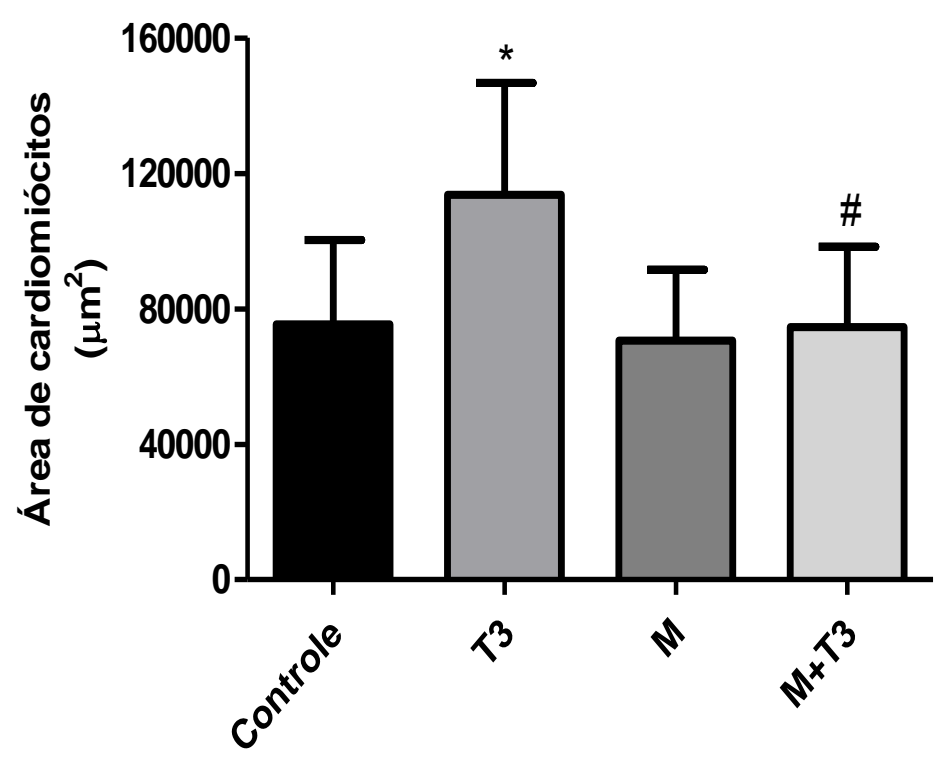

Figura 16. Análise da ativação da AMPK pela Metformina na hipertrofia de cardiomiócitos induzida pelo T3. Ensaio de incorporação de leucina triciada $(n=8)(A)$, análise dos níveis de RNA mensageiro para ANF e BNP $(n=4)(B)$ e medida da área dos cardiomiócitos $(n=3)(C)$. As

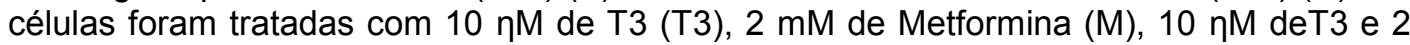
$\mathrm{mM}$ de Metformina $(\mathrm{M}+\mathrm{T} 3$ ), ou mantidas com DMEM (controle) por 24 horas. Os resultados são expressos em porcentagem em relação às células controle $(A, B)$ ou valores absolutos em $\mu \mathrm{m}^{2}$. ${ }^{*} \mathrm{P}<0.05$ vs. controle; $\# \mathrm{P}<0.05$ vs. T3.

Em relação ao tratamento das células com o Composto $C$, o qual age inibindo a atividade da AMPK, este promoveu significativo aumento de síntese protéica dos cardiomiócitos, quando administrado em conjunto com o T3, em comparação ao efeito observado nas células do grupo controle (Figura 17). No entanto, esta hipertrofia foi semelhante à promovida pelo T3. Se a AMPK realmente tem o papel de controlar o crescimento hipertrófico, esperava-se que a sua inibição, associada ao estímulo hipertrófico, aumentasse ainda mais a síntese protéica, resultando em uma hipertrofia mais acentuada destas células, quando comparadas às tratadas apenas com T3.

Considerando que esta intervenção farmacológica não foi totalmente eficiente na inibição da AMPK, e que outros trabalhos da literatura mostraram ineficiência similar deste composto em outros modelos experimentais, estes resultados talvez possam ser mais bem demonstrados com um procedimento mais específico de 
inibição da AMPK. Neste sentido, estamos atualmente padronizando uma intervenção molecular, através da técnica de RNA de interferência (RNAi), na tentativa de silenciar esta proteína e confirmar o seu papel na hipertrofia cardiomiocítica induzida pelo hormônio tiroideano.

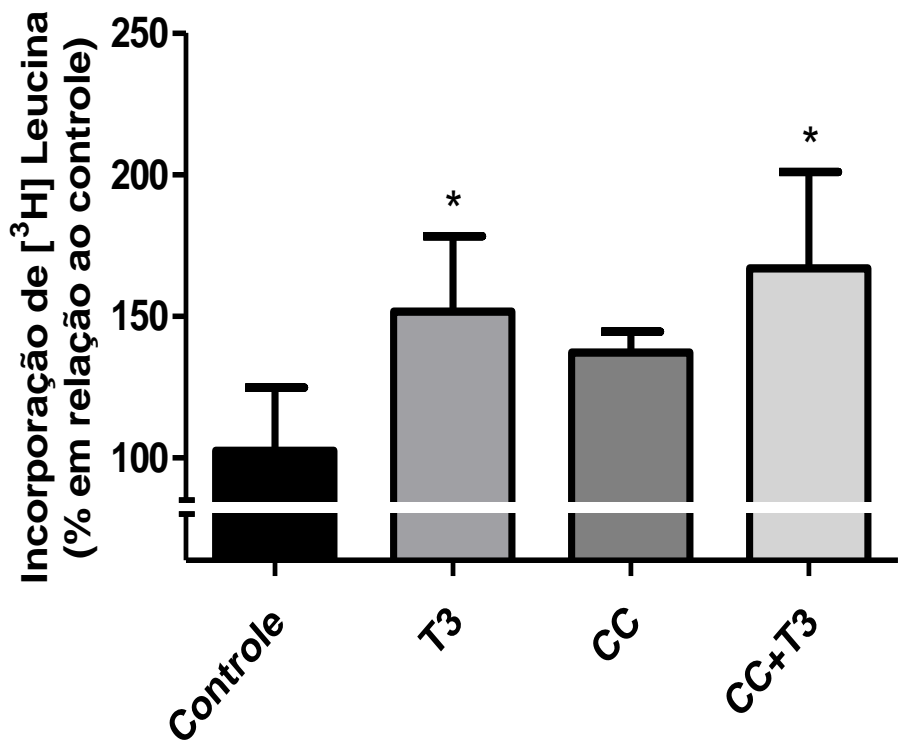

Figura 17. Análise da inibição farmacológica da AMPK com o Composto $C$ na hipertrofia de cardiomiócitos induzida pelo T3. Ensaio de incorporação de leucina triciada em células tratadas com $10 \eta \mathrm{M}$ de T3 (T3), $10 \mu \mathrm{M}$ de Composto C (CC), 10 ฤM de T3 e $10 \mu \mathrm{M}$ de Composto $\mathrm{C}(\mathrm{CC}+\mathrm{T} 3)$, ou mantidas com DMEM (controle) por 24 horas. Resultados são expressos em porcentagem em relação às células controle. * $P<0.05$ vs. controle $(n=3)$.

Com base nos resultados obtidos, evidenciamos que a AMPK, uma vez estimulada, pode ser considerada uma importante enzima moduladora da hipertrofia cardiomiocítica. Para tentar confirmar mais uma vez esta hipótese e considerando o fato de que a AMPK pode atuar na regulação de proteínas envolvidas com o processo de síntese protéica, com provável inibição da mTOR (CHAN e DYCK, 2005), avaliamos a expressão desta proteína ao tratarmos os cardiomiócitos com os fármacos ativadores da AMPK (AICAR e Metformina) (Figura 18). 

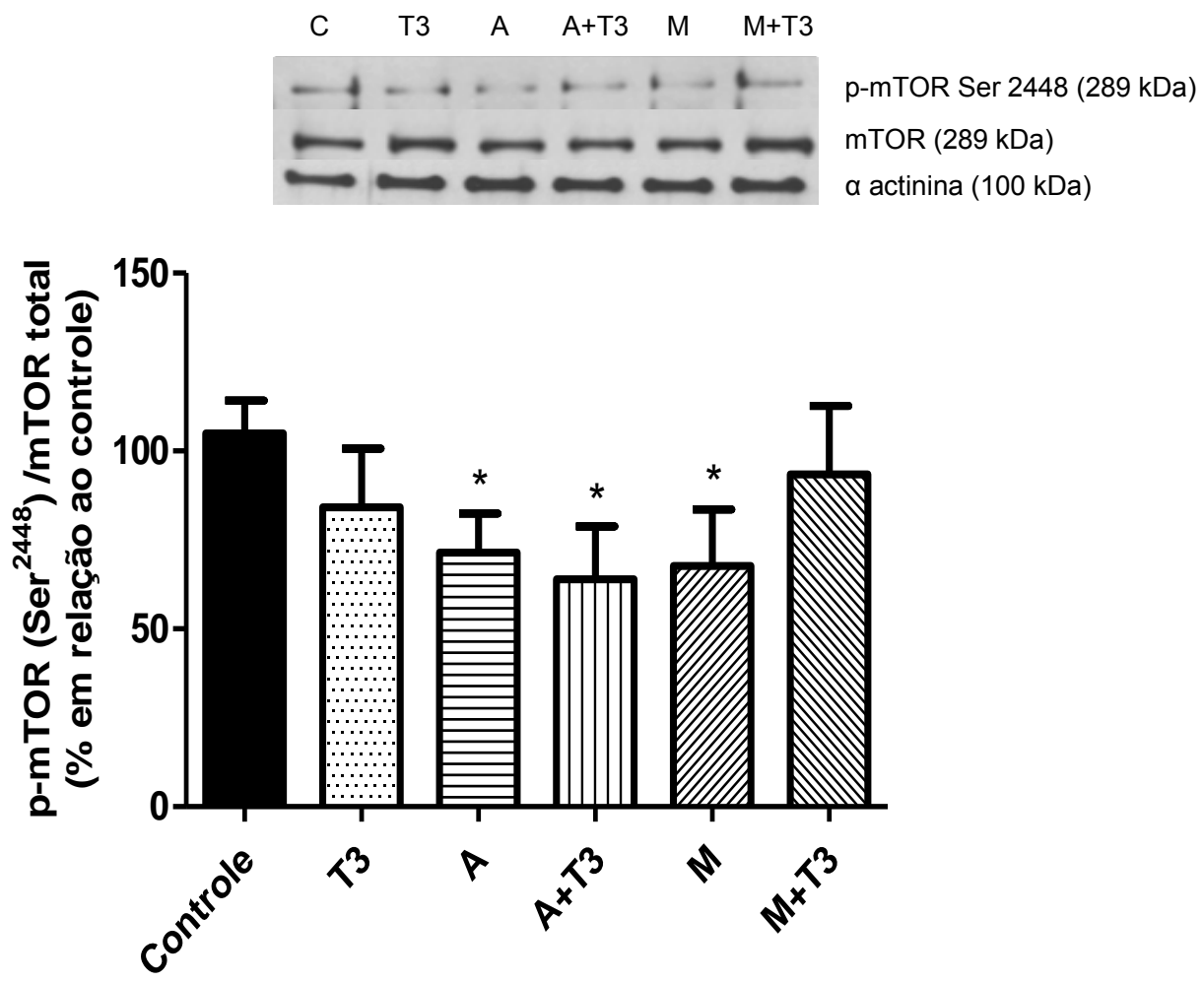

Figura 18. Efeito da ativação da AMPK na expressão protéica da mTOR em cardiomiócitos. As células foram mantidas em DMEM (controle) ou tratadas com 10 nM de T3 (T3), 0,5 mM de AICAR (A), $10 \eta M$ deT3 e 0,5 mM de AICAR (A+T3), e ainda com 2 mM de Metformina (M) e 10 nM de T3 juntamente com $2 \mathrm{mM}$ de Metformina (M+T3) por 24 horas. A expressão protéica da mTOR foi avaliada por Western Blotting e calculada a razão mTOR fosforilada na $\operatorname{Ser}^{2448} / \mathrm{mTOR}$ total. Os resultados são expressos em porcentagem em relação às células controle. ${ }^{*} P<0.05(n=4)$.

Como esperado, a ativação da AMPK com AICAR levou à diminuição da mTOR fosforilada na Ser 2448, mesmo quanto estimulada conjuntamente com T3. Por outro lado, a metformina não reduziu a ativação da mTOR nas células tratadas com T3 e este fármaco. Este resultado, aliado aos dados de avaliação da hipertrofia nas células estimuladas com metformina, indicam que este agente pode intervir no crescimento hipertrófico, porém com menor eficiência quando comparado ao efeito da ativação direta da AMPK pelo AICAR.

O esquema a seguir sintetiza os resultados obtidos no presente estudo e propões um modelo para explicar a contribuição da AMPK na hipertrofia estimulada pelo hormônio tiroideano (T3) em cardiomiócitos (Figura 19). 


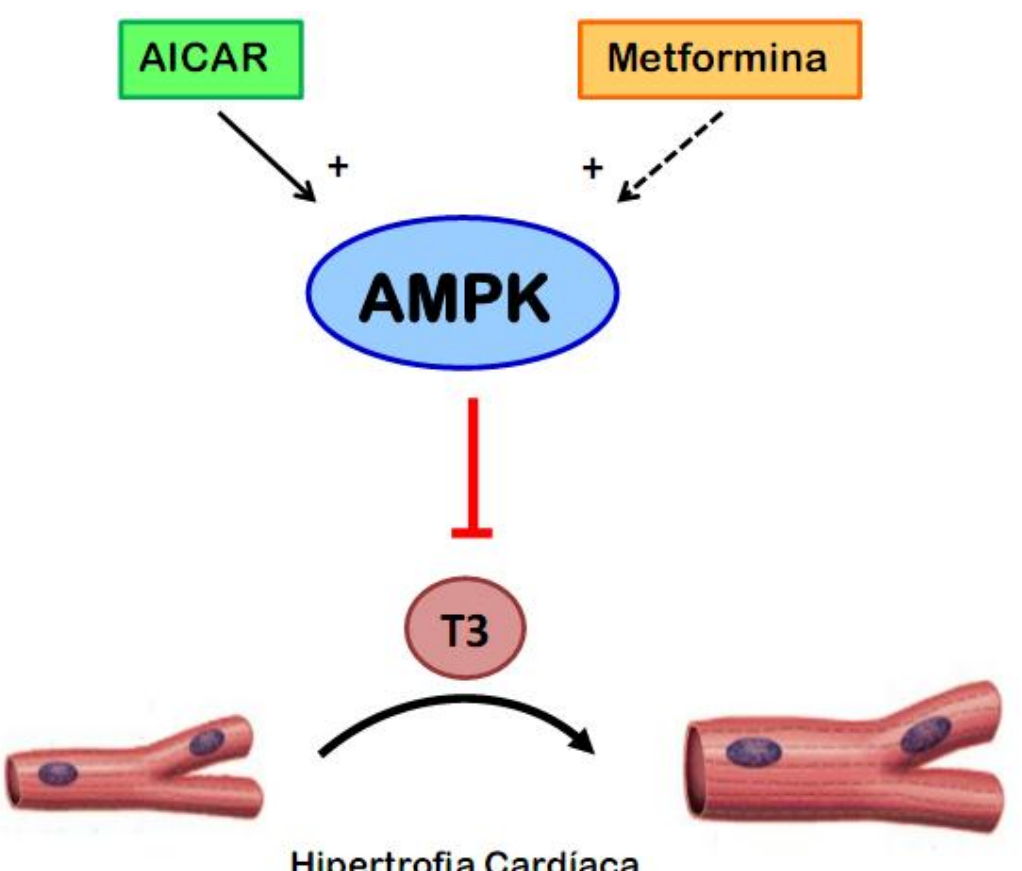

Figura 19. Modelo proposto para evidenciar a contribuição da AMPK na hipertrofia de cardiomiócitos induzida pelo T3. Como bem elucidado na literatura, o T3 é um potente agente hipertrófico capaz de estimular a síntese protéica e, consequentemente, o aumento do volume celular. Por outro lado, a AMPK é descrita como importante reguladora de mecanismos relacionados à sintese protéica. Desta forma, sua ativação farmacológica com AICAR e Metformina é capaz de atenuar o crescimento hipertrófico estimulado pelo T3. Seta contínua com sinal + indica ativação direta. Seta descontínua com sinal + indica ativação indireta. Traço em vermelho indica atenuação. 


\section{DISCUSSÃO}

No presente estudo, investigamos os efeitos do T3 na via de sinalização da proteína quinase ativada por AMP (AMPK), em culturas primárias de cardiomiócitos, assim como um possível envolvimento desta quinase na hipertrofia destas células cardíacas. A escolha de um modelo in vitro para esta análise foi proposta no sentido de investigar a ação direta deste hormônio nesta via de sinalização, que pode exercer influência no complexo processo do crescimento hipertrófico dos cardiomiócitos.

É cada vez maior o número de pesquisadores interessados em desvendar as bases moleculares envolvidas nas respostas desencadeadas a partir de diferentes estímulos para promover a resposta hipertrófica da célula muscular cardíaca. Assim, diversos grupos têm atuado na busca de tentar compreender e distinguir mecanismos responsáveis pelo crescimento fisiológico e compensado do coração, assim como aqueles que desencadeiam uma resposta descompensada, resultando na insuficiência cardíaca. Dentre estes vários estímulos, é bem estabelecido que os elevados níveis de hormônios tiroideanos $(\mathrm{HT})$ exercem ampla influência em todo o sistema cardiovascular e atuam diretamente estimulando o processo hipertrófico do tecido cardíaco, tanto in vivo quanto in vitro. Apesar de ainda haver controvérsias, a hipertrofia induzida por HT é, de maneira geral, fenotipicamente similar à hipertrofia induzida por estímulos fisiológicos, sendo considerada uma hipertrofia adaptativa com efeitos benéficos, e que recentemente recebe muita atenção como possível relevância terapêutica para hipertrofias descompensadas (DILLMANN, 2010; GERDES e IERVASI, 2010; HENDERSON et al., 2009). Por outro lado, há uma série de evidências de que estes hormônios interagem com outros sistemas (CARNEIRORAMOS et al., 2010; DINIZ; CARNEIRO-RAMOS; BARRETO-CHAVES, 2009), ativando vias e mecanismos que podem também resultar em crescimento hipertrófico não compensado, levando à insuficiência do miocárdio (WANG et al., 2010).

Algumas vias de sinalização recrutadas no processo de hipertrofia cardíaca induzida pelo hormônio tiroideano já foram previamente avaliadas pelo nosso grupo e por outros pesquisadores (DINIZ; CARNEIRO-RAMOS; BARRETO-CHAVES, 2009; OJAMAA, 2010), no entanto, o papel da sinalização deflagrada pela proteína quinase ativada pela AMP (AMPK) neste modelo experimental não havia sido ainda 
avaliado. Esta quinase atua como importante enzima moduladora de metabolismos essenciais para manutenção da homeostase energética (CARLING; SANDERS; WOODS, 2008), sendo uma candidata em potencial na sinalização de ações ligadas aos hormônios tiroideanos, os quais desempenham ações no sentido de aumentar de maneira geral o metabolismo celular. Em geral, a AMPK não é considerada um componente intrínseco de cascatas de sinalização de hipertrofia (DYCK e LOPASCHUK et al., 2006). Entretanto, uma vez ativada, inibe o crescimento hipertrófico via fosforilação e modulação de enzimas que participam do processo de síntese protéica (CHAN et al., 2004).

\subsection{Efeitos do T3 na fosforilação da AMPK}

Como não se conhecia a influência do T3 na fosforilação da AMPK em cardiomiócitos, foi pertinente a realização de uma curva concentração-resposta de T3, que induziu à fosforilação da AMPK de forma concentração-dependente. Esta prática de avaliar a resposta de algum efeito a diferentes concentrações de T3, inclusive para padronização da concentração a ser utilizada como tratamento, é habitualmente realizada em nossos trabalhos (CARNEIRO-RAMOS et al., 2004; CARRILLO-SEPÚLVEDA et al., 2010), assim como por outros grupos (HIROI et al., 2006; YAMAUCHI et al., 2008).

Os resultados apresentados neste estudo mostraram pela primeira vez que 0 T3 rapidamente ativa a AMPK, e que este estado de ativação parece ocorrer ainda por períodos mais longos, após 24 horas de tratamento. Da mesma forma, os níveis de ACC fosforilada, considerada a proteína alvo da AMPK, também aumentaram, confirmando a ação do T3 na ativação desta via nas células cardíacas. Recentemente, a rápida ativação da AMPK pelo T3 foi também relatada por Yamauchi et al. (2008) em linhagens celulares de mioblastos (C2C12), preadipócitos (3T3-L1) e células foliculares da tireóide (FRTL-5). Estes resultados podem ter ocorrido pelo fato do T3 exercer profundos efeitos no crescimento celular, diferenciação, termogênese (YAMAUCHI et al., 2008), além do aumento do metabolismo em geral e função contrátil do cardiomiócito (HEATHER et al., 2010), evidenciando a atuação deste hormônio em processos que levam ao consumo de considerável quantidade de ATP, podendo resultar na ativação da enzima que controla esse gasto energético, a AMPK. 
A ativação da AMPK é observada frente a diversos fatores, como hormônios e citocinas que são secretadas em resposta a estímulos externos. Uma vez que muitas patologias cardiovasculares, como hipertensão, hipertrofia ventricular, entre outras, deflagram ativação de mecanismos relacionados à injúria do tecido cardíaco, e de vasos de modo geral, é provável que a AMPK seja ativada e desempenhe uma função modulatória em muitas dessas condições (LI e KEANEY, 2010). Ainda, uma vez que a síntese protéica é um processo com alto gasto energético, é esperado que a AMPK desempenhe um papel essencial na regulação deste metabolismo, uma vez que esta quinase atua modulando uma série de enzimas permitindo que a tradução protéica diminua ou até cesse, durante o período de elongamento, até que os níveis de ATP sejam restaurados (KEMP et al., 2003).

Os resultados obtidos no presente estudo diferem daqueles obtidos previamente com outros modelos de hipertrofia, sugerindo que a ativação desta via de sinalização apresente um comportamento distinto dependendo do estímulo hipertrófico utilizado. Neste sentido, estudos mostram que quando cardiomiócitos foram tratados com fenilefrina por períodos agudos não foram observadas alterações nos níveis de AMPK fosforilada na Tre ${ }^{172}$ (PANG et al., 2010), bem como durante um período de 24 horas com o mesmo agente hipertrófico (CHAN et al., 2004). Por outro lado, cardiomiócitos que receberam angiotensina II rapidamente e por tempos mais longos de até 24 horas, apresentaram significativa redução nos níveis de AMPK fosforilada na $\operatorname{Tre}^{172}$ (STUCK et al., 2008) ou não apresentaram qualquer alteração significativa (JIANG et al., 2010). Coletivamente, estes dados demonstram que o papel desta quinase na hipertrofia cardíaca ainda não está bem elucidado. No entanto, estes resultados controversos sugerem que a AMPK possa apresentar distintas funções dependendo do estímulo hipertrófico. $O$ aumento da fosforilação na $\operatorname{Tre}^{172}$ e consequente ativação desta quinase pelo T3, de maneira similar ao observado durante o exercício físico (MUSI et al., 2005), podem funcionar como uma resposta compensatória, na tentativa de conter o crescimento hipertrófico, já que esta quinase atua na regulação de vias envolvidas com a síntese protéica, como mecanismo de controle do gasto energético. Por outro lado, é importante ressaltar que tanto a fenilefrina como a angiotensina II correspondem a estímulos que levam a uma hipertrofia descompensada, diferentemente do que se observa frente ao estímulo hipertrófico com HT. 
A sinalização da Akt está relacionada a diferentes funções celulares, incluindo - controle do crescimento celular e a função contrátil em cardiomiócitos (LATRONICO et al., 2004). Uma vez que a ativação da Akt negativamente regula a AMPK no coração (SOLTYS; KOVACIC; DYCK, 2006), e que a expressão de Akt é rapidamente aumentada quando os cardiomiócitos são estimulados com HT (DINIZ; CARNEIRO-RAMOS; BARRETO-CHAVES, 2009), era plausível investigar o efeito que o T3 exerceria na fosforilação da AMPK na Ser ${ }^{485 / 491}$, considerado o resíduo alvo da Akt, cuja fosforilação funciona como mecanismo de auto-regulação da AMPK, prevenindo a subsequente fosforilação na $\operatorname{Tre}^{172}$ por uma AMPKK, e, consequentemente, inativando a AMPK (HURLEY et al., 2006; SOLTYS; KOVACIC; DYCK, 2006).

Em estudo prévio do nosso grupo demonstramos que os níveis de Akt fosforilada também encontram-se elevados após 10 minutos de tratamento dos cardiomiócitos com T3 (DINIZ; CARNEIRO-RAMOS; BARRETO-CHAVES, 2009), o que sugere que a Akt foi capaz de modular várias de suas proteínas alvo, incluindo a AMPK, para permitir seus efeitos no aumento da área celular, podendo estar contribuindo para mediar alguns dos efeitos hipertróficos exercidos pelos HT nos cardiomiócitos. Recentemente, um grupo de pesquisa comparou os efeitos de dois estímulos, a angiotensina II e os hormônios tiroideanos, na fosforilação dos distintos sítios da AMPK tanto in vivo como in vitro. Demonstraram que o tratamento com angiotensina II, o qual resulta em um fenótipo de hipertrofia cardíaca descompensada, ou também denominada na literatura como patológica, leva a um aumento da AMPK fosforilada na Ser ${ }^{485 / 491}$, sem alteração nos níveis da AMPK fosforilada na Tre ${ }^{172}$. Já o tratamento com HT mostrou uma resposta oposta ao que ocorreu com a angiotensina II (JIANG et al., 2010). Assim, esse estudo sugere que, paralelamente aos níveis de fosforilação, os sítios fosforilados da AMPK parecem ser cruciais para a ativação da via de sinalização propriamente dita e, como consequência, para a resposta deflagrada em um determinado tipo celular.

$O$ fato de o T3 aumentar a fosforilação da AMPK em seu maior sítio regulatório, a Tre ${ }^{172}$, sem afetar praticamente a fosforilação da AMPK na Ser ${ }^{485 / 491}$, evitando desta forma o mecanismo de auto-inibição desta quinase, sugere, ao menos indiretamente, que a fosforilação seletiva da AMPK na Tre $^{172}$ represente um potencial mecanismo associado com o efeito anti-hipertrófico deste agente, uma vez que a ativação desta quinase, consequentemente, regulará diversas proteínas 
envolvidas com o processo de síntese protéica. Entretanto, essas hipóteses devem ser comprovadas com estudos adicionais mais conclusivos.

\subsection{Efeitos do T3 na fosforilação de AMPKKs}

Embora a quinase LKB1 seja originalmente identificada como supressora tumoral (HEMMINKI et al., 1998), e associada com proteínas que estão envolvidas no controle da proliferação celular, esta enzima também exerce efeitos na polaridade celular e na habilidade da célula de detectar e responder a baixos níveis de energia celular (ALESSI; SAKAMOTO; BAYASCAS, 2006), através da fosforilação e ativação da AMPK (HAWLEY et al., 2003). Neste sentido, LKB1 é considerada a maior quinase ativadora da AMPK e, desta forma, passamos a investigar se o T3 influenciaria a expressão desta quinase, assim como observado na AMPK fosforilada.

O rápido aumento da AMPK fosforilada em seu sítio de ativação ( Tre $^{172}$ ) pelo T3 foi parcialmente acompanhado do aumento dos níveis de LKB1 fosforilada (5 e 10 minutos). No entanto, esta relação não foi observada após tratamento por 24 horas. Este resultado também foi relatado por Kim et al. (2009), no qual os autores observaram que outros estímulos que ativam a AMPK não apresentaram efeitos diretos sobre a atividade da LKB1. Além disso, a atividade da LKB1 também não aumentou em modelo de coração isquêmico em ratos, apesar de ter sido notado importante aumento da AMPK fosforilada na Tre ${ }^{172}$ (ALTAREJOS et al., 2005).

Sabe-se que o T3 induz uma maior mobilização de $\mathrm{Ca}^{2+}$ intracelular em diferentes tipos celulares (D'AREZZO et al., 2004). Neste sentido, Yamauchi et al. (2008) mostraram que a ativação da AMPK pelo T3 em linhagem celular HeLa é resultante do aumento da mobilização de $\mathrm{Ca} 2+$ e consequente ativação de CaMKK $\beta$, outra importante AMPKK. Ainda, em camundongos knockout para LKB1, a fosforilação da AMPK ocorre via ativação desta mesma quinase dependente de cálcio/calmodulina (MCGEE et al., 2008). Ainda, em corações perfundidos de ratos hipertiroideos, a ativação da AMPK deve ocorrer via elevação dos níveis de cálcio e consequente ativação da CaMKK (HEATHER et al., 2010). Considerando estes achados, tornou-se necessária a investigação da participação da CaMKK em nosso modelo experimental. Após esta análise, encontramos um resultado interessante e que auxilia na tentativa de explicar a ausência da estimulação da AMPK, por ação 
da LKB1, em tempos mais prolongados de tratamento com T3 (24 horas). Assim, a AMPK pode ser estimulada pela ação de LKB1 após tempos curtos de tratamento e em períodos mais tardios de tratamento com T3, a sua ativação pode ser resultante da atuação de outra quinase ativadora, a CaMKKß .

\subsection{Efeitos do T3 na PP2C}

Sob estresses metabólicos agudos, a ativação da AMPK no coração está envolvida primariamente em promover a geração de energia para manter ou restaurar os níveis de ATP intracelular (LI; LI; REN, 2009). Desta forma, o clássico mecanismo de ativação da AMPK é constituído por uma sequência de 3 eventos: 1) um determinado estímulo leva a um aumento do AMP intracelular que se liga à AMPK; 2) que consequentemente leva a uma mudança conformacional na estrutura da AMPK, permitindo a fosforilação da AMPK por uma quinase reguladora, que é a AMPKK; 3) ainda, essa ligação do AMP inibe a defosforilação da AMPK por ação de fosfatases. Considerando que proteínas fosfatases negativamente regulam a atividade da AMPK através de sua defosforilação, a expressão protéica da fosfatase 2C (PP2C) foi explorada, uma vez que esta é considerada a principal fosfatase presente no tecido cardíaco (DAVIES et al., 1995).

Diferentemente do que esperávamos, os resultados mostraram que, paralelamente ao aumento da fosforilação da AMPK, houve um rápido aumento da expressão protéica de PP2C, embora este fato não tenha se mantido ao longo de 24 horas de tratamento com T3. Em estudo com cardiomiócitos tratados com UCF-101, um agente antidiabético, os níveis protéicos das duas fosfatases (do tipo 2A e 2C) diminuíram, evidenciando que este seja um dos processos que levaram ao aumento da atividade da AMPK nas células tratadas com este agente (LI; LI; REN, 2009). No entanto, o que podemos inferir dos nossos resultados é que os processos de fosforilação e defosforilação da AMPK em cardiomiócitos tratados com T3 por períodos agudos ocorrem simultaneamente, como um mecanismo regulatório da atividade desta quinase, uma vez que os níveis de AMPK fosforilada parecem estar reciprocamente correlacionados com a expressão das proteínas fosfatases (WANG e UNGER, 2005). Ainda, como dito anteriormente, embora seja a fosfatase $2 \mathrm{C}$ a principal fosfatase expressa no tecido cardíaco e tenha sido esta a única avaliada 
por nós, não podemos descartar a influência que outras fosfatases poderiam estar promovendo sobre os níveis de ativação da AMPK.

\subsection{Efeitos da ativação e inibição da AMPK na hipertrofia do cardiomiócito induzida pelo T3}

A hipertrofia cardíaca inicialmente representa uma adaptação do coração ao aumento da sobrecarga imposta a ele. Entretanto, progressivamente, uma série de eventos desencadeados pelo persistente estímulo hipertrófico pode resultar em um processo descompensado, levando à deterioração e à insuficiência deste órgão.

De maneira geral, as terapias para contenção da disfunção cardíaca se baseiam na inibição do sistema renina-angiotensina e da resposta às catecolaminas (EXNER et al., 1999; MILLER e PIÑA, 2009). Atualmente, muitos estudos estão em busca de terapias alternativas e talvez complementares às utilizadas, também com ações cardioprotetoras. Neste contexto, a AMPK aparece como um potencial alvo terapêutico pela atuação na regulação da homeostase energética cardíaca, sendo capaz de coordenar diferentes respostas intracelulares com efeitos cardioprotetores (BEAULOYE et al., 2010; KIM e TIAN, 2010). Sob condições normais a atividade desta quinase é muito baixa e sua função no coração intacto ainda não foi bem esclarecida (KIM e TIAN, 2010). No entanto, a ativação da AMPK é rápida e robusta em resposta a uma variedade de estímulos, como exercício e isquemia (LI et al., 2006; MUSI et al., 2005).

Para verificar se a AMPK tem importante papel na modulação da hipertrofia cardiomiocítica induzida pelo T3 foram utilizadas duas estratégias: análise de ganho, assim como, de perda de função através de intervenção farmacológica.

$\mathrm{Na}$ literatura são descritos alguns agentes capazes de ativar a AMPK de forma direta, como o AICAR ou também conhecido como acadesina, e o Composto A-769662. Estas drogas são captadas por transportadores de adenosina e, subsequentemente, fosforiladas a ZMP, um análogo de AMP, mimetizando desta forma os efeitos de AMP, que ativa a AMPK (WONG et al., 2009). Estes agentes farmacológicos, a princípio, por serem específicos e atuarem diretamente na ativação da AMPK são relevantes ferramentas experimentais para compreender o papel fisiológico desta quinase. Existem ainda os agentes que, sabidamente, levam à ativação da AMPK, porém de maneira indireta, como a Metformina, 
tiazolidinedionas e estatinas, que ainda não possuem um possível mecanismo de ativação da AMPK bem estabelecido. A Metformina é um agente farmacológico amplamente empregado para o tratamento da diabetes do tipo 2 (BAILEY e TURNER, 1996). Além desta ação antidiabética, estudos mostraram sua eficácia na ativação da AMPK, tanto em corações intactos (ZHANG; HE; BALSCHI, 2007), como em cardiomiócitos isolados (KOVACIC et al., 2003; YANG e HOLMAN 2006) ou em outros órgãos e tecidos (FRYER; PARBU-PATEL; CARLING, 2002; ZHOU et al., 2001). Embora o mecanismo de ativação ainda não esteja bem esclarecido, ele deve estar envolvido na inibição da produção de ATP, via seus efeitos no complexo I da cadeia respiratória mitocondrial (ZHOU et al., 2001), o que provocaria, dessa forma, uma alteração na carga energética, que ativaria indiretamente a AMPK pela diminuição de ATP e aumento de AMP intracelular (HARDIE, 2006; ZHANG; HE; BALSCHI, 2007). Por outro lado, também existem evidências de que a AMPK possa ser ativada pela metformina sem mudanças na razão de AMP/ATP intracelular (HAWLEY et al., 2002).

Baseando-se nestas informações, optamos por utilizar o AICAR e a Metformina por se tratarem de duas drogas capazes de ativar, respectivamente, de forma direta e indiretamente a AMPK, e por serem as mais utilizadas nos ensaios experimentais (SOLSKOV et al., 2008) e inclusive em estudos clínicos (CUTHBERTSON et al., 2007).

Ainda, uma avaliação de perda de função foi realizada no intuito de se confirmar o papel da AMPK na hipertrofia de cardiomiócitos tratados com T3. Em estudos in vitro, o bloqueador farmacológico da AMPK mais utilizado é o Composto C (6-[4-(2-piperidin-1-yl-ethoxy)-phenyl]-3-pyridin-4-yl-pyyrazolo[1,5-a] pyrimidine), que age como inibidor competitivo de ATP (ZHOU et al., 2001). A maioria dos trabalhos da literatura se utiliza basicamente desta inibição farmacológica, embora outros ainda realizem o bloqueio da AMPK por RNA de interferência (BOGACHUS e TURCOTTE, 2010), ou através de infecção por adenovírus da forma dominante negativa da AMPK (SAEEDI et al., 2009).

Os resultados mostrados neste trabalho indicam que a AMPK tem um papel crítico na regulação do crescimento hipertrófico induzido pelo T3 em cardiomiócitos isolados, como foi demonstrado pelos experimentos de avaliação da hipertrofia, quando realizada a análise de ganho de função, principalmente pela ativação direta da AMPK com AICAR. Dados da literatura mostraram a prevenção da hipertrofia de 
cardiomiócitos induzida por fenilefrina quando tratados com AICAR (PANG et al., 2010), ou por superexpressão de Akt, quando também tratados com AICAR ou ainda com Metformina (CHAN et al., 2004). Resultados semelhantes ocorreram quando cardiomiócitos foram tratados com angiotensina II e AICAR (STUCK et al., 2008). Estudos in vivo também mostraram que a ativação farmacológica da AMPK foi capaz de amenizar a hipertrofia cardíaca de ratos que foram submetidos à constrição transaórtica (TAC) (MENG et al., 2009).

Os mecanismos implicados nesta modulação do processo hipertrófico pela estimulação da AMPK ainda estão sendo investigados. Como a mTOR, entre outras proteínas relacionadas à síntese, foi descrita como alvo desta quinase, sua modulação foi confirmada quando estimulamos a AMPK com AICAR, mesmo na presença de T3. Outros mecanismos, no entanto, podem estar envolvidos; recentemente foi demonstrado que a ativação da AMPK resulta na modulação de enzimas e fatores de transcrição envolvidos com a degradação protéica (CHEN et al., 2010). Outras abordagens se fazem necessárias para um melhor entendimento dos eventos promovidos por esta estimulação neste modelo experimental. Recentemente, muitos trabalhos têm relatado o envolvimento desta quinase em hipertrofias desencadeadas por diferentes estímulos. Ainda, a maioria destes trabalhos indica que a AMPK possa ser considerada uma ferramenta para regulação do processo de hipertrofia cardíaca independente do estímulo hipertrófico, e possível prevenção de falência cardíaca. Desta forma, estes dados experimentais podem servir como base, direcionando futuras pesquisas que se propõem a investigar futuros alvos de intervenções terapêuticas para $\circ$ tratamento de patologias cardiovasculares, como ocorre com as hipertrofias descompensadas. 


\section{CONCLUSÕES}

Com base nos resultados obtidos no presente estudo podemos concluir que:

- O T3 ativa rapidamente a AMPK e proteínas relacionadas a esta sinalização, em cardiomiócitos em cultura, provavelmente de maneira independente de sua ligação a receptores nucleares, promovendo, sob essas condições, aumento dos níveis desta proteína fosforilada.

- O tratamento por 24 horas com T3, paralelamente ao efeito hipertrófico que promove nos cardiomiócitos em cultura, também promove ativação da AMPK.

- A estimulação da AMPK por intervenção farmacológica atenua a hipertrofia induzida pelo T3, o que pode sugerir uma possível e interessante ferramenta terapêutica em cardiopatias ligadas ao hipertiroidismo. 


\section{REFERÊNCIAS ${ }^{1}$}

ALESSI, D. R.; SAKAMOTO, K.; BAYASCAS, J. R. LKB1-dependent signaling pathways. Annu. Rev. Biochem., v. 75, p. 137-163, 2006.

ALTAREJOS, J. Y.; TANIGUCHI, M.; CLANACHAN, A. S.; LOPASCHUK, G. D. Myocardial ischemia differentially regulates LKB1 and an alternate 5'-AMP-activated protein kinase kinase. J. Biol. Chem., v. 280, n.1, p. 183-190, 2005.

ANDERSON, K. A.; MEANS, R. L.; HUANG, Q. H.; KEMP, B. E.; GOLDSTEIN, E. G.; SELBERT, M. A.; EDELMAN, A. M.; FREMEAU, R. T.; MEANS, A. R. Components of a calmodulin-dependent protein kinase cascade. J. Biol. Chem., v. 273, n. 48, p. 31880-31889, 1998.

ANJOS-RAMOS, L.; CARNEIRO-RAMOS, M. S.; DINIZ, G. P.; MARTINS-SILVA, J.; BARRETO-CHAVES, M. L. Early cardiac hypertrophy induced by thyroxine is accompanied by an increase in VEGF-A expression but not by an increase in capillary density. Virchows. Arch., v. 448, n. 4, p. 472-479, 2006.

ANVERSA, P.; KAJSTURA, J.; OLIVETTI, G. Myocyte death in heart failure. Curr. Opin. Cardiol., v. 11, n. 3, p. 245-251, 1996.

ARAD, M.; SEIDMAN, C. E.; SEIDMAN, J. G. AMP-Activated protein kinase in the heart: role during health and disease. Circ. Res., v. 100, n. 4, p. 474-488, 2007.

BAILEY, C. J.; TURNER, R. C. Metformin. N. Engl. J. Med., v. 334, n. 9, p. 574-579, 1996.

BARRETO-CHAVES, M. L. M.; HEIMANN, A.; KRIEGER, J. E. Stimulatory effect of dexamethasone on angiotensin-converting enzyme in neonatal rat cardiac myocytes. Braz. J. Med. Biol. Res., v. 33, n. 6, p. 661-664, 2000.

BEAULOYE, C.; BERTRAND, L.; HORMAN, S.; HUE, L. AMPK activation, a preventive therapeutic target in the transition from cardiac injury to heart failure. Cardiovasc. Res., v. 90, n. 2, p. 224-233, 2011.

BERGH, J. J.; LIN, H. Y.; LANSING, L.; MOHAMED, S. N.; DAVIS, F. B.; MOUSA, S.; DAVIS, P. J. Integrin alphaVbeta3 contains a cell surface receptor site for thyroid hormone that is linked to activation of mitogen-activated protein kinase and induction of angiogenesis. Endocrinology, v. 146, n. 7, p. 2864-2871, 2005.

\footnotetext{
${ }^{1}$ De acordo com: ASSOCIAÇÃO BRASILEIRA DE NORMAS TÉCNICAS. NBR 6023: informação e documentação: referências: elaboração. Rio de Janeiro, 2002.
} 
BOGACHUS, L. D.; TURCOTTE, L. P. Genetic downregulation of AMPK-\{alpha\} isoforms uncovers the mechanism by which metformin decreases FA uptake and oxidation in skeletal muscle cells. Am. J. Physiol. Cell. Physiol., v. 299, n. 6, p. C1549-1561, 2010.

BOHELER, K. R.; CHASSAGNE, C.; MARTIN, X.; WISNEWSKY, C.; SCHWARTZ, K. Cardiac expressions of alpha- and beta-myosin heavy chains and sarcomeric alpha-actins are regulated through transcriptional mechanisms. Results from nuclear run-on assays in isolated rat cardiac nuclei. J. Biol. Chem., v. 267, n. 18, p. 1297912985, 1992.

BRADFORD, M. M. A rapid and sensitive method for the quantitation of microgram quantities of protein utilizing the principle of protein-dye binding. Anal. Biochem., v. 72, p. 248-254, 1976.

BROWN, D. C.; MACFARLANE, C. E.; MCKENNA, W. J.; PATTON, M. A.; DUNGER, D. B.; SAVAGE, M. O.; KELNAR, C. J. Growth hormone therapy in Noonan's syndrome: non-cardiomyopathic congenital heart disease does not adversely affect growth improvement. J. Pediatr. Endocrinol. Metab., v.15, n. 6, p. 851-852, 2002.

CANARIS, G. J.; MANOWITZ, N. R.; MAYOR, G.; RIDGWAY, E. C. The Colorado thyroid disease prevalence study. Arch. Intern. Med., v. 160, n. 4, p. 526-534, 2000.

CARLING, D.; SANDERS, M. J.; WOODS, A. The regulation of AMP-activated protein kinase by upstream kinases. Int. J. Obes., v. 32, p. S55-59, 2008. Suppl. 4.

CARNEIRO-RAMOS, M. S.; DINIZ, G. P.; NADU, A. P.; ALMEIDA, J.; VIEIRA, R. L.; SANTOS, R. A.; BARRETO-CHAVES, M. L. M. Blockage of angiotensin II type 2 receptor prevents thyroxine-mediated cardiac hypertrophy by blocking Akt activation. Basic. Res. Cardiol., v. 105, n. 3, p. 325-335, 2010.

CARNEIRO-RAMOS, M. S.; SILVA, V. B.; COUTINHO JÚNIOR, M. B.; BATTASTINI, A. M. B.; SARKIS, J. J. F.; BARRETO-CHAVES, M. L. M. Thyroid hormone stimulates 5'-ecto-nucleotidase of neonatal rat ventricular myocytes. Mol. Cell. Biochem., v. 265, n.(1-2), p. 195-201, 2004.

CARRILLO-SEPÚLVEDA, M. A.; CERAVOLO, G. S.; FORTES, Z. B.; CARVALHO, M. H.; TOSTES, R.C.; LAURINDO, F. R.; WEBB. R. C.; BARRETO-CHAVES, M. L. Thyroid hormone stimulates NO production via activation of the PI3K/Akt pathway in vascular myocytes. Cardiovasc. Res., v. 85, n. 3, p. 560-570, 2010.

CHAN, A. Y. M.; DOLINSKY, V. W.; SOLTYS, C. L. M.; VIOLLET, B.; BAKSH, S.; LIGHT, P. E.; DYCK, J. R. B. Resveratrol inhibits cardiac hypertrophy via AMPactivated protein kinase and Akt. J. Biol. Chem., v. 283, n. 35, p. 24194-24201, 2008. 
CHAN, A. Y. M.; DYCK, J. R. B. Activation of AMP-activated protein kinase (AMPK) inhibits protein synthesis: a potential strategy to prevent the development of cardiac hypertrophy. Can. J. Physiol. Pharmacol., v. 83, n. 1, p. 24-28, 2005.

CHAN, A. Y. M.; SOLTYS, C. L. M; YOUNG, M. E.; PROUD, C. G.; DYCK, J. R. B. Activation of AMP-activated Protein Kinase Inhibits Protein Synthesis Associated with Hypertrophy in the Cardiac Myocyte. J. Biol. Chem., v. 279, n. 31, p. 32771-32779, 2004.

CHEN, B. L.; MA, Y. D.; MENG, R. S.; XIONG, Z. J.; WANG, H. N.; ZENG, J. Y.; LIU, C.; DONG, Y. G. Activation of AMPK inhibits cardiomyocyte hypertrophy by modulating of the FOX01/MuRF1 signaling pathway in vitro. Acta. Pharmacol. Sin., v. 31, n. 7, p. 798-804, 2010.

CUTHBERTSON, D. J.; BABRAJ, J. A.; MUSTARD, K. J.; TOWLER, M. C.; GREEN, K. A.; WACKERHAGE, H.; LEESE, G. P.; BAAR, K.; THOMASON-HUGHES, M.; SUTHERLAND, C.; HARDIE, D. G.; RENNIE, M. J. 5-aminoimidazole-4carboxamide 1- $\beta$-d-ribofuranoside acutely stimulates skeletal muscle 2-deoxyglucose uptake in healthy men. Diabetes, v. 56, n. 8, p. 2078-2084, 2007.

D'AREZZO, S.; INCERPI, S.; DAVIS, F. B.; ACCONCIA, F.; MARINO, M.; FARIAS, R. N.; DAVIS, P. J. Rapid nongenomic effects of 3,5,3-triiodo-L-thyronine on the intracellular $\mathrm{pH}$ of L-6 myoblasts are mediated by intracellular calcium mobilization and kinase pathways. Endocrinology, v. 145, n. 12, p. 5694-5703, 2004.

DAVIES, S. P.; HELPS, N. R.; COHEN, P. T.; HARDIE, D. G. 5'-AMP inhibits dephosphorylation, as well as promoting phosphorylation, of the AMP-activated protein kinase. Studies using bacterially expressed human protein phosphatase-2C alpha and native bovine protein phosphatase-2AC. FEBS. Lett., v. 377, n. 3, p. 421425, 1995.

DAVIS, P. J.; DAVIS, F. B. Nongenomic actions of thyroid hormone on the heart. Thyroid, v. 12, n. 6, p. 459-466, 2002.

DAVIS, P. J.; DAVIS, F. B.; CODY, V. Membrane receptors mediating thyroid hormone action. Trends. Endocrinol. Metab., v.16, n. 9, p. 429-435, 2005.

DAVIS, P. J.; LEONARD, J. L.; DAVIS, F. B. Mechanisms of nongenomic actions of thyroid hormone. Front. Neuroendocrinol., v. 29, n. 2, p. 211-218, 2008.

DILLMANN, W. Cardiac hypertrophy and thyroid hormone signaling. Heart. Fail. Rev., v. 15, n. 2, p. 125-132, 2010.

DINIZ, G. P.; CARNEIRO-RAMOS, M. S.; BARRETO-CHAVES, M. L. M. Angiotensin type 1 receptor mediates thyroid hormone-induced cardiomyocyte hypertrophy through the Akt/GSK-3 $\beta /$ mTOR signaling pathway. Basic. Res. Cardiol., v. 104, n. 6, p. $653-667,2009$. 
DOLINSKY, V. W.; DYCK, J. R. B. Role of AMP-activated protein kinase in healthy and diseased hearts. Am. J. Physiol. Heart. Circ. Physiol., v. 291, n. 6, p. H25572569, 2006.

DYCK, J. R. B.; LOPASCHUK, G. D. AMPK alterations in cardiac physiology and pathology: enemy or ally? J. Physiol., v. 574, n. 1, p. 95-112, 2006.

EPPENBERGER, E. M.; AIGNER, S.; DONATH, M. Y.; KURER, V.; WALTHER, P.; ZUPPINGER, C.; SCHAUB, M. C.; EPPENBERGER, H. M. IGF-I and bFGF differentially influence atrial natriuretic factor and alpha-smooth muscle actin expression in cultured atrial compared to ventricular adult rat cardiomyocytes. J. Mol. Cell. Cardiol., v. 29, n. 8, p. 2027-2039, 1997.

EXNER, D. V.; DRIES, D. L.; WACLAWIW, M. A.; SHELTON, B.; DOMANSKI, M. J. Beta-adrenergic blocking agent use and mortality in patients with asymptomatic and symptomatic left ventricular systolic dysfunction: a post hoc analysis of the Studies of Left Ventricular Dysfunction. J. Am. Coll. Cardiol., v. 33, n. 4, p. 916-923, 1999.

FIEDLER, B.; WOLLERT, K. C. Interference of antihypertrophic molecules and signaling pathways with the Ca2+-calcineurin-NFAT cascade in cardiac myocytes. Cardiovasc. Res., v. 63, n. 3, p. 450-457, 2004.

FREY, N.; KATUS, H. A.; OLSON, E. N.; HILL, J. A. Hypertrophy of the heart: a new therapeutic target? Circulation, v. 109, n. 13, p. 1580-1589, 2004.

FRYER, L. G.; PARBU-PATEL, A.; CARLING, D. The anti-diabetic drugs rosiglitazone and metformin stimulate AMP-activated protein kinase through distinct signaling pathways. J. Biol. Chem., v. 277, n. 28, p. 25226-25232, 2002.

GERDES, A. M. Remodeling of ventricular myocytes during cardiac hypertrophy and heart failure. J. Fla. Med. Assoc., v. 79, n. 4, p. 253-255, 1992.

GERDES, A. M.; IERVASI, G. Thyroid replacement therapy and heart failure. Circulation, v. 122, n. 4, p. 385-393, 2010.

HARDIE, D. G. Minireview: the AMP-activated protein kinase cascade: the key sensor of cellular energy status. Endocrinology, v. 144, n. 12, p. 5179-5183, 2003.

HARDIE, D. G. Neither LKB1 nor AMPK are the direct targets of metformin. Gastroenterology, v. 131, n. 3, p. 973-975, 2006.

HAWLEY, S. A.; BOUDEAU, J.; REID, J. L.; MUSTARD, K. J.; UDD, L.; MAKELA, T. P.; ALESSI, D. R.; HARDIE, D. G. Complexes between the LKB1 tumor suppressor, STRAD $\alpha / \beta$ and MO25 $\alpha / \beta$ are upstream kinases in the AMP-activated protein kinase cascade. J. Biol., v. 2, n. 4, p. 28, 2003. 
HAWLEY, S. A.; GADALLA, A. E.; OLSEN, G. S.; HARDIE, D. G. The antidiabetic drug metformin activates the AMP-activated protein kinase cascade via an adenine nucleotide-independent mechanism. Diabetes, v. 51, n. 8, p. 2420-2425, 2002.

HAWLEY, S. A.; PAN, D. A.; MUSTARD, K. J.; ROSS, L.; BAIN, J.; EDELMAN, A. M.; FRENGUELLI, B. G.; HARDIE, D. G. Calmodulin-dependent protein kinase kinase- $\beta$ is an alternative upstream kinase for AMP-activated protein kinase. Cell. Metab., v. 2, n. 1, p. 9-19, 2005.

HEATHER, L. C.; COLE, M. A.; ATHERTON, H. J.; COUMANS, W. A.; EVANS, R. D.; TYLER, D. J.; GLATZ, J. F. C.; LUIKEN, J. J. F. P.; CLARKE, K. Adenosine monophosphate-activated protein kinase activation, substrate transporter translocation, and metabolism in the contracting hyperthyroid rat heart. Endocrinology, v. 24, n. 1, p. 422-431, 2010.

HEMMINKI, A.; MARKIE, D.; TOMLINSON, I.; AVIZIENYTE, E.; ROTH, S.; LOUKOLA, A.; BIGNELL, G.; WARREN, W.; AMINOFF, M.; HOGLUND, P.; JÄRVINEN, H.; KRISTO, P.; PELIN, K.; RIDANPÄÄ, M.; SALOVAARA, R.; TORO, T.; BODMER, W.; OLSCHWANG, S.; OLSEN, A. S.; STRATTON, M. R.; DE LA CHAPELLE, A.; AALTONEN, L. A. A serine/threonine kinase gene defective in Peutz-Jeghers syndrome. Nature, v. 391, n. 6663, p. 184-187, 1998.

HENDERSON, K. K.; DANZI, S.; PAUL, J. T.; LEYA, G.; KLEIN, I.; SAMAREL, A. M. Physiological replacement of T3 improves left ventricular function in an animal model of myocardial infarction-induced congestive heart failure. Circ. Heart. Fail., v. 2, n. 3, p. 243-252, 2009.

HIROI, Y.; KIM, H. H.; YING, H.; FURUYA, F.; HUANG, Z.; SIMONCINI, T.; NOMA, K.; UEKI, K.; NGUYEN, N. H.; SCANLAN, T. S.; MOSKOWITZ, M. A.; CHENG, S. Y.; LIAO, J. K. Rapid nongenomic actions of thyroid hormone. Proc. Natl. Acad. Sci. USA, v. 103, n 38, p. 14104-14109, 2006.

HORMAN, S.; VERTOMMEN, D.; HEAT, R.; NEUMANN, D.; MOUTON, V.; WOODS A.; SCHLATTNER, U.; WALLIMANN, T.; CARLING, D.; HUE, L.; RIDER, M. H. Insulin antagonizes ischemia-induced Thr172 phosphorylation of AMP-activated protein kinase a-subunits in heart via hierarchical phosphorylation of Ser485/491. J. Biol. Chem., v. 281, n. 9, p. 5335-5340, 2006.

HU, L. W.; LIBERTI, E. A.; BARRETO-CHAVES, M. L. M. Myocardial ultrastructure in cardiac hypertrophy induced by thyroid hormone--an acute study in rats. Virchows. Arch., v. 46, n. 3, p. 265-269, 2005.

HUNTER, W. M.; GREENWOOD, F. C. Preparation of iodine-131 labelled human growth hormone of high specific activity. Nature, v. 194, p. 495-496, 1962.

HURLEY, R. L.; BARRÉ, L. K.; WOOD, S. D.; ANDERSON, K. A.; KEMP, B. E.; MEANS A. R.; WITTERS, L. A. Regulation of AMP-activated protein kinase by 
multisite phosphorylation in response to agents that elevate cellular cAMP. J. Biol. Chem., v. 281, n. 48, p. 36662-36672, 2006.

HUTCHINSON, D. S.; SUMMERS, R. J.; BENGTSSON, T. Regulation of AMPactivated protein kinase activity by G-protein coupled receptors: potential utility in treatment of diabetes and heart disease. Pharmacol. Ther., v. 119, n. 3, p. 291-310, 2008.

JIANG, S. Y.; XU, M.; MA, X. W.; XIAO, H.; ZHANG, Y. Y. Distinct AMPK phosphorylation site characterizes cardiac hypertrophy induced by L-thyroxine and angiotensin II. Clin. Exp. Pharmacol. Physiol., v. 37, n. 9, p. 919-925, 2010.

KAHALY, G. J.; DILLMANN, W. H. Thyroid hormone action in the heart. Endocr. Rev., v. 26, n. 5, p. 704-728, 2005.

KEMP, B. E.; STAPLETON, D.; CAMPBELL, D. J.; CHEN, Z. P.; MURTHY, S.; WALTER, M.; GUPTA, A.; ADAMS, J. J.; KATSIS, F.; VAN DENDEREN, B.; JENNINGS, I. G.; ISELI, T.; MICHELL, B. J.; WITTERS, L. A. AMP-activated protein kinase, super metabolic regulator. Biochem. Soc. Trans., v. 31, n. 1, p. 162-168, 2003.

KENESSEY, A.; OJAMAA, K. Thyroid hormone stimulates protein synthesis in the cardiomyocyte by activating the Akt-mTOR and p70S6K pathways. J. Biol. Chem., v. 281, n. 30, p. 20666-20672, 2006.

KIM, A. S.; MILLER, E. J.; YOUNG, L. H. AMP-activated protein kinase: a core signalling pathway in the heart. Acta. Physiol., v. 196, n. 1, p. 37-53, 2009.

KIM, M.; TIAN, R. Targeting AMPK for cardiac protection: Opportunities and challenges. J. Mol. Cell. Cardiol., 2010. In press.

KLEIN, I. Thyroid hormone and cardiac contractility. Am. J. Cardiol., v. 91, n. 11, p. 1331-1332, 2003.

KLEIN, I.; LEVEY, G. S. New perspectives on thyroid hormone, catecholamines, and the heart. Am. J. Med., v. 76, n. 2, p. 167-172, 1984.

KLEIN, I. E.; OJAMAA, K. Thyroid hormone and the cardiovascular system. N. Engl. J. Med., v. 344, n. 7, p. 501-509, 2001.

KOVACIC, S.; SOLTYS, C. L.; BARR, A. J.; SHIOJIMA, I.; WALSH, K.; DYCK, J. R. Akt activity negatively regulates phosphorylation of AMP-activated protein kinase in the heart. J. Biol. Chem., v. 278, n. 41, p. 39422-39427, 2003. 
KUZMAN, J. A.; O'CONNELL, T. D.; GERDES, A. M. Rapamycin prevents thyroid hormone-induced cardiac hypertrophy. Endocrinology, v. 148, n. 7, p. 3477-3484, 2007.

LATRONICO, M. V.; COSTINEAN, S.; LAVITRANO, M. L.; PESCHLE, C.; CONDORELLI, G. Regulation of cell size and contractile function by Akt in cardiomyocytes. Ann. N. Y. Acad. Sci., v. 1015, p. 250-260, 2004.

LI, C.; KEANEY, J. F. AMP-activated protein kinase: a stress-responsive kinase with implications for cardiovascular disease. Curr. Opin. Pharmacol., v. 10, n. 2, p. 111115, 2010.

LI, J.; COVEN, D. L.; MILLER, E. J.; HU, X.; YOUNG, M. E.; CARLING, D.; SINUSAS, A. J.; YOUNG, L. H. Activation of AMPK alpha- and gamma-isoform complexes in the intact ischemic rat heart. Am. J. Physiol. Heart. Circ. Physiol., v. 291, n. 4, p. H1927-1934, 2006.

LI, Q.; LI, J.; REN, J. UCF-101 mitigates streptozotocin-induced cardiomyocyte dysfunction: role of AMPK. Am. J. Physiol. Endocrinol. Metab., v. 297, n. 4, p. E965-973, 2009.

LIN, H. Y.; DAVIS, F. B.; GORDINIER, J. K.; MARTINO, L. J.; DAVIS, P. J. Thyroid hormone induces activation of mitogen-activated protein kinase in cultured cells. Am. J. Physiol., v. 276, n. 5, p. C1014-1024, 1999.

MACHIDA, S.; KARIYA, F.; KOBAYASHI, K.; NARUSAWA, M. Lack of effect of running training at two intensities on cardiac myosin isozyme composition in rats. Jpn. J. Physiol., v. 50, n. 6, p. 577-583, 2000.

MCGEE, S. L.; MUSTARD, K. J.; HARDIE, D. G.; BAAR, K. Normal hypertrophy accompanied by phosphoryation and activation of AMP-activated protein kinase alpha1 following overload in LKB1 knockout mice. J. Physiol., v. 586, n. 6, p. 173141, 2008.

MENG, R. S.; PEI, Z. H.; YIN, R.; ZHANG, C. X.; CHEN, B. L.; ZHANG, Y.; LIU, D.; XU, A. L.; DONG, Y. G. Adenosine monophosphate-activated protein kinase inhibits cardiac hypertrophy through reactivating peroxisome proliferator-activated receptor- $\alpha$ signaling pathway. Eur. J. Pharmacol., v. 620, n.1-3, p. 63-70, 2009.

MILLER, A. B.; PIÑA, I. L. Understanding heart failure with preserved ejection fraction: clinical importance and future outlook. Congest. Heart. Fail., v. 15, n. 4, p. 186-192, 2009.

MORGAN, H. E.; BAKER, K. M. Cardiac hypertrophy. Mechanical, neural, and endocrine dependence. Circulation, v. 83, n. 1, p. 13-25, 1991. 
MUSI, N.; HIRSHMAN, M. F.; ARAD, M.; XING, Y.; FUJII, N.; POMERLEAU, J.; AHMAD, F.; BERUL, C. I.; SEIDMAN, J. G.; TIAN, R.; GOODYEAR, L. J. Functional role of AMP-activated protein kinase in the heart during exercise. FEBS. Lett., v. 579, n. 10, p. 2045-2050, 2005.

OAKHILL, J. S.; SCOTT, J. W.; KEMP, B. E. Structure and function of AMP-activated protein kinase. Acta. Physiol., v. 196, n. 1, p. 3-14, 2009.

OJAMAA, K. Signaling mechanisms in thyroid hormone-induced cardiac hypertrophy Vascul. Pharmacol., v. 52, n. (3-4), p. 113-119, 2010.

OWEN, M. R.; DORAN, E.; HALESTRAP, A. P. Evidence that metformin exerts its anti-diabetic effects through inhibition of complex 1 of the mitochondrial respiratory chain. Biochem. J., v. 348, n. 3, p. 607-614, 2000.

PANG, T.; RAJAPUROHITAM, V.; COOK, M. A.; KARMAZIN, M. Differential AMPK phosphorylation sites associated with phenylephrine vs antihypertrophic effects of adenosine agonists in neonatal rat ventricular myocytes. Am. J. Physiol. Heart. Circ. Physiol., v. 298, n. 5, p. H1382-390, 2010.

PANTOS, C.; DRITSAS, A.; MOUROUZIS, I.; DIMOPOULOS, A.; KARATASAKIS, G.; ATHANASSOPOULOS, G.; MAVROGENI, S.; MANGINAS, A.; COKKINOS, D. V. Thyroid hormone is a critical determinant of myocardial performance in patients with heart failure: potential therapeutic implications. Eur. J. Endocrinol., v. 157, n. 4, p. 515-520, 2007.

POPESCU, L. M.; GHERGHICEANU, M.; HINESCU, M. E.; CRETOIU, D.; CEAFALAN, L.; REGALIA, T.; POPESCU, A. C.; ARDELEANU, C.; MANDACHE, E. Insights into the interstitium of ventricular myocardium: interstitial Cajal-like cells (ICLC). J. Cell. Mol. Med., v. 10, n. 2, p. 429-458, 2006.

PORTMAN, M. A. Thyroid Hormone Regulation of Heart Metabolism. Thyroid, v. 18, n. 2, p. 217-225, 2008.

RAPP, J. P. Genetic analysis of inherited hypertension in the rat. Physiol. Rev., v. 80 , n. 1, p. 135-172, 2000.

SADOSHIMA, J.; IZUMO, S. Molecular characterization of angiotensin II--induced hypertrophy of cardiac myocytes and hyperplasia of cardiac fibroblasts. Critical role of the AT1 receptor subtype. Circ. Res., v. 73, n. 3, p. 413-423, 1993.

SAEEDI, R.; SARAN, V. V.; WU, S. S.; KUME, E. S.; PAULSON, K.; CHAN, A. P.; PARSONS, H. L.; WAMBOLT, R. B, DYCK, J. R.; BROWNSEY, R. W.; ALLARD, M. F. AMP-activated protein kinase influences metabolic remodeling in $\mathrm{H} 9 \mathrm{c} 2$ cells hypertrophied by arginine vasopressin. Am. J. Physiol. Heart. Circ. Physiol., v. 296, n. 6, p. H1822-1832, 2009. 
SAKAMOTO, K.; ZARRINPASHNEH, E.; BUDAS, G. R.; POULEUR, A. C.; DUTTA, A.; PRESCOTT, A. R.; VANOVERSCHELDE, J. L.; ASHWORTH, A.; JOVANOVIC, A.; ALESSI, D. R.; BERTRAND, L. Deficiency of LKB1 in heart prevents ischemiamediated activation of AMPKalpha2 but not AMPKalpha1. Am. J. Physiol. Endocrinol. Metab., v. 290, n. 5, p. E780-788, 2006.

SCHMIDT-OTT, U. M.; ASCHEIM, D. D. Thyroid hormone and heart failure. Curr. Heart. Fail. Rep., v. 3, n. 3, p. 114-119, 2006.

SHIH, A.; LIN, H. Y.; DAVIS, F. B; DAVIS, P. J. Thyroid hormone promotes serine phosphorylation of p53 by mitogen-activated protein kinase. Biochemistry, v. 40, n. 9, p. 2870-2878, 2001.

SHUBEITA, H. E.; MARTINSON, E. A.; VAN BILSEN, M.; CHIEN, K. R.; BROWN, J. $\mathrm{H}$. Transcriptional activation of the cardiac myosin light chain 2 and atrial natriuretic factor genes by protein kinase $\mathrm{C}$ in neonatal rat ventricular myocytes. Proc. Natl. Acad. Sci. USA, v. 89, n. 4, p. 1305-1309, 1992.

SOLSKOV, L.; LØFGREN, B.; KRISTIANSEN, S. B.; JESSEN, N.; POLD, R.; NIELSEN, T. T.; BØTKER, H. E.; SCHMITZ, O.; LUND, S. Metformin induces cardioprotection against ischaemia/reperfusion injury in the rat heart 24 hours after administration. Basic. Clin. Pharmacol. Toxicol., v. 103, n. 1, p. 82-87, 2008.

SOLTYS, C. L. M.; KOVACIC, S.; DYCK, J. R. B. Activation of cardiac AMP-activated protein kinase by LKB1 expression or chemical hypoxia is blunted by increased Akt activity. Am. J. Physiol. Heart. Circ. Physiol., v. 290, n. 6, p. H2472-2479, 2006.

STUCK, B. J.; LENSKI, M.; BÖHM, M.; LAUFS, U. Metabolic switch and hypertrophy of cardiomyocytes following treatment with angiotensin ii are prevented by AMPactivated protein kinase. J. Biol. Chem., v. 283, n. 47, p. 32562-32569, 2008.

TIAN, R.; MUSI, N.; D'AGOSTINO, J.; HIRSHMAN, M. F.; GOODYEAR, L. J. Increased adenosine monophosphate-activated protein kinase activity in rat hearts with pressure-overload hypertrophy. Circulation, v. 104, n. 14, p. 1664-1669, 2001.

TOWLER, M. C.; HARDIE, D. G. AMP-activated protein kinase in metabolic control and insulin signaling. Circ. Res., v. 100, n. 3, p. 328-341, 2007.

ZHANG, L.; HE, H.; BALSCHI, J. A. Metformin and phenformin activate AMPactivated protein kinase in the heart by increasing cytosolic AMP concentration. Am. J. Physiol. Heart. Circ. Physiol., v. 293, n. 1, p. H457-466, 2007.

ZHOU, G.; MYERS, R.; LI, Y.; CHEN, Y.; SHEN, X.; FENYK-MELODY, J.; WU, M.; VENTRE, J.; DOEBBER, T.; FUJII, N.; MUSI, N.; HIRSHMAN, M. F.; GOODYEAR, L. J.; MOLLER, D. E. Role of AMP-activated protein kinase in mechanism of metformin action. J. Clin. Invest., v. 108, n. 8, p. 1167-1174, 2001. 
YAMAUCHI, M.; KAMBE, F.; CAO, X.; LU, X.; KOZAKI, Y.; OISO, Y.; SEO, H. Thyroid hormone activates adenosine 5'-monophosphate-activated protein kinase via intracellular calcium mobilization and activation of calcium/calmodulin-dependent protein kinase kinase- $\beta$. Mol. Endocrinol., v. 22, n. 4, p. 893-903, 2008.

YANG, J.; HOLMAN, G. D. Long-term metformin treatment stimulates cardiomyocyte glucose transport through an AMP-activated protein kinase-dependent reduction in GLUT4 endocytosis. Endocrinology, v. 147, n. 6, p. 2728-2736, 2006.

WANG, M. Y.; UNGER, R. H. Role of PP2C in cardiac lipid accumulation in obese rodents and its prevention by troglitazone. Am. J. Physiol. Endocrinol. Metab., v. 288, n. 1, p. E216-221, 2005.

WANG, Y. Y.; JIAO, B.; GUO, W. G.; CHE, H. L.; YU, Z. B. Excessive thyroxine enhances susceptibility to apoptosis and decreases contractility of cardiomyocytes. Mol. Cell. Endocrinol., v. 320, n. 1-2, p. 67-75, 2010.

WEBER, K. T.; BRILLA, C. G. Pathological hypertrophy and cardiac interstitium. Fibrosis and renin-angiotensin-aldosterone system. Circulation, v. 83, n. 6, p. 18491865, 1991.

WOODS, A.; DICKERSON, K.; HEATH, R.; HONG, S. P.; MOMCILOVIC, M.; JOHNSTONE, S. R.; CARLSON, M.; CARLING, D. Ca2+/calmodulin-dependent protein kinase kinase- $\beta$ acts upstream of AMP-activated protein kinase in mammalian cells. Cell. Metab., v. 2, n. 1, p. 21-33, 2005.

WONG, A. K. F.; HOWIE, J.; PETRIE, J. R.; LANG, C. C. AMP-activated protein kinase pathway: a potential therapeutic target in cardiometabolic disease. Clin. Sci. (Lond), v. 116, n. 8, p. 607-620, 2009. 